\title{
FEASIBILITY STUDY FOR LOWERING \\ THE MINIMUM GAS PRESSURE IN \\ SOLUTION-MINED CAVERNS BASED \\ ON GEOMECHANICAL ANALYSES OF \\ CREEP-INDUCED DAMAGE AND HEALING
}

\author{
Topical Report RSI-0969 \\ DE-AC26-97FT34350 \\ by \\ Kerry L. DeVries \\ Joel D. Nieland \\ Joe L. Ratigan \\ RESPEC \\ P.O. Box 725
}

Rapid City, South Dakota 57709-0725

\author{
prepared for \\ U.S. Department of Energy \\ Federal Technology Center \\ P.O. Box 880 \\ Morgantown, West Virginia 26507-0880
}

May 1998 


\section{Disclaimer}

This report was prepared as an account of work sponsored by an agency of the United States Government. Neither the United States Government nor any agency thereof, nor any of their employees, makes any warranty, express or implied, or assumes any legal liability or responsibility for the accuracy, completeness, or usefulness of any information, apparatus, product, or process disclosed, or represents that its use would not infringe privately owned rights. Reference herein to any specific commercial product, process, or service by trade

name, trademark, manufacturer, or otherwise does not necessarily constitute or imply its endorsement, recommendation, or favoring by the United States Government or any agency thereof. The views and opinions of authors expressed herein do not necessarily state or reflect those of the United States Government or any agency thereof. 


\section{EXECUTIVE SUMMARY}

This report presents the results of a study to evaluate the potential of increasing the working gas volume of new and existing compressed natural gas (CNG) storage caverns by using an advanced constitutive model for rock salt in the cavern design procedure. Geomechanical finite element analyses were made to determine the minimum gas pressure allowable based on an existing stress-based criterion (the Damage Potential method) and an advanced constitutive model (the Multimechanism Deformation Coupled Fracture (MDCF) model) capable of modeling damage and healing in rock salt. The MDCF model is a constitutive model developed by Sandia National Laboratories and their subcontractors to provide a description of damage, healing, and deformation of salt for safe disposal of radioactive waste at the Waste Isolation Pilot Plant. The MDCF model has the capability to track damage development and healing and to provide a quantitative measure for the damage. Additionally, the healing behavior of the salt (included with the MDCF model) was to be analyzed to determine if complete healing of the damaged rock zone would occur during the time period when the cavern was at maximum gas pressure.

In order to demonstrate the capability of the MDCF model to predict the evolution of damage and healing around CNG storage caverns, geomechanical analyses were performed of two actual CNG storage caverns. The two caverns, referred to as Cavern A and Cavern B, have different depth, volume, geometry, temperature, and proximity to other caverns. Cavern depth is nominally 2,000 and 4,000 feet to the casing shoe for Cavern A and Cavern B, respectively. Two natural gas service cycles were used in the simulations and are referred to as Case 1 and Case 2. Both cycles are initiated at maximum gas pressure and are drawn down to minimum gas pressure over a 10-day period. The Case 1 gas pressure cycle is held at minimum gas pressure for a period of 10 days, and the Case 2 gas pressure cycle is held at minimum gas pressure for 100 days. After the minimum pressure service, both cycles repressurize to maximum gas pressure over a 10-day period. Both cycles are then held at maximum gas pressure for 100 days. The scenarios simulated for each of the caverns include:

- A 10-day gas withdrawal from maximum gas pressure to atmospheric pressure to determine the minimum gas pressures that ensure no salt dilation based on the Damage Potential method and the MDCF model with various salt impurity levels. ${ }^{1}$ The pressures determined with the Damage Potential method were designated the baseline minimum gas pressures.

- Simulations with 5-day and 20-day gas withdrawal periods to evaluate the impact of the gas withdrawal rate.

\footnotetext{
${ }^{1}$ The salt "impurity level" is an input quantity in the MDCF model. Throughout this study, the "impurity level" should actually be thought of as a porosity level.
} 
- A single Case 1 gas cycle was simulated at minimum gas pressures equal to 50 and 90 percent of the baseline minimum gas pressure to examine the sensitivity to the minimum gas pressure.

- A long-term simulation at minimum gas pressure to determine the maximum allowable time at minimum gas pressure. Minimum gas pressures of both 50 and 90 percent of the baseline minimum gas pressure were evaluated.

- Simulations of five consecutive gas pressure cycles were made to evaluate long-term damage accumulation and healing. The simulations were made with both Case 1 and Case 2 gas pressure cycles. The simulations were made with a minimum gas pressure equal to 50 percent of the baseline minimum gas pressure.

During the first part of this study, the minimum gas pressure that would completely suppress dilation of the salt was determined using the Damage Potential method and the MDCF model with impurity levels of $0,1,2$, and 3 percent. The minimum gas pressures to completely suppress dilation predicted using the Damage Potential method were 0.14 and $0.22 \mathrm{psi} /$ foot of depth at the casing shoe for Cavern A and Cavern B, respectively. The minimum gas pressure predicted by the MDCF model that completely suppresses dilation of the salt for Cavern $A$ ranged from 0.0 to $0.73 \mathrm{psi} /$ foot of depth at the casing shoe. Similarly, the minimum gas pressure predicted by the MDCF model ranged between 0.12 and $0.63 \mathrm{psi} /$ foot of depth at the Cavern $B$ casing shoe. Impurity levels of 0,1 , and 2 percent resulted in minimum gas pressures lower than that predicted using the Damage Potential method for Cavern A. However, for Cavern $B$, only impurity levels of 0 and 1 percent resulted in minimum gas pressures less than that predicted using the Damage Potential method.

The minimum gas pressure necessary to suppress salt dilation predicted by the MDCF model is greater than that predicted by the Damage Potential method for salt containing high levels of impurities (typically greater than 2 percent). This does not imply that the MDCF model predicts the cavern will become unstable if the gas pressure is dropped below the pressure that is needed to completely suppress dilation. It simply means that microcracking and dilation of the salt can be expected and that the size and severity of the damaged zone will depend on the stress conditions, temperature, and length of time the salt is subjected to a condition that is conducive to damage development.

In order to assess the stability of the salt on the periphery of the storage caverns using the MDCF model, a criterion was established as the limiting value that should not be exceeded. It was assumed here that the salt surrounding the caverns will remain stable if it does not reach the tertiary creep stage. Geomechanical analyses of the two CNG storage caverns were performed to determine the stability of the caverns based on the aforementioned design criterion using the MDCF model. Results of these analyses showed that if the caverns are operated and held at a minimum gas pressure of 50 percent of the minimum pressure determined using the Damage Potential method, the salt surrounding Cavern A will not reach the design limit until about 7 years at the minimum pressure. However, only 12 days were required for a volume of 
salt in Cavern B to exceed the design limit at a minimum gas pressure of 50 percent of the baseline minimum pressure. If a minimum gas pressure of 90 percent of the baseline pressure is specified, the salt around Cavern $B$ will not exceed the design limit until approximately 65 days at minimum gas pressure. Thus, a gas pressure lower than that determined by the existing Damage Potential method can be allowed for a short period of time while maintaining cavern stability. The maximum time that the cavern can be held at minimum pressure will vary, depending on the damage characteristics of the salt and operating conditions of the cavern.

Gas storage caverns are not typically held at minimum pressure for extended periods of time. It was shown in this study that damaged salt (salt that has experienced dilation) could be healed when the cavern is held at maximum gas pressure. The time required to heal the salt (reduce the porosity to its initial level) increases for increasingly lower minimum gas pressures and longer periods of operation at minimum gas pressure. Complete healing of the salt was predicted within the 100-day period at maximum gas pressure for both Cavern A and Cavern B after the caverns had experienced a 10-day period at minimum gas pressure. Complete healing of the salt was also predicted within 100 days for Cavern $A$ following a 100-day period at minimum pressure, but not for Cavern B. This is because higher levels of damage were predicted in the salt surrounding Cavern B during the period the cavern was held at minimum pressure.

It was demonstrated in this study that if a conservative dilation boundary and damage criterion are specified for the MDCF model, it is still possible to use a lower minimum gas pressure than that predicted by the Damage Potential method without jeopardizing cavern stability. However, site-specific evaluation of the damage and healing characteristics of salt core should be undertaken and further refinements in the MDCF model are recommended. 


\section{TABLE OF CONTENTS}

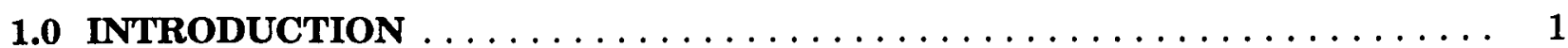

1.1 BACKGROUND $\ldots \ldots \ldots \ldots \ldots \ldots \ldots \ldots \ldots \ldots \ldots \ldots \ldots \ldots$

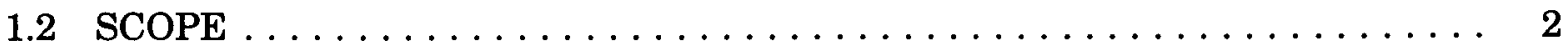

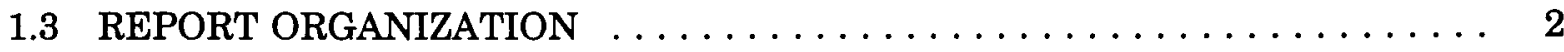

2.0 ROCK MECHANICS ISSUES AND CAVERN STABILITY $\ldots \ldots \ldots \ldots \ldots$

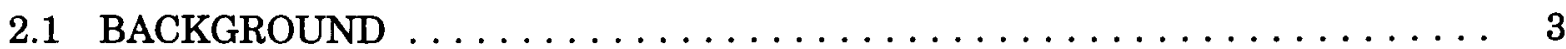

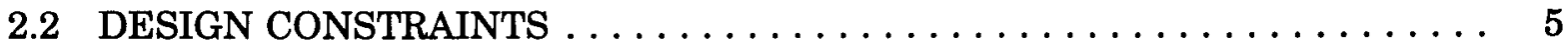

2.3 DAMAGE VARIABLES $\ldots \ldots \ldots \ldots \ldots \ldots \ldots \ldots \ldots \ldots \ldots \ldots \ldots \ldots$

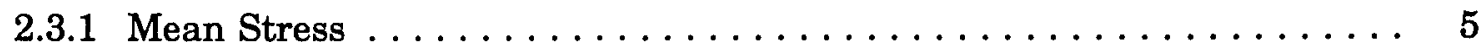

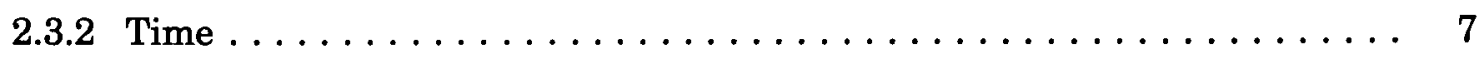

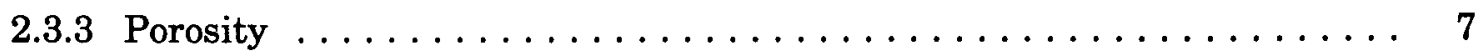

2.3.4 Temperature $\ldots \ldots \ldots \ldots \ldots \ldots \ldots \ldots \ldots \ldots \ldots \ldots \ldots \ldots$

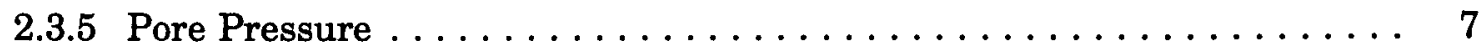

3.0 TECHNICAL APPROACH FOR PREDICTING CAVERN STABILITY $\ldots \ldots \ldots$

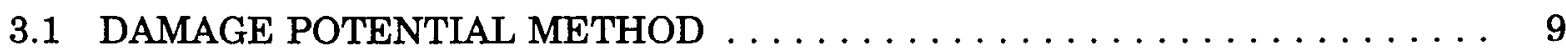

3.2 MDCF CONSTITUTIVE MODEL FOR ROCK SALT $\ldots \ldots \ldots \ldots \ldots \ldots \ldots$

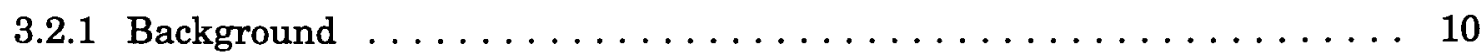

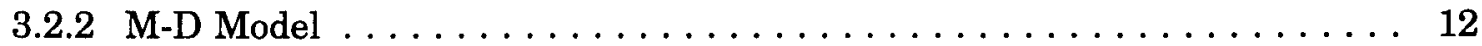

3.2.3 Extension of the M-D Model $\ldots \ldots \ldots \ldots \ldots \ldots \ldots \ldots \ldots \ldots \ldots$

3.2.4 Dilatancy Boundary $\ldots \ldots \ldots \ldots \ldots \ldots \ldots \ldots \ldots \ldots \ldots \ldots \ldots$

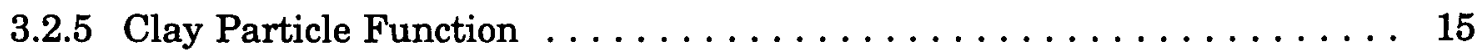

3.2 .6 Damage Variable . . . . . . . . . . . . . . . . 17

3.2 .7 Cavern Stability Design Criterion . . . . . . . . . . . . . 17

3.2 .8 Damage Healing . . . . . . . . . . . . . . . . . . . . 19

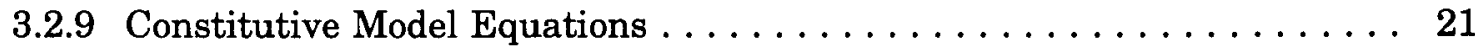

4.0 FINITE ELEMENT PROGRAM AND GEOMECHANICAL MODELS $\ldots \ldots$. . . 22

4.1 FINITE ELEMENT PROGRAM $\ldots \ldots \ldots \ldots \ldots \ldots \ldots \ldots \ldots \ldots \ldots \ldots$

4.2 GEOMECHANICAL MODELS OF STORAGE CAVERNS . . . . . . . . . . 22

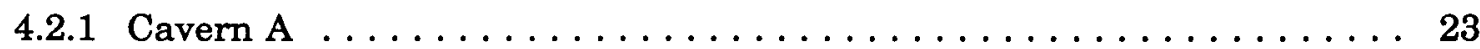

4.2.1.1 In Situ Temperature Profile . . . . . . . . . . . . . 23

4.2.1.2 In Situ Stress Distribution . . . . . . . . . . . . . 23 


\section{TABLE OF CONTENTS}

(Continued)

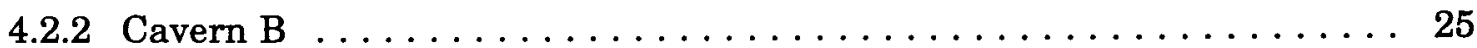

4.2.2.1 In Situ Temperature Profile ................. 27

4.2.2.2 In Situ Stress Distribution . . . . . . . . . . . . . 27

4.2.3 Cavern A and Cavern B Model Boundary Conditions ......... 27

4.3 PROPERTIES OF WELL FLUIDS $\ldots \ldots \ldots \ldots \ldots \ldots \ldots \ldots \ldots \ldots \ldots$

5.0 NUMERICAL RESULTS OF CAVERN STABILITY BASED ON DILATANCY

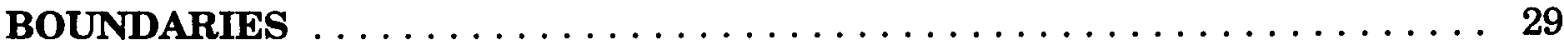

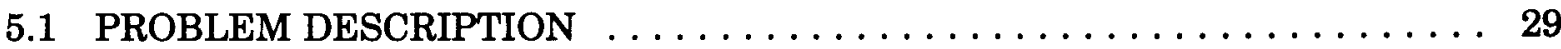

5.2 MODELING RESULTS $\ldots \ldots \ldots \ldots \ldots \ldots \ldots \ldots \ldots \ldots \ldots \ldots \ldots \ldots \ldots \ldots \ldots$

6.0 NUMERICAL RESULTS OF CAVERN STABILITY BASED ON DAMAGE

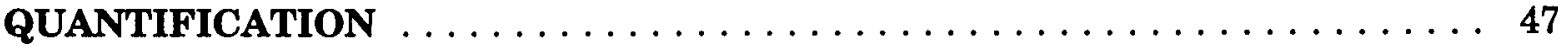

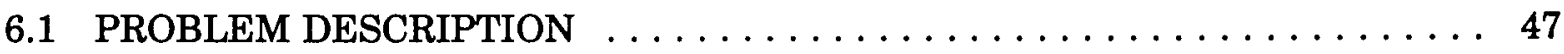

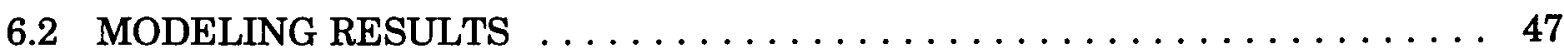

6.2.1 Evaluation of Minimum Gas Pressure $\ldots \ldots \ldots \ldots \ldots \ldots \ldots \ldots 4$

6.2.2 Maximum Allowable Time at Minimum Gas Pressure $\ldots \ldots \ldots \ldots .53$

6.2.3 Long-Term Damage Accumulation . ................. 53

7.0 SUMMARY AND CONCLUSIONS $\ldots \ldots \ldots \ldots \ldots \ldots \ldots \ldots \ldots$

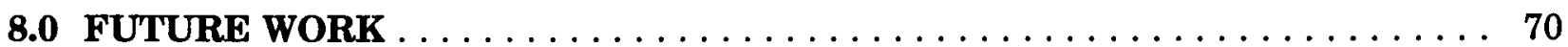

8.1 DETERMINATION OF AN EFFICIENT TEST MATRIX . . . . . . . . 70

8.2 TEMPERATURE EFFECTS AND HEALING CHARACTERISTICS . . . . . . 70

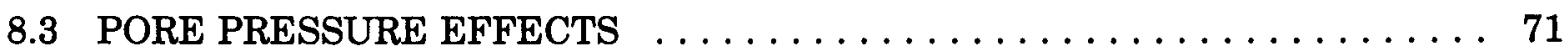

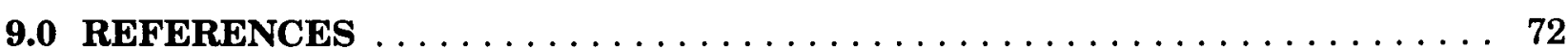

APPENDIX A. SUMMARY OF THE MDCF MODEL $\ldots \ldots \ldots \ldots \ldots \ldots \ldots$ A-1

APPENDIX B. MDCF PARAMETER VALUES $\ldots \ldots \ldots \ldots \ldots \ldots \ldots \ldots$ B-1

APPENDIX C. PROPERTIES OF WELL FLUIDS $\ldots \ldots \ldots \ldots \ldots \ldots \ldots$ C-1 


\section{LIST OF TABLES}

TABLE

PAGE

4-1 Characteristics of Gas Storage Caverns . . . . . . . . . . . . 25

5-1 Casing Shoe Pressures (psi/Foot of Depth) at Which Dilation Begins . . . . . . 34

B-1 MDCF Elastic and Dislocation Creep Model Constants . . . . . . . . . . . B-3

B-2 MDCF Damage Model Constants . . . . . . . . . . . . . . . . . B-4 


\section{LIST OF FIGURES}

FIGURE

PAGE

2-1 Shear Stress Regions Around a Typical Cavern in Salt Expressed in Terms of the Second Invariant of the Deviator Stress Tensor . . . . . . . . . . . . . . . . 4

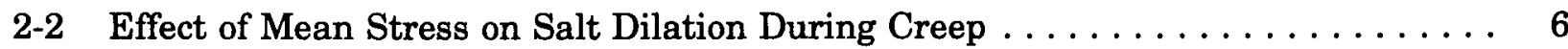

2-3 Axial and Volumetric Strain Versus Time for Salt Depicting Effect of Initial Porosity on Dilation . . . . . . . . . . . . . . . . . . . . 8

3-1 Dilation Boundary for Damage Potential Method $\ldots \ldots \ldots \ldots \ldots \ldots$

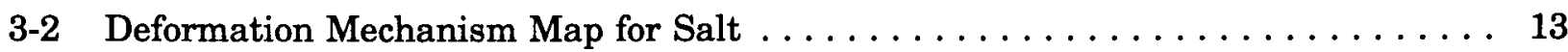

3-3 Comparison of Dilation Boundaries Predicted Using the MDCF Model for WIPP

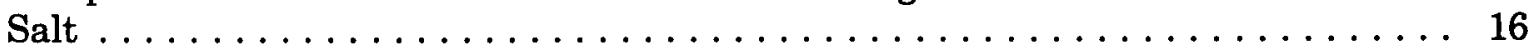

3-4 Comparison of Calculated and Measured Time-to-Rupture Results of WIPP Salt as

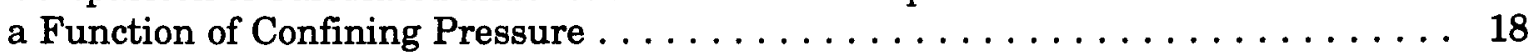

3-5 A Semilog Plot of Normalized Volumetric Strain Versus Time for Damage Healing of WIPP Salt at $70^{\circ} \mathrm{C}\left(158^{\circ} \mathrm{F}\right)$ Under a Hydrostatic Pressure of $15 \mathrm{MPa}$

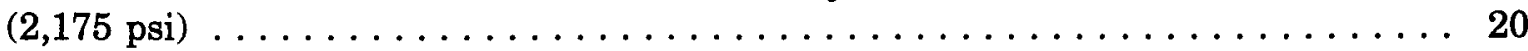

4-1 Cavern A Finite Element Mesh . . . . . . . . . . . . . . . . . . . . . 24

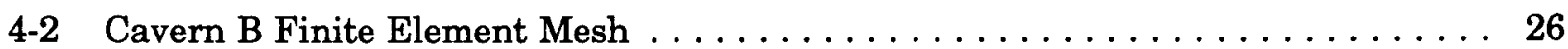

5-1 Dilation Boundaries Based on the MDCF and the Damage Potential Methods . . . 30

5-2 Predicted Normalized Volume of Dilating Salt Above Cavern A Midheight Versus

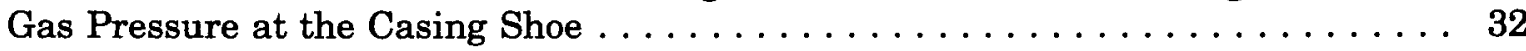

5-3 Predicted Normalized Volume of Dilating Salt Above Cavern B Midheight Versus Gas Pressure at the Casing Shoe . . . . . . . . . . . . . . . . 33

5-4 Regions of Predicted Salt Dilation Based on the Damage Potential Method for Cavern A at a Gas Pressure of 0.07 psi/Foot of Depth at the Casing Shoe . . . . . 35

5-5 Regions of Predicted Salt Dilation Based on the MDCF Model With no Salt Impurity for Cavern A at a Gas Pressure of $0.07 \mathrm{psi} / \mathrm{Foot}$ of Depth at the Casing

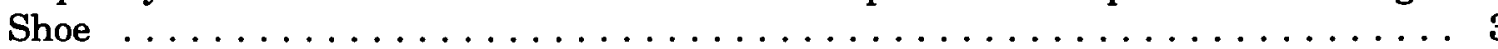

5-6 Regions of Predicted Salt Dilation Based on the MDCF Model With a Salt Impurity of 1 Percent for Cavern A at a Gas Pressure of $0.07 \mathrm{psi} /$ Foot of Depth at the Casing

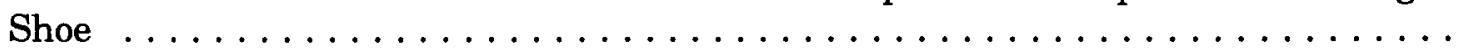

5-7 Regions of Predicted Salt Dilation Based on the MDCF Model With a Salt Impurity of 2 Percent for Cavern A at a Gas Pressure of $0.07 \mathrm{psi} /$ Foot of Depth at the Casing

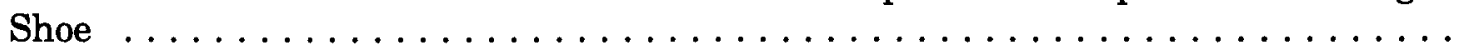

5-8 Regions of Predicted Salt Dilation Based on the MDCF Model With a Salt Impurity of 3 Percent for Cavern A at a Gas Pressure of 0.07 psi/Foot of Depth at the Casing Shoe 


\section{LIST OF FIGURES \\ (Continued)}

5-9 Regions of Predicted Salt Dilation Based on the Damage Potential Method for Cavern B at a Gas Pressure of 0.11 psi/Foot of Depth at the Casing Shoe . . . . . 40

5-10 Regions of Predicted Salt Dilation Based on the MDCF Model With no Salt Impurity for Cavern B at a Gas Pressure of 0.11 psi/Foot of Depth at the Casing

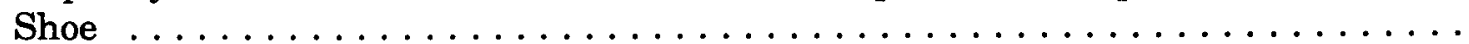

5-11 Regions of Predicted Salt Dilation Based on the MDCF Model With a Salt Impurity of 1 Percent for Cavern B at a Gas Pressure of 0.11 psi/Foot of Depth at the Casing

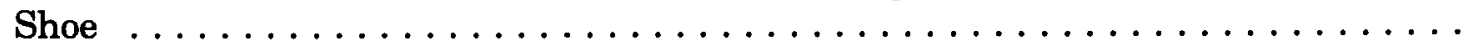

5-12 Regions of Predicted Salt Dilation Based on the MDCF Model With a Salt Impurity of 2 Percent for Cavern B at a Gas Pressure of 0.11 psi/Foot of Depth at the Casing

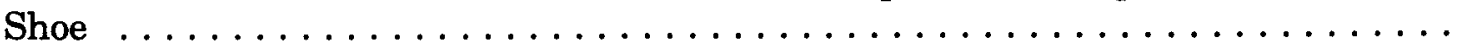

5-13 Regions of Predicted Salt Dilation Based on the MDCF Model With a Salt Impurity of 3 Percent for Cavern B at a Gas Pressure of 0.11 psi/Foot of Depth at the Casing

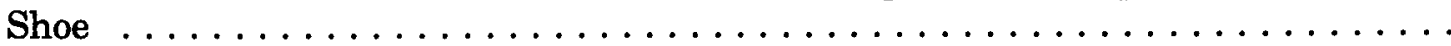

5-14 The Predicted Normalized Volume of Dilating Salt Above the Cavern Midheight Versus Gas Pressure for Cavern A Using the Damage Potential Method Dilatancy Boundary for Three Different Withdrawal Rates . . . . . . . . . . . . .

5-15 The Predicted Normalized Volume of Dilating Salt Above the Cavern Midheight Versus Gas Pressure for Cavern B Using the Damage Potential Method Dilatancy Boundary for Three Different Withdrawal Rates . . . . . . . . . . . . . 46

6-1 Natural Gas Service Cycles Analyzed . . . . . . . . . . . . . . . . 48

6-2 Normalized Volume of Salt Above the Cavern Midheight With Dilatant Volumetric Strain Greater Than $0.1 \mu \varepsilon$ Throughout a Single Case 1 Gas Pressure Cycle for Cavern A . . . . . . . . . . . . . . . . . . . . . . . .

6-3 Normalized Volume of Salt Above the Cavern Midheight With Dilatant Volumetric Strain Greater Than $0.1 \mu \varepsilon$ Throughout a Single Case 1 Gas Pressure Cycle for

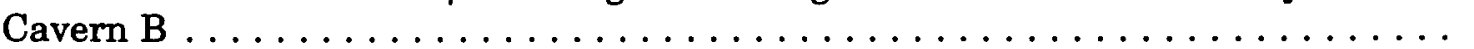

6-4 MDCF Damage Stress Measure and the Radial, Vertical, and Tangential Stresses for an Element in the Cavern Wall During a Single Case 1 Gas Pressure Cycle . .

6-5 MDCF Damage State Variable in the Wall of Cavern A as a Function of Time at Minimum Gas Pressure for the Two Minimum Gas Pressures Evaluated . . . . . 54

6-6 MDCF Damage State Variable in the Wall of Cavern B as a Function of Time at Minimum Gas Pressure for the Two Minimum Gas Pressures Evaluated . . . . . 55

6-7 Normalized Volume of Salt Above the Cavern Midheight With Dilatant Volumetric Strain Greater Than $0.1 \mu \varepsilon$ for Cavern A Throughout Five Consecutive Case 1 Gas Pressure Cycles . . . . . . . . . . . . . . . . . . . . . 


\section{LIST OF FIGURES \\ (Continued)}

6-8 Normalized Volume of Salt Above the Cavern Midheight With Dilatant Volumetric Strain Greater Than $0.1 \mu \varepsilon$ for Cavern A Throughout Five Consecutive Case 2 Gas Pressure Cycles ............................ 5

6-9 Contours of the Dilatant Volumetric Strain in the Salt Surrounding Cavern A at the End of the First Case 1 Gas Cycle $\ldots \ldots \ldots \ldots \ldots \ldots \ldots \ldots \ldots \ldots$

6-10 Contours of the Dilatant Volumetric Strain in the Salt Surrounding Cavern A at

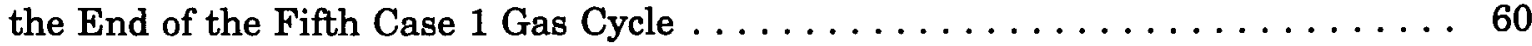

6-11 Contours of the Dilatant Volumetric Strain in the Salt Surrounding Cavern A at the End of the 10-Day Period at Minimum Gas Pressure During the First Case 1

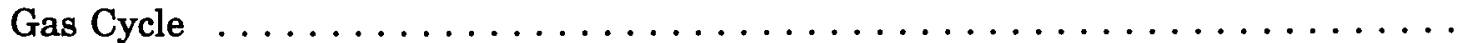

6-12 Contours of the Dilatant Volumetric Strain in the Salt Surrounding Cavern A at the End of the 10-Day Period at Minimum Gas Pressure During the Fifth Case 1

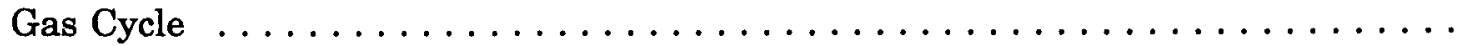

6-13 Normalized Volume of Salt Above the Cavern Midheight With Dilatant Volumetric Strain Greater Than $0.1 \mu \varepsilon$ for Cavern B Throughout Five Consecutive Case 1 Gas Pressure Cycles . . . . . . . . . . . . . . . . . . . . . . .

6-14 Normalized Volume of Salt Above the Cavern Midheight With Dilatant Volumetric Strain Greater Than $0.1 \mu \varepsilon$ for Cavern B Throughout Five Consecutive Case 2 Gas Pressure Cycles . . . . . . . . . . . . . . . . . . . . .

6-15 Contours of the Dilatant Volumetric Strain in the Salt Surrounding Cavern B at the End of the First Case 1 Gas Cycle $\ldots \ldots \ldots \ldots \ldots \ldots \ldots$

6-16 Contours of the Dilatant Volumetric Strain in the Salt Surrounding Cavern B at

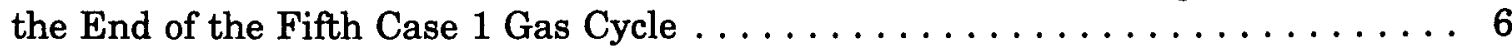

6-17 Contours of the Dilatant Volumetric Strain in the Salt Surrounding Cavern B at the End of the 10-Day Period at Minimum Gas Pressure During the First Case 1

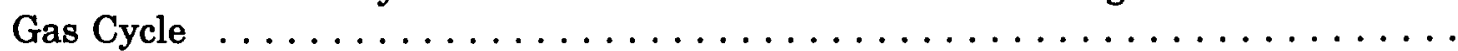

6-18 Contours of the Dilatant Volumetric Strain in the Salt Surrounding Cavern B at the End of the 10-Day Period at Minimum Gas Pressure During the Fifth Case 1 Gas Cycle 


\subsection{INTRODUCTION}

\subsection{BACKGROUND}

With the projected growth in natural gas demand exceeding the current pipeline and underground storage capacities, innovative concepts are being sought to meet the needs of the natural gas industry and end-use markets. Much of the growth will be met through increased pipeline capacity and conventional storage. Typically, natural gas is stored underground in depleted oil and gas fields, aquifers, and salt caverns. The purpose of this report is to investigate advanced design techniques for salt caverns which could potentially increase the working gas capacity of new and existing natural gas storage caverns in salt formations.

The storage of compressed natural gas (CNG) in salt caverns is a growing industry. According to statistics provided by the Gas Research Institute (GRI), there are 25 salt cavern CNG facilities, consisting of 127 individual caverns, in the United States and Canada as of April 1995 [Harrison and Ellis, 1995]. Product movement to and from CNG storage caverns is accomplished simply by compression and expansion of the stored gas. Consequently, the internal pressure on the walls of a CNG storage cavern can vary considerably. Since a minimum level of internal pressure is necessary to ensure cavern stability, a certain quantity of gas must always remain in a cavern. This gas is referred to as the base or cushion gas. The quantity of gas that can be withdrawn from a cavern is referred to as the working gas volume.

The economics of CNG storage in salt caverns are largely dependent on maximizing the ratio between the working gas and the cushion gas volumes. This ratio depends directly on the relative values of the maximum and minimum gas pressures permitted in the storage cavern. The maximum storage pressure is limited to a fraction of the weight of the overburden (typically $0.75-0.85$ of the vertical stress) in order to prevent fracturing and loss of containment. The minimum pressure required to ensure the structural stability of the cavern is much more difficult to determine, and numerical simulations of cavern response during typical gas service cycles and conservative design criteria are used to evaluate the cavern stability at the minimum gas pressure (e.g., Ratigan et al. [1993]). Advanced constitutive models for salt that incorporate damage accumulation and healing have not been used in these simulations. Application of these advanced constitutive models may indicate that the minimum gas pressure can be decreased in many CNG storage caverns without compromising the stability of the surrounding salt. If this proves to be the case, the working gas capacity and the economics of CNG storage in salt caverns can be improved. 


\subsection{SCOPE}

Over the last few years, research has been performed to develop a theoretical model based on experimental data of damage accumulation and healing for disposal of radioactive waste at the Waste Isolation Pilot Plant (WIPP) near Carlsbad, New Mexico. This research has led to the development of an advanced constitutive model that provides a more accurate description of the behavior of rock salt. The objective of this report is to determine if this advanced technology can be transferred to the natural gas storage industry. Before this technology can be transferred to the CNG industry, both technical and economical issues must be answered to determine the feasibility of using the advanced constitutive model. This study provides a preliminary assessment for use of the model by the CNG industry.

Geomechanical analyses of two typical natural gas storage caverns were performed to determine if the constitutive model developed for the WIPP is potentially feasible for use in the CNG industry. The analyses were performed using both the advanced constitutive model developed for the WIPP and the current approach used to evaluate cavern stability (e.g., Ratigan et al. [1993]). The purpose of these analyses is to determine if the working gas volume of the caverns can be increased by reducing the minimum storage pressures, without jeopardizing cavern stability, based on a more accurate prediction of the salt.

\subsection{REPORT ORGANIZATION}

This report contains nine chapters and three appendices. Chapter 2.0 discusses cavern stability requirements. The technical approach used to predict cavern stability is presented in Chapter 3.0. Chapter 4.0 describes the finite element computer program and the geomechanical models used in the analysis. Chapter 5.0 presents the cavern stability results based only on dilatancy boundaries. The cavern stability results based on damage accumulation and healing are presented in Chapter 6.0. Chapter 7.0 provides a summary of the study and the conclusions drawn from it. Chapter 8.0 describes future work required to make the use of the Multimechanism Deformation Coupled Fracture (MDCF) model viable and is followed by a list of references (Chapter 9.0). Appendix A gives a full description of the MDCF model. The MDCF model parameters used for the two cavern sites are given in Appendix B. Appendix C describes how natural gas and brine were modeled in the simulations. 


\subsection{ROCK MECHANICS ISSUES AND CAVERN STABILITY}

\subsection{BACKGROUND}

The development of storage caverns in salt for the containment of liquids (e.g., brine, oil, etc.) has been a popular alternative to surface storage since the early $1950 \mathrm{~s}$ and is also becoming common practice for the containment of gaseous fluids such as natural gas, compressed air, etc. Natural rock salt is an excellent containment medium because of the extremely low permeability $\left(<1 \times 10^{-21} \mathrm{~m}^{2}\right)$ that results from the low porosity and tightly bonded grain boundaries of the salt and the lack of large fluid-conducting fractures within the formation comprising the salt.

The development of caverns disturbs the natural stress state that exists in the salt before cavern development and induces deviatoric (or shear) stresses in the salt near the cavern, as shown in Figure 2-1, where $J_{2}$ is the second invariant of the deviatoric stress tensor. ${ }^{2}$ The deviatoric stresses are highest near the cavern walls, especially at abrupt changes in geometry, but decrease with distance away from the cavern. Furthermore, the magnitude of the deviatoric stresses is proportional to the cavern depth and inversely proportional to the cavern pressure.

Deviatoric stress states activate three general deformation mechanisms in salt: (1) instantaneous elastic deformation, (2) inelastic viscoplastic deformation, and (3) inelastic brittle deformation. Both inelastic deformation mechanisms are time-dependent which gives salt its well known creep characteristics; however, the mechanisms differ in two important aspects. First, the inelastic brittle deformation mechanism induces microcracks in the salt which produce a volume increase or dilation. In contrast, the viscoplastic deformation mechanism occurs without changes in salt volume. Second, the brittle mechanism is activated only when the magnitude of the deviatoric stress is high relative to the mean stress (average of the three principal stresses). In contrast, viscoplastic deformation occurs virtually whenever a deviatoric stress is induced, regardless of the magnitude of the mean stress.

Even though salt has low porosity and provides good containment of fluids in most applications, there are conditions that produce damage in salt which, in turn, lead to an increase in salt porosity, an enhancement in salt permeability, and a degradation in strength. Under these conditions, stability of the cavern and/or the ability of the salt to contain liquid or gaseous fluids within a storage cavern may be compromised, and as such, must be considered in the cavern design process.

\footnotetext{
${ }^{2}$ Before a cavern is created, the deviatoric or shear stress is assumed to be zero.
} 


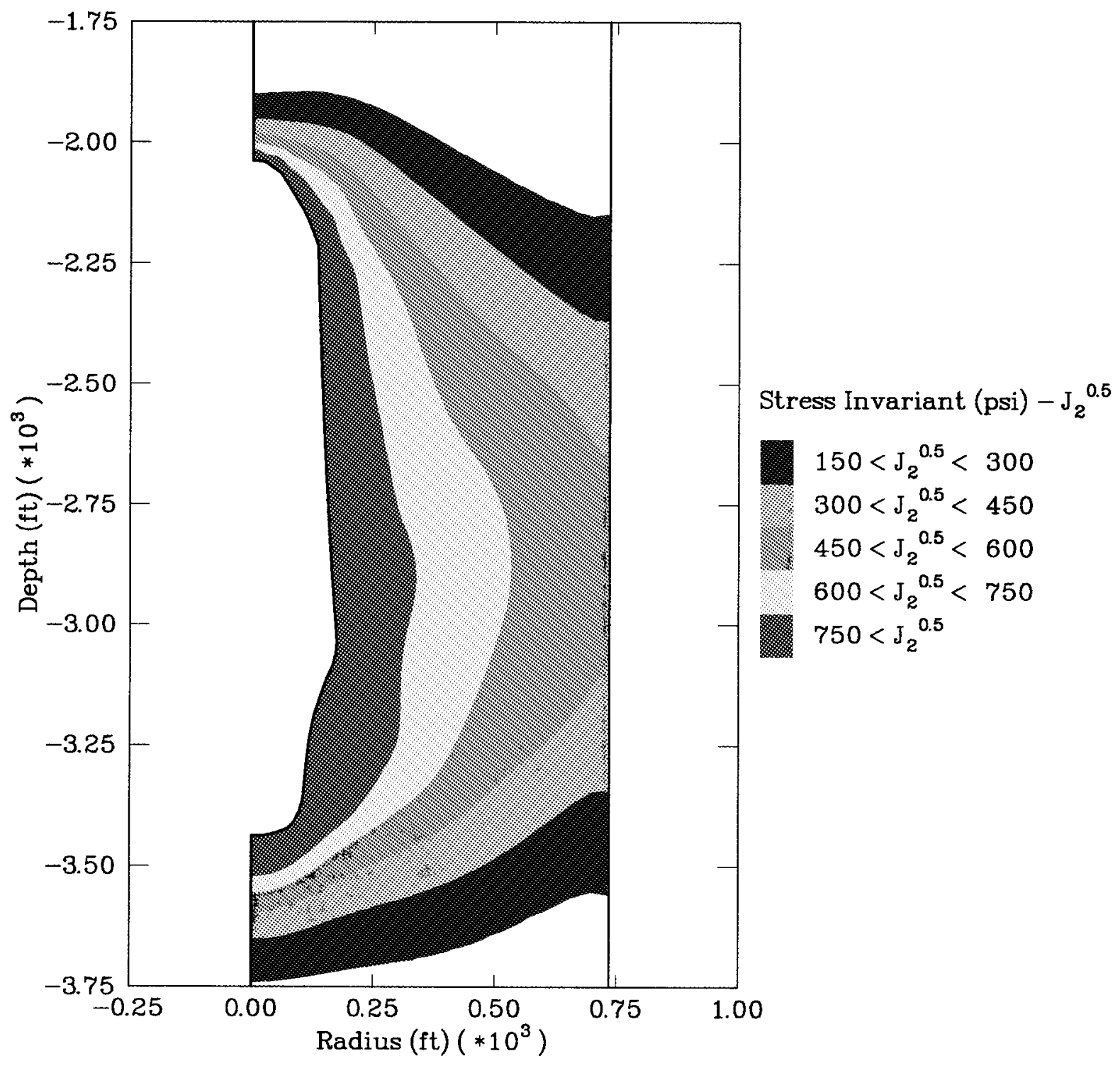

Figure 2-1. Shear Stress Regions Around a Typical Cavern in Salt Expressed in Terms of the Second Invariant of the Deviator Stress Tensor. 


\subsection{DESIGN CONSTRAINTS}

The approach generally used in the geomechanics evaluation of a salt cavern to be used for CNG storage is to determine an acceptable operating pressure range while meeting various design constraints [Ratigan et al., 1993]. These constraints typically include the following:

- Negligible potential for salt dilation that can lead to spalling in the cavern roof and/or walls and subsequent damage to the cavern or hanging string(s).

- Acceptable closure rates which will not result in excessive subsidence and/or damage to adjacent caverns and well casings.

- For bedded salts, an acceptable factor of safety in the overlying nonsalt layers to prevent roof collapse.

- Sufficient cavern spacing to negate cavern connectivity during (1) normal operations and (2) Mechanical Integrity Testing of the subject well or adjacent wells.

Of these constraints, the first is often the one that limits the minimum gas pressure in a natural gas storage cavern. When the deviatoric stress state (caused by the difference between the gas pressure inside a cavern and the in situ stress of the surrounding salt) becomes too large, dilation (microfracturing resulting in increased porosity) occurs in the salt. Spalling of the salt along the roof or wall of a cavern can occur when the dilation in the salt becomes severe enough to initiate macrofracturing.

\subsection{DAMAGE VARIABLES}

The onset of damage (or dilatant volumetric strain) in salt, as well as damage accumulation, is affected by a number of variables, including the following:

- Mean stress

- Time

- Porosity

- Temperature

- Pore pressure.

The effect that each of these variables has on damage is described below.

\subsubsection{Mean Stress}

High mean stress is known to suppress brittle deformations in most rocks, including salt. Examples of the effect of mean stress on dilatant volumetric strain are shown in Figure 2-2. This figure shows axial and volumetric strain as a function of time for four creep tests conducted 


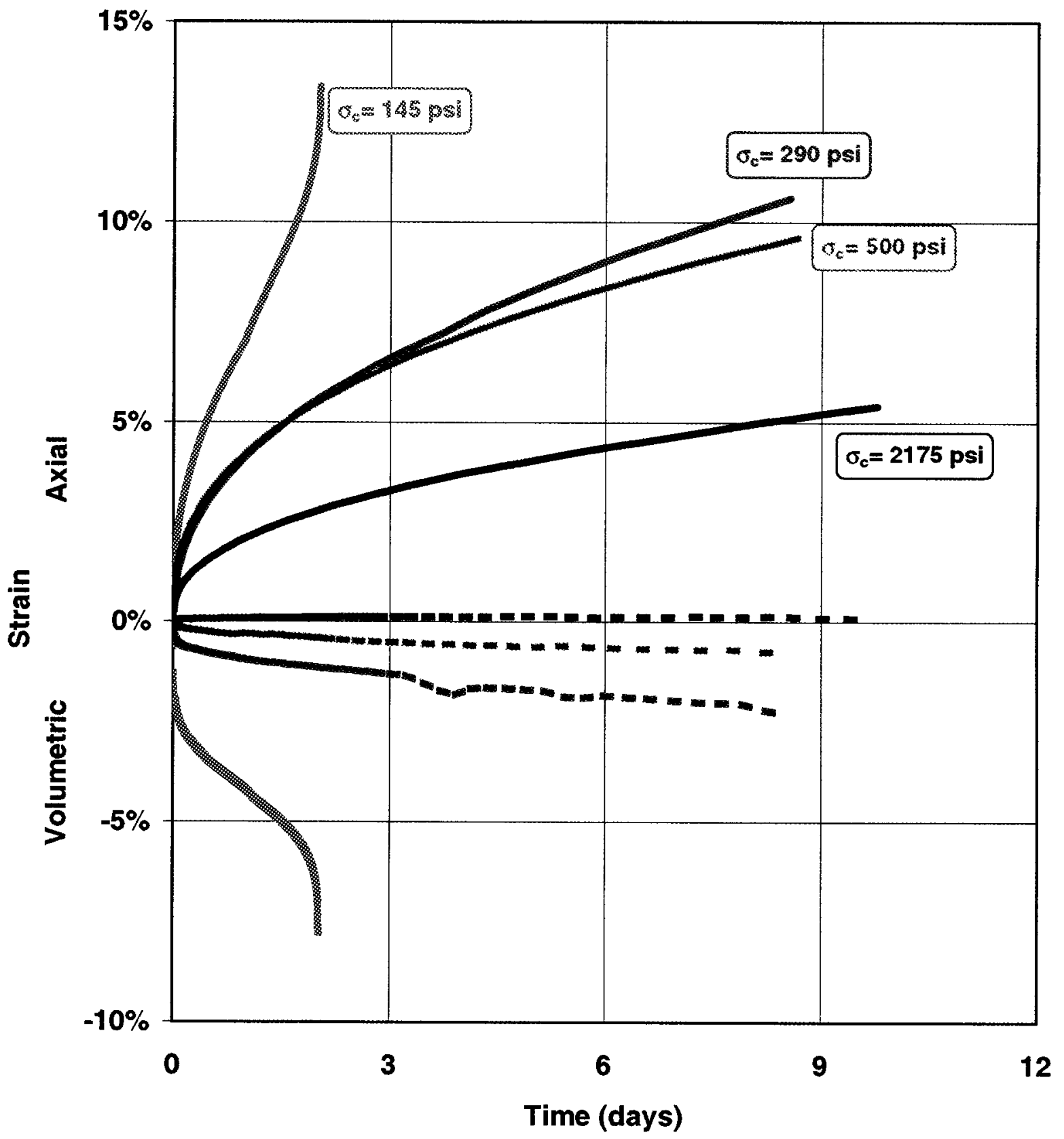

Figure 2-2. Effect of Mean Stress on Salt Dilation During Creep. 
at identical stress differences $(3,625 \mathrm{psi})$ and temperatures $\left(77^{\circ} \mathrm{F}\right)$, but at different confining pressures; i.e., 145, 290, 500, and 2,175 psi. At the highest confining pressure (i.e., 2,175 psi), the dilatant volumetric strain is completely suppressed so only constant-volume deformation occurs. In subsequent tests at lower confining pressures (or mean stresses), dilatant volumetric strain accumulates at increasingly higher rates, and in some cases, actually leads to rupture at the lowest confining pressures.

\subsubsection{Time}

Assuming the dilation stress has been exceeded in a creep test, the dilatant volumetric strain accumulates with time, as shown in the creep curves provided in Figure 2-2. The dilatant volumetric strain continues to accumulate until one of the following occurs: (1) the salt ruptures/fails or (2) the stress state is changed so that the dilation stress is no longer exceeded. In the latter case, evidence exists that damage can actually heal under conditions approaching hydrostatic compression [Costin and Wawersik, 1980; Brodsky, 1990; Pfeifle and Hurtado, 1998].

\subsubsection{Porosity}

Pfeifle and Hurtado [1998] have recently presented evidence from creep tests that suggests that salt damage (in terms of dilatant volumetric strain) increases with the initial porosity of the salt. These data are reproduced in Figure 2-3 which shows results for initial porosity levels of 0.62 percent to 3.22 percent. These results are consistent with Chan et al. [1996a] who have suggested that dilatant volumetric strain increases as a function of soft impurity content (e.g., clay minerals). The explanation for this relationship is that the interface between the salt and clay particles is weak such that all particles debond from the salt matrix, resulting in a distribution of pores containing detached clay particles.

\subsubsection{Temperature}

Although no direct evidence was found in the literature to assess the effect of temperature on damage in salt, it is well known that salt becomes much more ductile at elevated temperature. Based on this observation, it is assumed that the damage in salt will be suppressed under conditions of elevated temperature.

\subsubsection{Pore Pressure}

Fokker [1995] has shown that salt dilates in laboratory fracture tests at pore pressures that approach and/or exceed the confining pressure level used during the tests. If the Terzaghi effective stress concept (effective stress is equal to the difference between the total applied stress and the pore pressure) is invoked, then the effect of pore pressure on damage may be incorporated with the mean stress variable described above. That is to say, the effective mean stress could be substituted for the mean stress because pore pressure does not affect the manner in which stress difference is defined. 
RSI-621-98-049

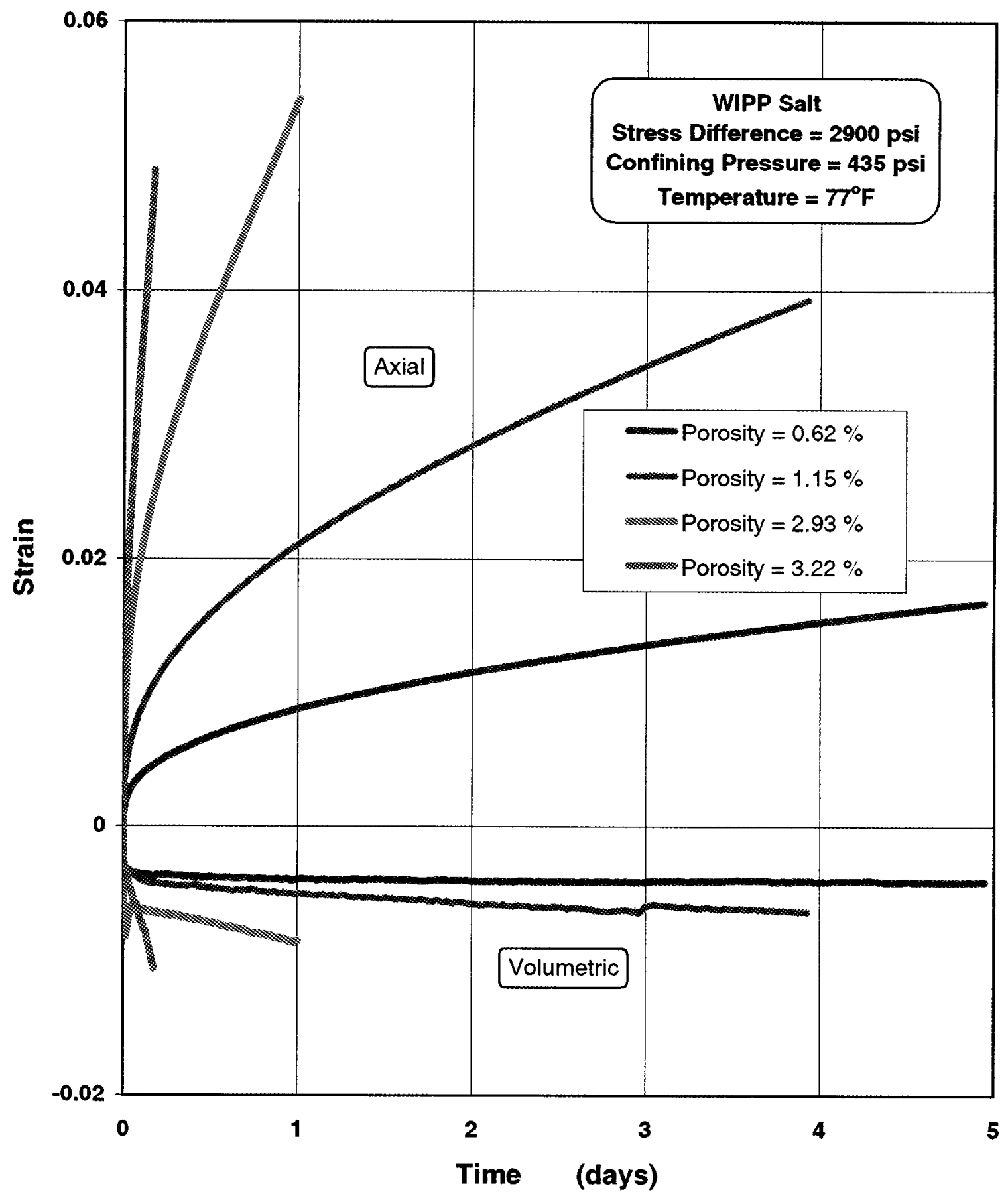

Figure 2-3. Axial and Volumetric Strain Versus Time for Salt Depicting Effect of Initial Porosity on Dilation. 


\subsection{TECHNICAL APPROACH FOR PREDICTING CAVERN STABILITY}

Currently, two methods are available to estimate the potential for salt dilation. The Damage Potential method indicates whether or not salt could dilate based only on the stress states in the salt [Ratigan et al., 1991]. This method has been used extensively in the last several years for estimating the potential for salt dilation around salt storage caverns (e.g., Ratigan et al. [1993]) and dry-mined excavations in salt at the WIPP in New Mexico (e.g., Hansen et al. [1993]; Lin and Van Sambeek [1992]; Van Sambeek et al. [1993]). The Multimechanism Deformation Coupled Fracture (MDCF) method [Chan et al., 1992] is based not only on the stress state, but also the stress history. This model not only gives an indication of whether or not the salt may dilate (or heal), but also quantifies the degree of dilation.

The idea that the minimum gas pressure in CNG salt caverns may be reduced with a different design analysis method is based on the concept that a more accurate prediction of the behavior of salt can be obtained by an advanced model that tracks the history of damage and healing within the salt. This is in contrast to the Damage Potential method approach which simply indicates whether or not the salt has experienced a stress state that could cause dilation. By incorporating damage accumulation and healing in the dilation model, some of the uncertainty can be reduced, and a more accurate dilation criterion may be established. If a more precise design criterion could be established for cavern analysis, the uncertainty in the minimum gas pressure requirement would also be reduced. This reduction of uncertainty may allow less conservative estimates of minimum gas pressure to be made, which could result in increased economic benefits for the CNG storage industry.

The key to demonstrating that the MDCF model is technically and economically feasible for use in the CNG industry requires that the new approach be compared to the current approach. This comparison is an analytical exercise that requires a geomechanics evaluation of typical CNG storage caverns using the Damage Potential method and the MDCF model to evaluate the cavern stability. The following two sections describe these two methods in more detail.

\subsection{DAMAGE POTENTIAL METHOD}

The Damage Potential method is based on the stress states that result in the dilation of rock salt in laboratory experiments. Ratigan et al. [1991] show that potential for dilation in the salt surrounding an underground opening in salt can be described as:

$$
\text { damage potential }=\frac{\sqrt{J_{2}}}{I_{1}}
$$


where $I_{1}$ is the first invariant of the stress tensor and $J_{2}$ is the second invariant of the deviatoric stress tensor. These stress measures are defined as follows:

$$
\begin{gathered}
I_{1}=\sigma_{1}+\sigma_{2}+\sigma_{3} \\
\sqrt{J_{2}}=\left(\frac{1}{6}\left[\left(\sigma_{1}-\sigma_{2}\right)^{2}+\left(\sigma_{1}-\sigma_{3}\right)^{2}+\left(\sigma_{2}-\sigma_{3}\right)^{2}\right]\right)^{1 / 2}
\end{gathered}
$$

where:

$$
\sigma_{1}, \sigma_{2}, \sigma_{3}=\text { principal stresses. }
$$

Based on creep tests on salt from the WIPP site and the Avery Island salt mine, dilation is expected when the damage potential is greater than about 0.27 . This value of the damage potential defines the dilation boundary and differentiates between dilating and nondilating stress states. This boundary is shown by the straight line in Figure 3-1. Salt with stress states in the region above this boundary are expected to dilate; those that are below the boundary are not expected to dilate. The Damage Potential method does not quantify the degree of dilation or microfracturing. Although this criterion is based on only WIPP and Avery Island salt, it has been found to characterize many Gulf Coast domal salts reasonably well [Ratigan et al., 1993].

\subsection{MDCF CONSTITUTIVE MODEL FOR ROCK SALT}

Considerable improvements in the ability to predict the deformation and deformation rate around underground openings in salt deposits have been obtained as a result of research efforts in various countries related to the permanent disposal of radioactive waste. Most of the constitutive models formulated have assumed that during creep deformation, the volume of the rock salt is constant and driven by deviatoric stresses induced by the excavation, independent of mean stress. The coupling of creep deformation and damage on the creep response of rock salt is treated by only a few constitutive models (e.g., Cristescu and Hunsche [1992]; Chan et al. [1996a; 1996b]; Aubertin et al. [1993]). The MDCF constitutive model given by Chan et al. [1996a; 1996b] is used here to describe the time-dependent inelastic deformation of rock salt.

\subsubsection{Background}

Development of the MDCF model was an evolutionary process. In the first published paper of the MDCF model, Chan et al. [1992] formulated a damage-based kinematic equation which was added to the dislocation-based kinetic equation of the multimechanism deformation (M-D) model given by Munson et al. [1989]. Thus, the MDCF model is an extension of the M-D model, which was developed to provide an accurate constitutive model for the constant-volume creep response of rock salt. Like the MDCF model, development of the M-D model was motivated by the need to develop a predictive technology for the safe disposal of radioactive waste for the 


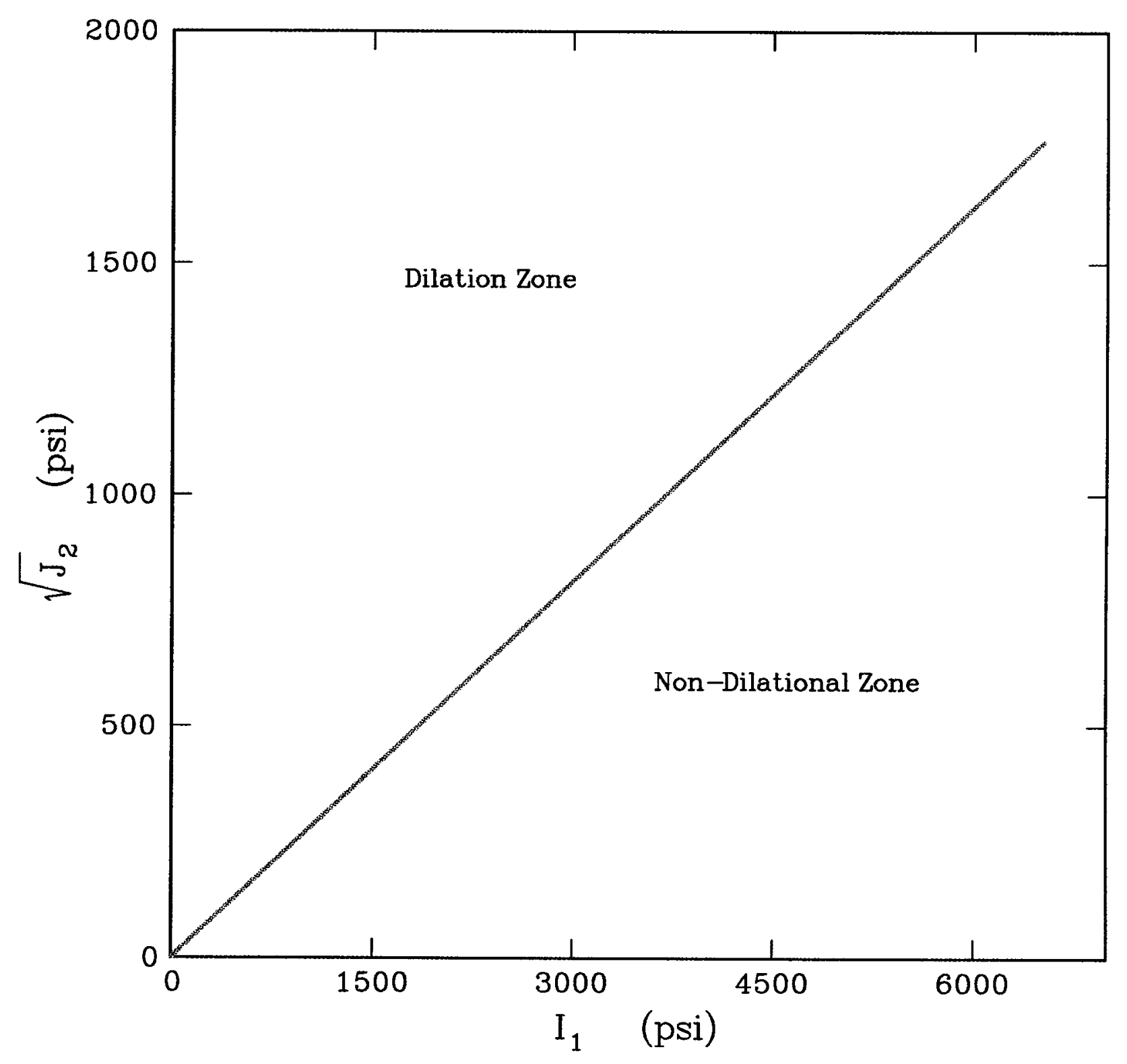

Figure 3-1. Dilation Boundary for Damage Potential Method (Developed by Ratigan et al. [1991]). 
WIPP. Therefore, a description of the MDCF model begins with a brief discussion of the M-D model.

\subsubsection{M-D Model}

The M-D model is based on micromechanistic concepts using the deformation mechanism map constructed by Munson [1979]. A deformation mechanism map is a representation in stress and temperature space of those micromechanical mechanisms controlling the deformation. Each mechanism has a constitutive equation that specifies the deformation or strain rate as a function of the imposed conditions of stress and temperature and the material properties. The deformation mechanism map constructed by Munson [1979] from available theoretical and experimental information on steady-sate creep of salt is shown in Figure 3-2. The map plots the dimensionless quantities of normalized stress (shear stress/shear modulus) against the homologous temperature (temperature/melting temperature). Five regimes are identified in this figure where separate mechanism dominate the deformation of salt: (1) defectless flow, (2) dislocation glide, (3) dislocation climb creep with two subregimes denoted by volume and pipe self diffusion, (4) diffusional creep with two subregimes denoted by volume and grain boundary self diffusion, and (5) a regime whose creep mechanism is undefined. The undefined mechanism has no micromechanical model, but is empirically well defined on the basis of laboratory testing.

In Figure 3-2, boundaries or portions of boundaries whose locations are confirmed by experimental evidence are shown as solid lines, boundaries whose locations are the result of calculations based on constitutive equations are shown as dashed lines, and boundaries whose locations are based on interpolation or extrapolation are shown as dotted lines. Inclusion of a question mark means the boundary is based on conjecture only. Constant strain-rate trajectories are shown on the map for strain rates of $10^{-12}, 10^{-10}$, and $10^{-8} / \mathrm{s}$ as determined by the micromechanistic models using site-specific parameter estimates established for rock salt. The constant strain-rate trajectories were placed on the deformation map by Munson [1979] for illustrative purposes since strain rate is specified for many laboratory applications.

Munson [1979] identified the probable WIPP repository stress and temperature conditions on the deformation mechanism map. As shown in Figure 3-2, only three mechanisms need to be incorporated into the constitutive model for the expected repository conditions. These three mechanisms are also applicable for the conditions expected for most, if not all, CNG storage caverns. Based on the deformation mechanism map and the three rate-controlling mechanisms, a constitutive model was proposed by Munson and Dawson [1979] which was later called the M-D model. The model assumes that each of the three mechanism act in parallel; thus, the total steady-state creep rate is just the sum of the creep rates of the individual mechanism. Primary (transient) creep was incorporated into the model by multiplying the steady-state creep rate by a transient function which was later modified as described by Munson et al. [1989]. The transient function is composed of a work-hardening branch, equilibrium branch, and a recovery branch for an internal variable whose development is governed by a separate evolution equation. This model provides the framework for the development of the MDCF model which extends the 


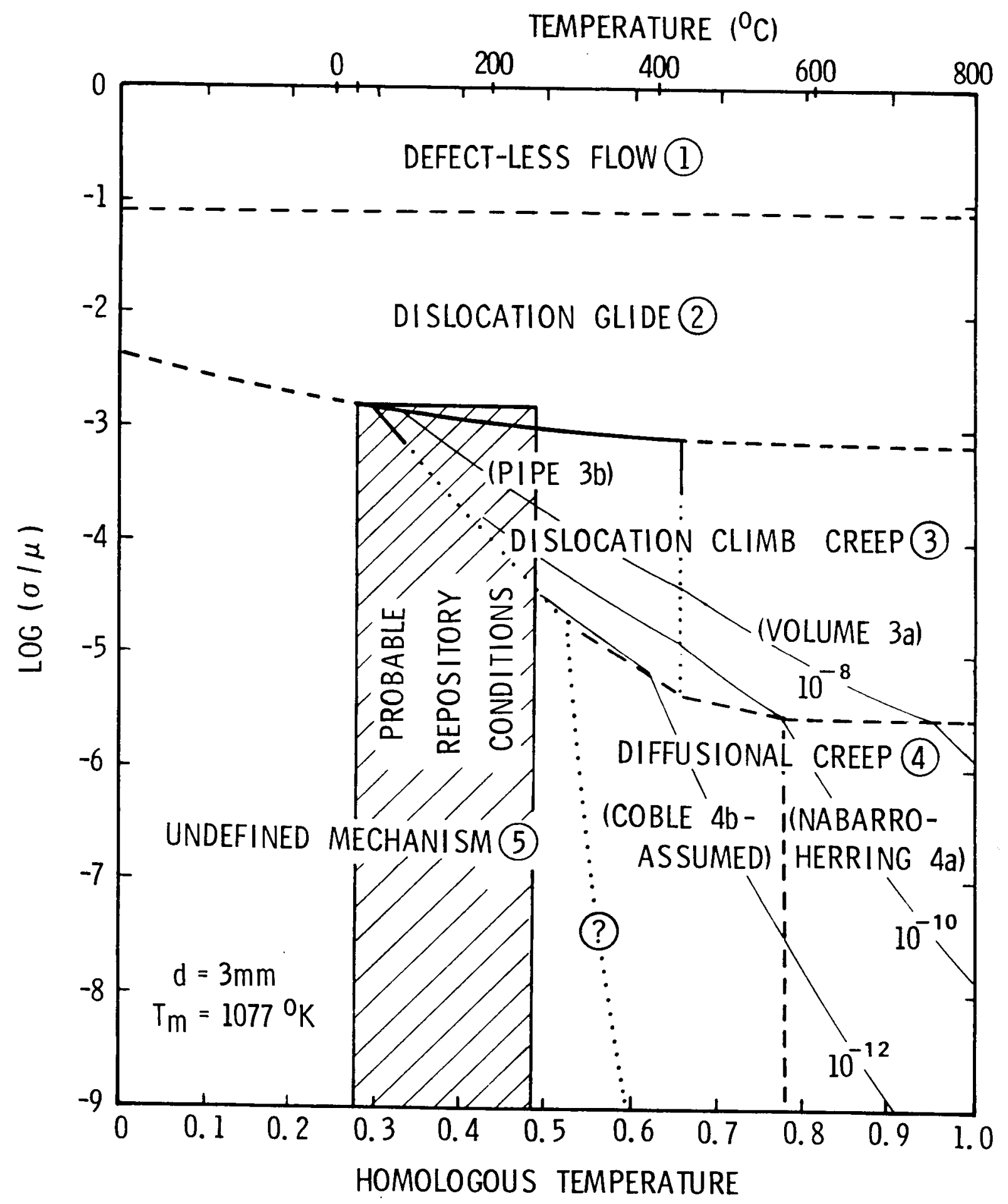

Figure 3-2. Deformation Mechanism Map for Salt (After Munson [1979]). 
M-D model by incorporating an expression for describing the contribution of cavities or microcracks to the macroscopic inelastic strain rate.

\subsubsection{Extension of the M-D Model}

Several papers have been published since the initial paper by Chan et al. [1992] documenting enhancements and revisions of the MDCF model (e.g., Chan et al. [1994; 1995a; 1995b; 1996a; 1996b; 1996c; 1997]). Modifications and enhancements include, among others, development of a nonassociated damage-induced flow law, clay particle function, cleavage fracture mechanism, and healing mechanism. The latest known version of the model was used in this study with minor exceptions as described below.

The total inelastic strain rate in the MDCF model is represented by two components, dislocation creep and creep-induced damage, that contribute to the macroscopic strain rate. Two kinetic equations describe the damage component of the model, one for shear-induced damage and one for cleavage fracture. These kinetic equations account for creep-induced damage during the transient, steady-state, and tertiary creep stages, with the damage that accumulates in the transient creep region not leading to tertiary creep immediately. Important characteristics of the model include the ability to predict pressure-dependent flow and plastic dilatancy.

\subsubsection{Dilatancy Boundary}

Based on laboratory experiments, damage-induced inelastic flow in rock salt is nonassociated, dilational, and contributes significantly to the macroscopic strain rate at low confining pressures. The inelastic strain rate and volumetric strain due to damage decreases with increasing confining pressures and is suppressed at sufficiently high confining pressures. Unlike the Damage Potential method, a dilatancy boundary is not given in terms of the second invariant of the deviatoric stress tensor and the first invariant of the Cauchy stress tensor. Instead, the MDCF model was formulated using a work-conjugate stress measure (damage stress) to determine dilational stress states in terms of principal stresses. Dilation is expected when the damage stress measure is greater than zero. The damage stress is given by:

$$
\sigma_{e q}^{\omega}=\left|\sigma_{1}-\sigma_{3}\right|+\left(1-p_{1} \rho\right) x_{2} x_{7} \operatorname{sgn}\left(I_{1}-\sigma_{3}\right)\left[\frac{I_{1}-\sigma_{3}}{3 x_{7} \operatorname{sgn}\left(I_{1}-\sigma_{3}\right)}\right]^{x_{8}}+x_{1} \sigma_{1} H\left(\sigma_{1}\right)
$$

where $I_{1}$ is the first invariant of the Cauchy stress tensor; the $x$ 's and $p_{1}$ are material constants; $\rho$ is the impurity (clay) content; and $\sigma_{1}$ and $\sigma_{3}$ are the maximum and minimum principal stress; respectively, with compression assumed to be negative. The first term represents the driving force for shear-induced damage, which leads to the opening of "wing-tip" microcracks or grain boundary cracks. The second term in Equation 3-4 represents the suppression of microcrack growth by a confining pressure. This term was recently extended to account for the increase in damage accumulation associated with increasing impurity of clay content [Chan et al., 1996a]. The third term represents the opening of microcracks by the maximum tensile 
stress, $\sigma_{1}$. Given the parameter $x_{1}$ is positive and the Heaviside step function $\left(H\left(\sigma_{1}\right)\right)$, the damage stress measure is positive whenever the maximum principal stress is tensile.

A dilatancy boundary for the MDCF model can be presented in terms of $J_{2}$ and $I_{1}$ if the intermediate principal stress is expressed in terms of the minimum or maximum principal stress. In Figure 3-3, dilation boundaries are presented for salt at the WIPP site that have been categorized as clean and argillaceous. The boundaries were calculated using Equation 3-4, assuming values for $\rho$ of 0.0 percent for clean salt and 2.9 percent for argillaceous salt. The dilation boundaries presented in this figure assume stress states where the two maximum principal stresses are equal (i.e., triaxial test condition). However, the dilation boundaries do not differ significantly when three-dimensional stress states or varying load paths are considered. Again, salt is expected to dilate when the stress state is above the dilation boundary. Likewise, no dilation is expected for stress states below the dilation boundary corresponding to a stress measure given by Equation 3-4 that is equal or less than zero. The dilation boundary determined using the Damage Potential method is included in Figure 3-3 for comparative purposes. As shown in Figure 3-3, the dilatancy boundary is very sensitive to the value specified for the clay content parameter $\rho$. The clay particle function is discussed in more detail in the following section.

\subsubsection{Clay Particle Function}

The MDCF model contains a clay particle function to account for the possible effects of soft impurity content on the creep and damage responses in argillaceous salt. The clay particle function was developed, in part, based on the results reported by Nemat-Nasser [1983] of brittle materials with embedded inclusions. The experimental evidence indicated that the weak damage process associated with pores, holes, and inclusions was the nucleation of microcracks by tensile stresses induced at the poles. Chan et al. [1996a] assumed that the interface between the clay particles and salt is weak such that all particles are debonded from the salt matrix, resulting in a distribution of pores containing detached clay particles.

As mentioned in Chapter 2.0, Pfeifle and Hurtado [1998] have recently presented evidence from creep tests that suggests that salt damage (in terms of dilatant volumetric strain) increases with the initial porosity of the salt. This data was shown in Figure 2-3 for porosity levels up to 0.62 percent. These results are consistent with Chan et al. [1996a] for similar values of percent clay content. Conversely, Pfeifle and Hurtado [1998] did not observe a strong correlation between clay content and salt damage. However, limited data are available to characterize the damage response of impure salt and is the subject of future research. Therefore, it is postulated here that the increase in the inelastic strain rate and dilatant volumetric strain observed for impure salt results from pores or inclusion, either brine filled, gas filled, or soft impurity content, that is weakly bonded to the salt matrix. For this reason, the term impurity content is used in this report instead of volume fraction of clay to describe the behavior of salt with pores, holes, and/or inclusions. 


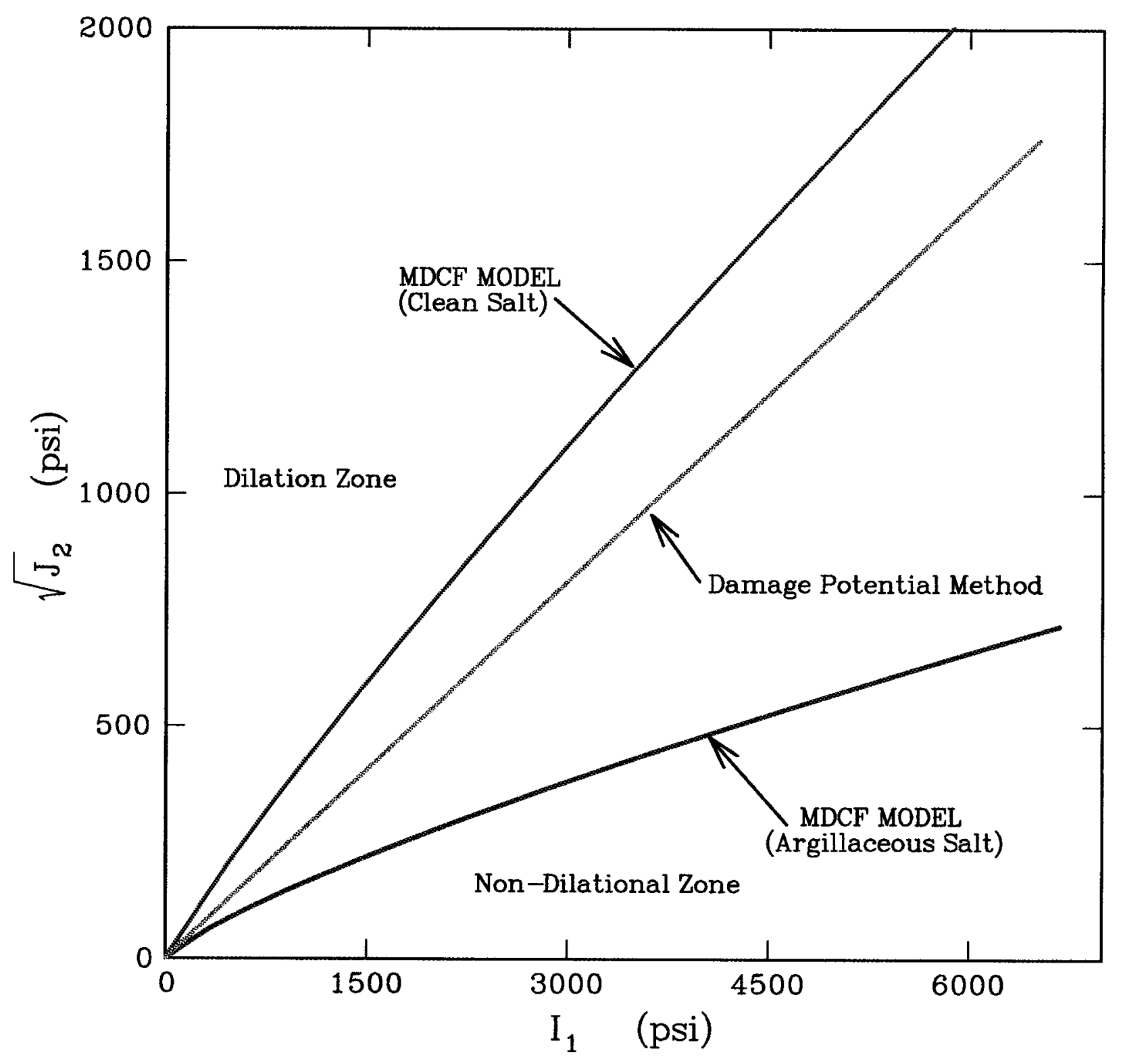

Figure 3-3. Comparison of Dilation Boundaries Predicted Using the MDCF Model for WIPP Salt. 


\subsubsection{Damage Variable}

In addition to a direct contribution to the inelastic strain rate, the MDCF model was formulated such that damage also produces a softening effect as proposed by Kachanov [1958]. The Kachanov damage variable reduces the load-bearing capacity through a reduction in the effective area using a continuum damage mechanics approach. For the MDCF model, the Kachanov damage variable $(\omega)$ is determined from an evolutionary equation and provides a scalar measure for the level of damage. In addition to the damage state variable, damage is quantified through model prediction of dilatant volumetric strain.

\subsubsection{Cavern Stability Design Criterion}

Coupling of creep and damage in the MDCF model allows calculation of the entire creep curve, including tertiary creep. The onset of tertiary creep is traditionally defined as the time the minimum strain rate is observed in a creep test. Experimental evidence shows that the time to the onset of tertiary creep and the strain to creep rupture increases with confining pressure at a constant stress difference. The mechanical strength of salt decreases rapidly during the tertiary creep stage; consequently, the stability of a storage cavern in salt could be jeopardized if the salt undergoes tertiary creep. Chan et al. [1996c; 1997] have proposed using critical values of the damage variable, $\omega$, as indicators of the onset of tertiary creep and creep rupture. Chan et al. [1996c; 1997] estimate critical damage values of 0.015 and 0.15 to represent the onset of tertiary creep and creep rupture in WIPP salt, respectively.

A comparison of the measured and calculated time-to-rupture responses of WIPP salt in triaxial compression is shown in Figure 3-4. The experimental results shown in this figure were obtained from triaxial compression creep tests conducted on cylindrical specimens at $77^{\circ} \mathrm{F}$ and a stress difference of 3,625 psi under various confining pressures. Test points indicated by closed circles indicate rupture, while those with an arrow did not fail at the time the test was terminated. Based on this figure, a critical damage value of 0.015 may not be a conservative estimate for the onset of tertiary creep because two of the eight experimental tests ruptured before the model predicted the onset of tertiary creep. A more conservative estimate for the time-to-creep rupture is obtained with a critical damage value of 0.0025 . Comparison of calculated and experimental creep rupture times using a critical damage values of 0.0025 is shown in Figure 3-4. As shown in this figure, the time predicted by the MDCF model to obtain a damage level of 0.0025 is less than the measured time-to-rupture for all of the experiments. Therefore, a critical damage value of 0.0025 is proposed as the design criterion to be used here for evaluating the stability of CNG storage caverns.

The rate of evolution of the damage variable depends on a number of variables, including stress, impurity content, and material parameters. Because of the variability of salt and limited availability of data, additional research is warranted to increase confidence in the limiting value of the damage variable for evaluating cavern stability. However, the proposed critical damage value of 0.0025 should provide a conservative estimate for material damage that does not 


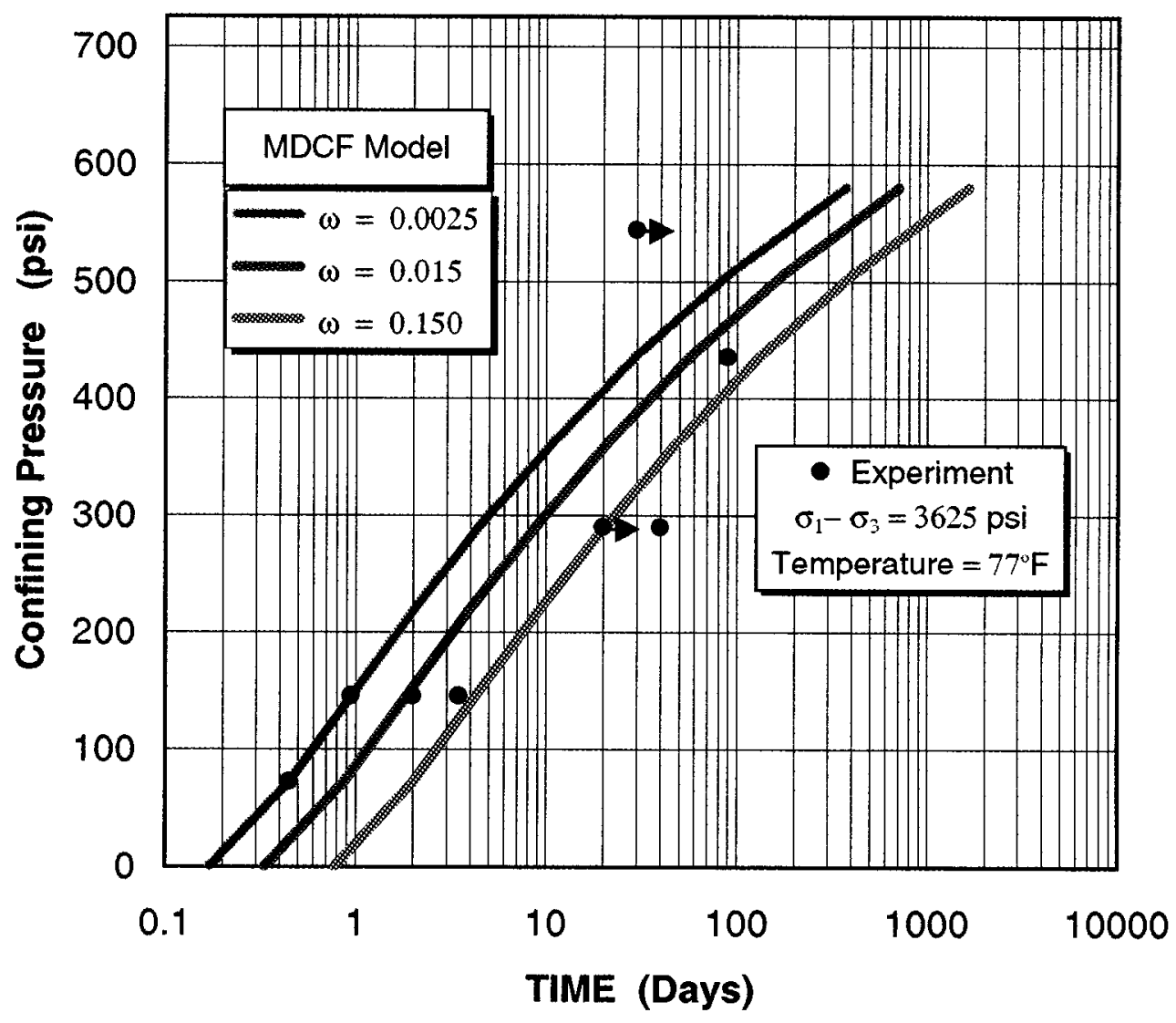

Figure 3-4. Comparison of Calculated and Measured Time-to-Rupture Results of WIPP Salt as a Function of Confining Pressure. 
greatly influence the structural integrity of salt using parameter estimates established for the WIPP.

\subsubsection{Damage Healing}

The work of Chan et al. [1995b] represents one of the first steps in simulating the healing of salt. Development of the healing term was based largely on the results of a series of hydrostatic compression tests performed by RESPEC on WIPP salt at 68,115 , and $158^{\circ} \mathrm{F}$ and reported by Brodsky and Munson [1994]. In these experiments, damage was introduced by straining cylindrical specimens with a constant axial strain rate to 1.5 percent axial strain at low confining pressure $(72.5 \mathrm{psi})$. The predamaged specimens were then compressed under a hydrostatic pressure of 2,175 psi to isolate the damage healing processes from dislocation creep. The amount of volumetric strain recovered by damage healing was quite rapid during the early stages of these tests and nearly the same magnitude for all the tests regardless of the temperature. The rapid healing behavior is thought to arise from the closure of open microcracks. During the later stages of the healing tests, the rate of healing was much slower; the amount of volumetric strain recovered increased with temperature and with the time of healing, consistent with sintering of microcracks by a diffusion controlled process.

Figure 3-5 shows a plot of the normalized volumetric strain measurements versus time for one of the hydrostatic compression tests reported by Brodsky and Munson [1994]. In this figure, normalized volumetric strain is presented in terms of the volumetric strain due to healing

$\left(\varepsilon_{v}^{h}\right)$ and the initial volumetric strain at the beginning of the healing process $\left(\varepsilon_{v o}\right)$. Two healing mechanisms are indicated in this figure by the bilinear plots of two different slopes. It has been suggested that Mechanisms 1 and 2 correspond to closing and healing of microcracks, respectively [Chan et al., 1995b] and can be represented by identical kinetic equations with different time constants.

Instead of having separate terms for individual healing mechanisms, the current form of the MDCF model [Chan et al., 1996b] uses a single healing term. To account for the experimental observation of two characteristic times (two healing mechanism rates), a variable time constant is used that is a function of the volumetric strain. When the volumetric strain is relatively large, the value of the time constant represents the characteristic time constant for damage healing by crack closure. As the volumetric strain becomes small, the value of the time constant is increased to correspond to the characteristic time constant for Mechanism 2.

Both isotropic and anisotropic healing behavior can be described by the MDCF model. The healing inelastic damage flow is anisotropic in nature because damage will typically accumulate normal to the major principal stress (compression negative). To implement the anisotropic nature of the healing, Chan et al. [1996b] have developed the flow potential based on stress-induced anisotropy. However, the state of stress does not provide information regarding the direction of damage. For this reason, isotropic flow based only on mean stress was adopted for this study. 


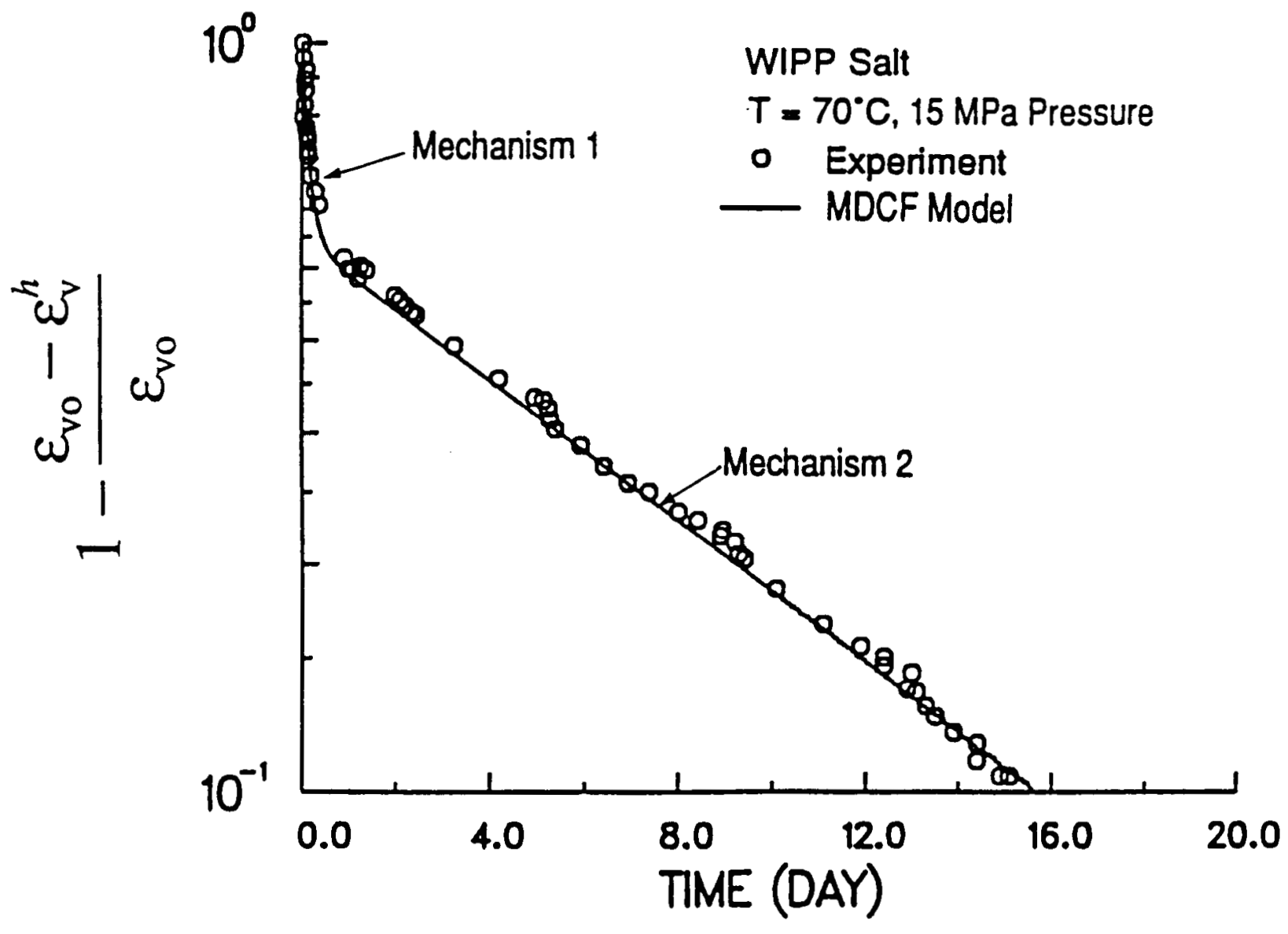

Figure 3-5. A Semilog Plot of Normalized Volumetric Strain Versus Time for Damage Healing of WIPP Salt at $70^{\circ} \mathrm{C}\left(158^{\circ} \mathrm{F}\right)$ Under a Hydrostatic Pressure of $15 \mathrm{MPa}$ (2,175 psi) (After Chan et al. [1996b]). 


\subsubsection{Constitutive Model Equations}

The MDCF model incorporated into the finite element code SPECTROM-32 [Callahan et al., 1989] follows the work of Chan et al. [1996a] and includes an extension of the model to represent damage healing given by Chan et al. [1996b] with minor exceptions. A detailed description of the model used in this study is provided in Appendix A. 


\subsection{FINITE ELEMENT PROGRAM AND GEOMECHANICAL MODELS}

The finite element method was used to predict the minimum gas pressure and continuum damage around two natural gas storage caverns at different depths. Axisymmetric models were developed for both of the caverns used in this study to demonstrate the applicability of the MDCF model to predict the minimum gas pressure of CNG storage caverns. A description of the finite element program, the modeled geometry, in situ conditions, and fluid properties of the two natural gas storage caverns used for demonstrative purposes is described below.

\subsection{FINITE ELEMENT PROGRAM}

The finite element program SPECTROM-32 [Callahan et al., 1989] was used to model the mechanical behavior of the generic cavern described above. SPECTROM-32 is a thermomechanical, finite element program that has been developed by RESPEC for the solution of rock mechanics problems. It was designed specifically for the simulation of underground openings and structures. SPECTROM-32 not only has the capability to model the elastic-plastic response that is commonly associated with brittle rock types, but it also has the capability to simulate the viscoplastic behavior that is observed in salt. The features and capabilities of SPECTROM-32 that were required specifically for the simulation of the storage caverns include:

- Options for two-dimensional and axisymmetric geometries.

- Kinematic and traction boundary conditions.

- MDCF constitutive model for viscoplastic behavior of salt, including damage.

- Capability to represent arbitrary in situ stress and temperature fields.

- Capability to simulate excavation or solution-mining operations.

\subsection{GEOMECHANICAL MODELS OF STORAGE CAVERNS}

A geomechanics evaluation of a storage well field is usually a three-dimensional problem. However, it is not usually practical to solve three-dimensional rock mechanics problems using the finite element method when the material displays time-dependent deformation (creep). Practical solutions can be realized if the problem can be reduced to one or more two-dimensional problems. For the caverns used in this study, axisymmetric models are a very good representation of the in situ geometry. The geometry and depth of the models used in this study represent existing storage caverns in domal salt. Site-specific material properties were used where possible to provide a realistic example of the expected results for these caverns. The geometry and in situ conditions for the two caverns are discussed separately below. 


\subsubsection{Cavern A}

Cavern $A$ is a natural gas storage cavern located in a salt dome that includes a number of other caverns used for storage or brine production. A few of these caverns are in close proximity to Cavern A such that their presence will have an impact on the stress state of the salt near Cavern A. The finite element mesh for Cavern A is shown in Figure 4-1, and specific characteristics are listed in Table 4-1. The cavern is modeled between the depth interval 2,009 and 3,438 feet below ground surface. The geometry (radius as a function of depth) for this cavern was determined based on a design solution-mining simulation. The model extends vertically from the top of the salt dome at a depth of 669 feet to a depth of 7,000 feet. Because the cavern is located in a salt dome, no stratigraphic members are included in the model and each element represents a volume of salt. An outer radius of 735 feet was specified for this model to approximate the effects of other storage caverns that are in near proximity to Cavern A. The mesh contains 4,639 nodes and 1,480 eight-noded elements. Elements near the cavern walls are very finely subdivided with the first layer of elements having a thickness of only about 3 feet. This extremely fine subdivision was used to accurately represent the large stress gradients anticipated near the cavern.

\subsubsection{In Situ Temperature Profile}

Although the circulation of brine during leaching of the well and the compression and decompression of gas during natural gas storage would perturb the ambient temperature distribution in the immediate vicinity of the well, these perturbations were assumed to have negligible effects on the mechanical behavior of the well and were not modeled. A temperature gradient that is constant with depth was assumed for analyses of Cavern $A$. The temperature as a function of depth is given by:

$$
T=79.3+0.0106 z
$$

where $T$ is the temperature in degrees Fahrenheit and $z$ is the depth in feet. This temperature profile results in a temperature of approximately $100^{\circ} \mathrm{F}$ and $115^{\circ} \mathrm{F}$ at the top and bottom of Cavern A, respectively.

\subsubsection{In Situ Stress Distribution}

The in situ stress distribution was assumed to be isotropic and equal to the weight of the overburden. The top of the salt above Cavern $A$ is at a depth of approximately 669 feet below ground surface. The caprock and sediment overlying the salt were modeled as a pressure traction boundary and were estimated based on an average density of $161.6 \mathrm{pcf}$. The resulting overburden pressure at the top of the salt dome is 749 psi. The density of the salt was assumed to be $135 \mathrm{pcf}$, which results in a vertical gradient in stress of $0.94 \mathrm{psi} /$ foot below the top of the salt dome. Consequently, the in situ stress distribution prior to solutioning of the well was assumed to be: 


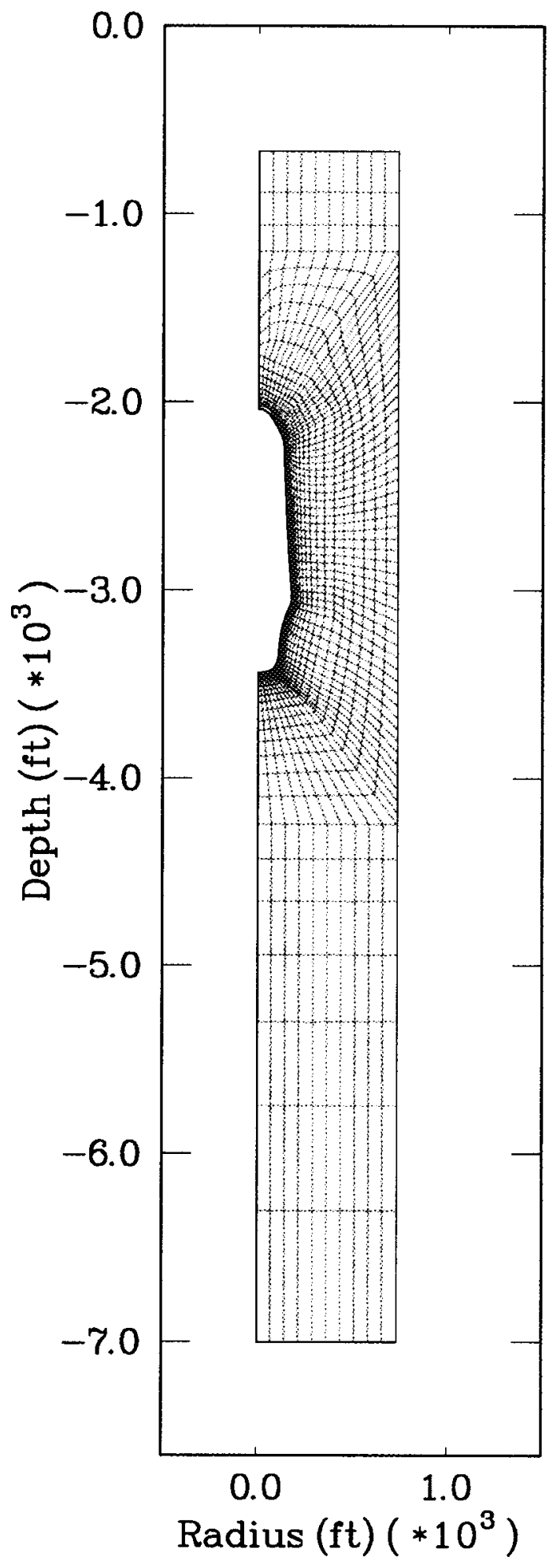

Figure 4-1. Cavern A Finite Element Mesh. 


$$
\sigma_{r}=\sigma_{\theta}=\sigma_{z}=0.94(z-669)+749
$$

where $\sigma_{r}, \sigma_{\theta}$, and $\sigma_{z}$ are the radial, tangential, and vertical stress components in psi, and $z$ is the depth in feet. At the casing shoe depth (2,009 feet), the vertical stress is estimated to be about 2,009 psi based on Equation 4-2.

Table 4-1. Characteristics of Gas Storage Caverns

\begin{tabular}{|l|c|c||}
\hline \multicolumn{1}{|c|}{ Cavern Characteristic } & \multicolumn{2}{c|}{ Cavern } \\
\cline { 2 - 3 } & A & B $^{(\mathrm{a})}$ \\
\hline \hline Casing Shoe Depth (ft) & 2,009 & 4,088 \\
\hline Approximate Cavern Total Depth (ft) & 3,438 & 5,080 \\
\hline Approximate Cavern Maximum Diameter (ft) & 350 & 200 \\
\hline Approximate Cavern Volume (MMbbls) $)^{(\mathrm{b})}$ & 15.2 & 3.7 \\
\hline $\begin{array}{l}\text { Approximate Design Minimum Cavern Pressure at the } \\
\text { Casing Shoe (psig) }\end{array}$ & 603 & 1,200 \\
\hline $\begin{array}{l}\text { Approximate Design Maximum Cavern Pressure at the } \\
\text { Casing Shoe (psig) }\end{array}$ & 1,707 & 3,475 \\
\hline Approximate Maximum Working Gas Volume (Bcf) ${ }^{(\mathrm{c})}$ & 7.3 & 3.2 \\
\hline Approximate Minimum Cushion Gas Volume (Bcf) & 3.3 & 1.8 \\
\hline Approximate Total Gas Volume (Bcf) & 10.6 & 5.0 \\
\hline
\end{tabular}

(a) The minimum cavern pressure, working gas volume, and cushion gas volume for this well were incorrectly listed in Ratigan [1997].

(b) Millions of petroleum barrels.

(c) Billion standard cubic feet.

\subsubsection{Cavern B}

The finite element mesh for Cavern $B$ is shown in Figure 4-2. The cavern is modeled between the depth interval of 4,088 and 5,080 feet. This mesh contains 7,247 nodes and 2,340 eight-noded elements. The model extends vertically from the top of the salt at a depth of 1,680 feet to a depth of 7,100 feet. Because Cavern B is essentially isolated from other caverns, an outer radius of 1,500 feet was used to approximate an infinite boundary. Again, elements near the cavern walls are very finely subdivided to accurately represent the large stress gradients anticipated near the caverns. Specific characteristics for this cavern are listed in Table 4-1. 
RSI-621-98-046

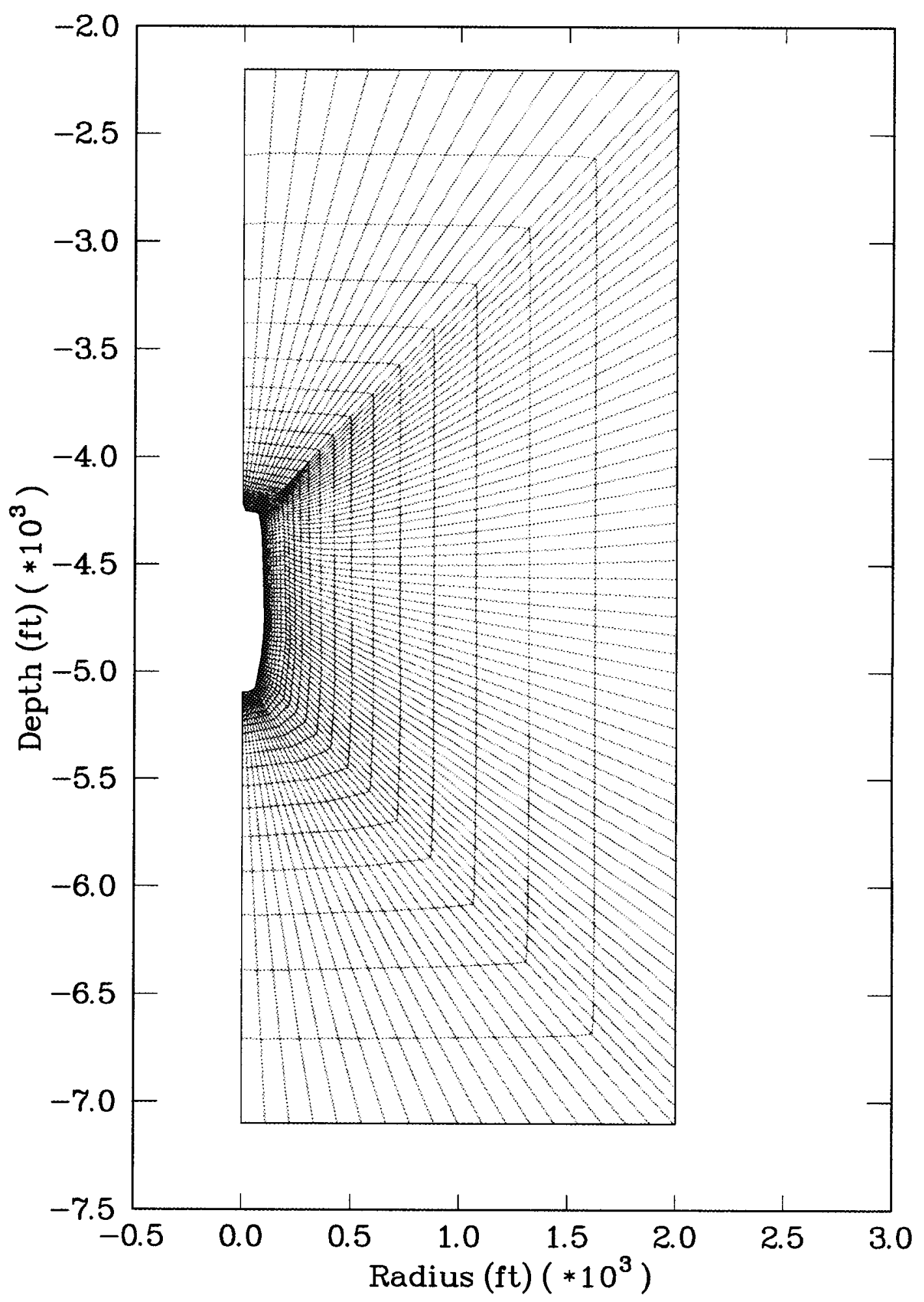

Figure 4-2. Cavern B Finite Element Mesh. 


\subsubsection{In Situ Temperature Profile}

Although leaching of the well and normal movement of product would perturb the ambient temperature distribution in the immediate vicinity of the well, these perturbations were assumed to have negligible effects on the mechanical behavior of the well and were not modeled. A temperature gradient that is constant with depth was assumed for analyses of Cavern B. The temperature as a function of depth is given by:

$$
T=102.9+0.005662 z
$$

where $T$ is the temperature in degrees Fahrenheit and $z$ is the depth in feet. This temperature profile results in a temperature of approximately $126^{\circ} \mathrm{F}$ and $132^{\circ} \mathrm{F}$ at the top and bottom of Cavern B, respectively.

\subsubsection{In Situ Stress Distribution}

The in situ stress distribution was assumed to be isotropic and equal to the weight of the overburden. The density of the salt was assumed to be 135 pcf, which results in a vertical gradient in stress of $0.94 \mathrm{psi} /$ foot below the top of the salt above Cavern B. The caprock and sediment overlying the salt were modeled as a pressure traction boundary and were assumed to have an average density of $144 \mathrm{pcf}$, which results in an overburden stress of $1,680 \mathrm{psi}$ at the top of the salt. Consequently, the in situ stress distribution prior to leaching of the well was assumed to be:

$$
\sigma_{r}=\sigma_{\theta}=\sigma_{z}=0.94(z-1,680)+1,680
$$

where $\sigma_{r}, \sigma_{\theta}$, and $\sigma_{z}$ are the radial, tangential, and vertical stress components in psi. and $z$ is the depth in feet.

\subsubsection{Cavern A and Cavern B Model Boundary Conditions}

The kinematic boundary conditions specified along the sides of the axisymmetric models for Cavern A and Cavern B were:

- No radial displacement along the centerline.

- No radial displacement along the outer radius.

- No vertical displacement along the bottom surface.

The upper surfaces of the models are free to move in both the radial and vertical directions. After the excavation of the salt was simulated, normal tractions were specified along the surface of the cavern to simulate the fluid pressure inside the cavern. The magnitudes of these tractions are equal to the hydrostatic pressure based on the densities of the fluids in the cavern plus the pressure specified at the wellhead. 


\subsection{PROPERTIES OF WELL FLUIDS}

The mechanical response of the storage caverns not only depends on the material properties of the salt surrounding the well but also on the material properties of the fluids inside the well. The wells were assumed to be filled with saturated brine before being dewatered. The wells are subsequently filled with compressed natural gas. In the simulations, these fluids are represented by their pressures applied as normal tractions to the surfaces of the well. An equation of state relating the fluid's pressure to its density and temperature was assumed for each fluid. The assumed equations of state used to predict the resultant vertical pressure gradients for brine and natural gas used in this study are provided in Appendix C. 


\subsection{NUMERICAL RESULTS OF CAVERN STABILITY BASED ON DILATANCY BOUNDARIES}

\subsection{PROBLEM DESCRIPTION}

In this task, the dilatancy boundary predicted with the Damage Potential method is compared to that of the MDCF model. Finite element models were used to make the comparison of the boundaries of the two methods during simulated gas withdrawal from the two subject caverns.

In Figure 5-1, the dilation boundaries based on the MDCF model and the Damage Potential method are shown in $I_{1}-\sqrt{J_{2}}$ stress space. The Damage Potential method dilation boundary is represented by a straight line, as described in Section 3.1. The four MDCF dilation boundaries shown are based on Equation 3-4 with impurity or porosity levels between 0 and 3 percent. Also shown in Figure 5-1 are test data on salt samples from each of the cavern sites. Tests on salt from the Cavern A site include both Standard Triaxial Compression (STC) tests in which the confining pressure is held constant as the axial load is increased and Constant Mean Stress (CMS) tests where the confining pressure is decreased as the axial load is increased. Creep tests were used to determine the dilation boundary for salt from the Cavern B site. Because the stress state is held constant in creep tests, these test data only determine whether or not dilation is occurring at a given stress state; a single test cannot be used to determine the dilation boundary.

Finite element simulations were used to demonstrate the use of dilation boundaries in developing minimum gas pressure design constraints for natural gas storage caverns. Typically, using the Damage Potential method, the design minimum gas pressure for a cavern is determined by simulating gas withdrawal from the cavern while monitoring the magnitude and location of the damage potential values. As gas is withdrawn from the cavern, the difference between the cavern pressure and the in situ stress state in the salt surrounding the cavern increases, resulting in higher damage potential values. The design minimum gas pressure is determined when the damage potential values in the salt surrounding the cavern reach the value determined through laboratory testing which results in dilation of the salt or a value which represents the desired factor of safety with respect to this value. Typically, only the salt surrounding the upper portion of the cavern is evaluated since dilation in the lower portion of a cavern generally does not have an adverse impact on cavern stability.

In the finite element simulations used to compare the salt dilation boundaries, cavern development was simulated by instantaneously excavating the cavern with a brine pressure head and allowing the surrounding salt to creep for a time equal to the actual solutioning period. After the solutioning period, dewatering of the caverns was simulated. Cavern A was dewatered at maximum gas pressure. Cavern $B$ was dewatered at a pressure less than the 


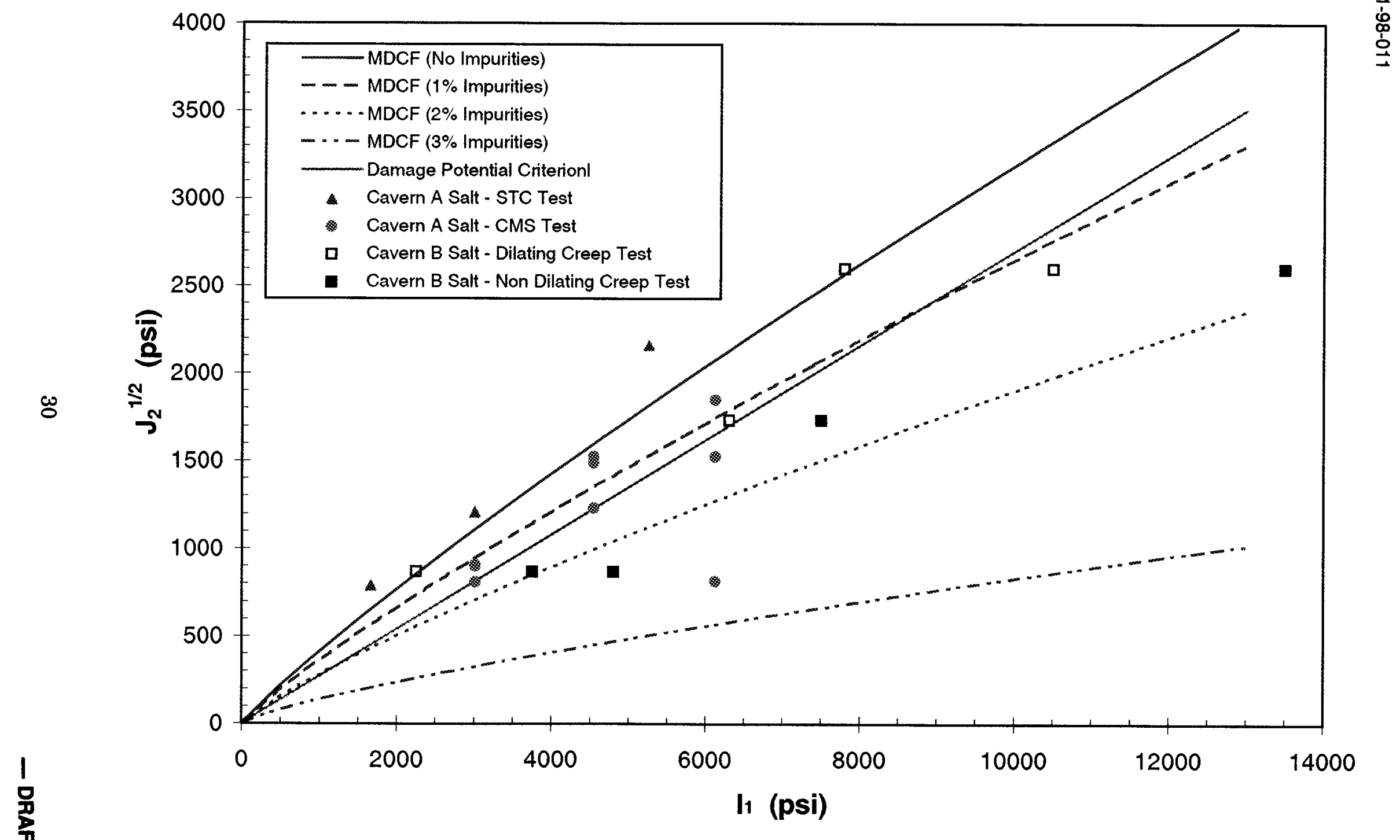

Figure 5-1. Dilation Boundaries Based on the MDCF and the Damage Potential Methods. 
maximum, then pressurized to the maximum gas pressure immediately after dewatering. The maximum gas pressure for both caverns is $0.85 \mathrm{psi} /$ foot of depth at the casing shoe.

The simulations for both caverns were then initiated with the caverns at maximum gas pressure. The gas in the caverns was completely withdrawn over a period of 10 days. For each cavern, the volume of dilating salt above the cavern midheight was calculated based on both the Damage Potential method and on the MDCF model with impurity levels of $0,1,2$, and 3 percent. Also, because of the significant difference in volume between the two caverns, the volume of dilating salt was normalized by dividing by the cavern volume.

\subsection{MODELING RESULTS}

Figures 5-2 and 5-3 show the predicted normalized dilational salt volume above the cavern midheight versus gas pressure at the casing shoe for Cavern A and Cavern B, respectively. The predicted dilation volumes are significantly higher for Cavern $A$ which is not as deep, but several times as large as Cavern B. For the MDCF model, there is a large difference between the 2 and 3 percent impurity levels in the predicted volumes of dilation for both caverns. The difference in predicted dilation volumes for impurity levels between 0 and 2 percent is much smaller. For both caverns, the dilation volume predicted with the Damage Potential method is between the dilation volumes predicted with the MDCF model with 1 and 2 percent impurities levels. Table 5-1 summarizes the casing shoe pressures at which salt dilation begins based on both dilation criteria (the Damage Potential method and the MDCF model method).

Figures 5-4 through 5-8 show the regions of predicted salt dilation based on the Damage Potential method and the MDCF model for the four impurity levels evaluated for Cavern $A$ at a gas pressure of $0.07 \mathrm{psi} /$ foot of depth at the casing shoe. This pressure represents 50 percent of the pressure required to initiate salt dilation in Cavern A with the Damage Potential method and is used as the minimum gas pressure for most of the simulations presented in Chapter 6.0. As shown in the figures, the volumes of salt predicted to dilate at this pressure are quite small for the Damage Potential method and also the MDCF model with impurity levels of 0 and 1 percent. In fact, as shown in Figure 5-2, none of the salt above the cavern midheight is predicted to dilate by the MDCF model with impurity levels of 0 and 1 percent. For the MDCF model with an impurity of 2 percent, a small volume of salt above the midheight is expected to dilate. At an impurity level of 3 percent, the volume of salt expected to dilate is substantially larger and surrounds the entire cavern.

Figures 5-9 through 5-13 show the regions of predicted salt dilation for Cavern $B$ at a gas pressure of $0.11 \mathrm{psi} /$ foot of depth at the casing shoe. This pressure represents 50 percent of the pressure required to initiate salt dilation in Cavern B with the Damage Potential method and is used as the minimum gas pressure for most of the simulations presented in Chapter 6.0. Again, the volumes of salt predicted to dilate at this pressure are quite small for the Damage Potential method and also the MDCF model with impurity levels of 0 and 1 percent. Only very 


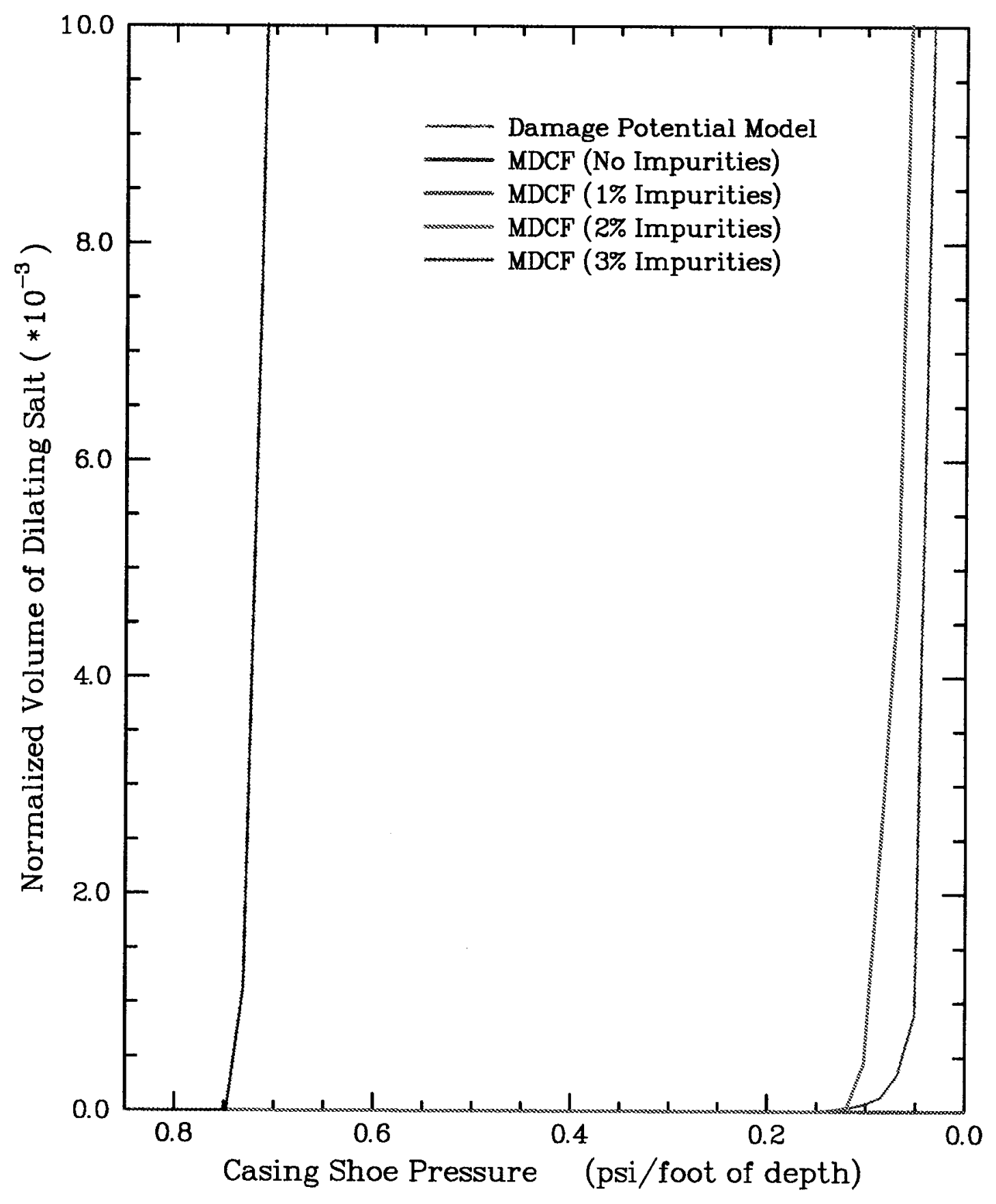

Figure 5-2. Predicted Normalized Volume of Dilating Salt Above Cavern A Midheight Versus Gas Pressure at the Casing Shoe. 


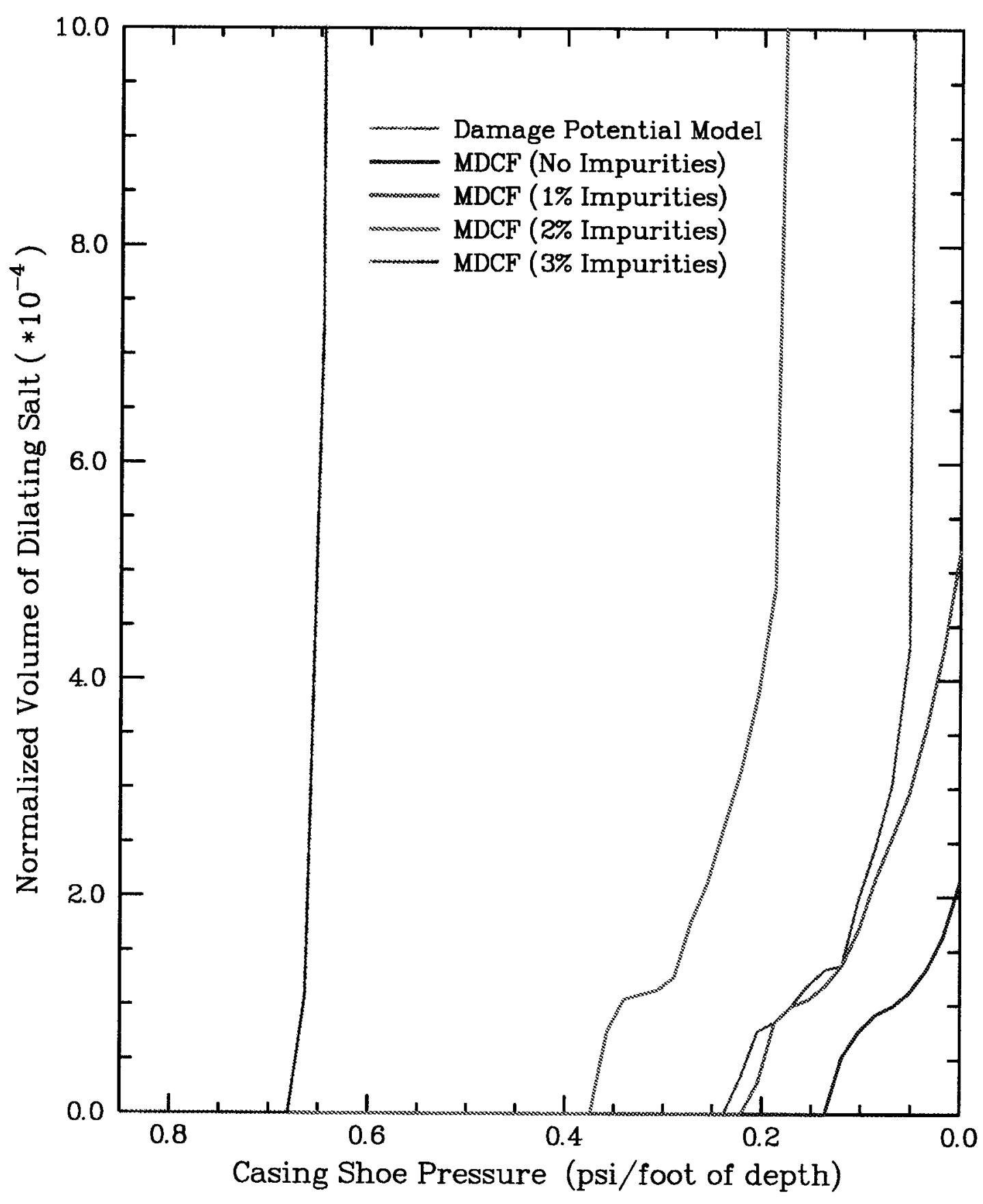

Figure 5-3. Predicted Normalized Volume of Dilating Salt Above Cavern B Midheight Versus Gas Pressure at the Casing Shoe. 
small volumes of salt near the top of the cavern are predicted to dilate under these model assumptions. For the MDCF model with an impurity of 2 percent, a thin skin of salt around most of the cavern is predicted to dilate. As with Cavern A, at an impurity level of 3 percent, the volume of salt expected to dilate is very large and surrounds the entire cavern.

Table 5-1. Casing Shoe Pressures (psi/Foot of Depth) at Which Dilation Begins

\begin{tabular}{||c|c|c|c|}
\hline \hline Dilation Boundary Criterion & Cavern A & Cavern B \\
\hline \hline \multicolumn{2}{|c|}{ Damage Potential Method } & 0.14 & 0.22 \\
\hline \multirow{3}{*}{ MDCF Model } & No Impurities & (a) & 0.12 \\
\cline { 2 - 4 } & $1 \%$ Impurities & (a) & 0.20 \\
\cline { 2 - 4 } & 2\% Impurities & 0.12 & 0.36 \\
\cline { 2 - 4 } & $3 \%$ Impurities & 0.73 & 0.63 \\
\hline
\end{tabular}

(a) No elements exceeded the dilation boundary criterion.

To ensure that the dilatancy boundary results presented here are not significantly impacted by the gas withdrawal rate used in the simulations, similar analyses were made with withdrawal periods of 5 days and 20 days. The predicted normalized volume of dilating salt above the cavern midheight versus gas pressure for Cavern A using the Damage Potential method dilatancy boundary is shown in Figure 5-14 for each of the three withdrawal periods evaluated. Figure 5-15 shows similar graphs for Cavern B. As shown in the figures, the results are nearly the same for all three withdrawal rates. Although not shown in the figures, results for the MDCF dilatancy boundaries also show very little dependence on the gas withdrawal rate. ${ }^{3}$

\footnotetext{
${ }^{3}$ The thermodynamics of the gas withdrawal are not included in these simulations. The change in gas temperature associated with rapid withdrawals could have an impact on the cavern periphery and well casings.
} 


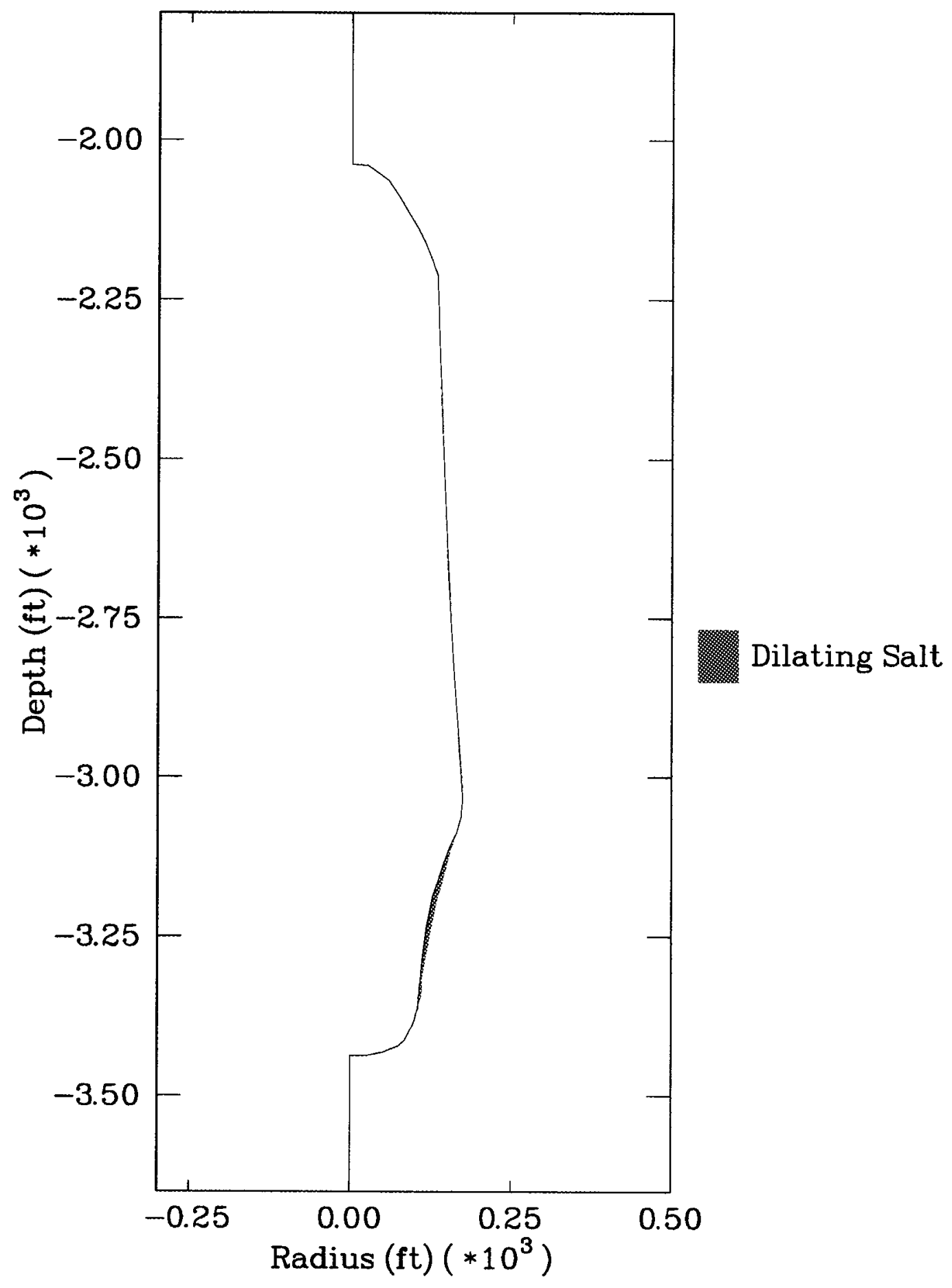

Figure 5-4. Regions of Predicted Salt Dilation Based on the Damage Potential Method for Cavern $A$ at a Gas Pressure of $0.07 \mathrm{psi} /$ Foot of Depth at the Casing Shoe. 


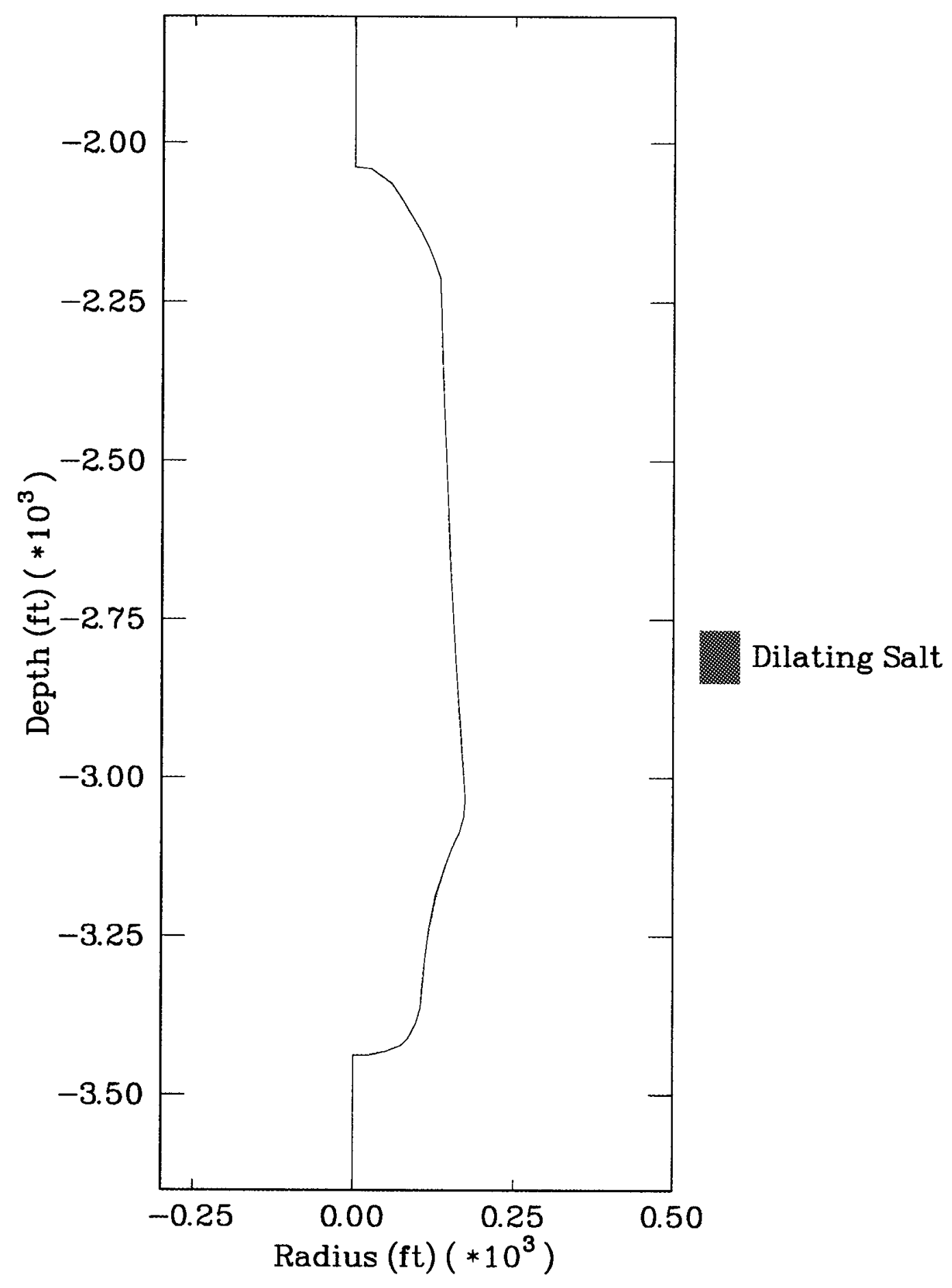

Figure 5-5. Regions of Predicted Salt Dilation Based on the MDCF Model With no Salt Impurity for Cavern A at a Gas Pressure of $0.07 \mathrm{psi} /$ Foot of Depth at the Casing Shoe. 


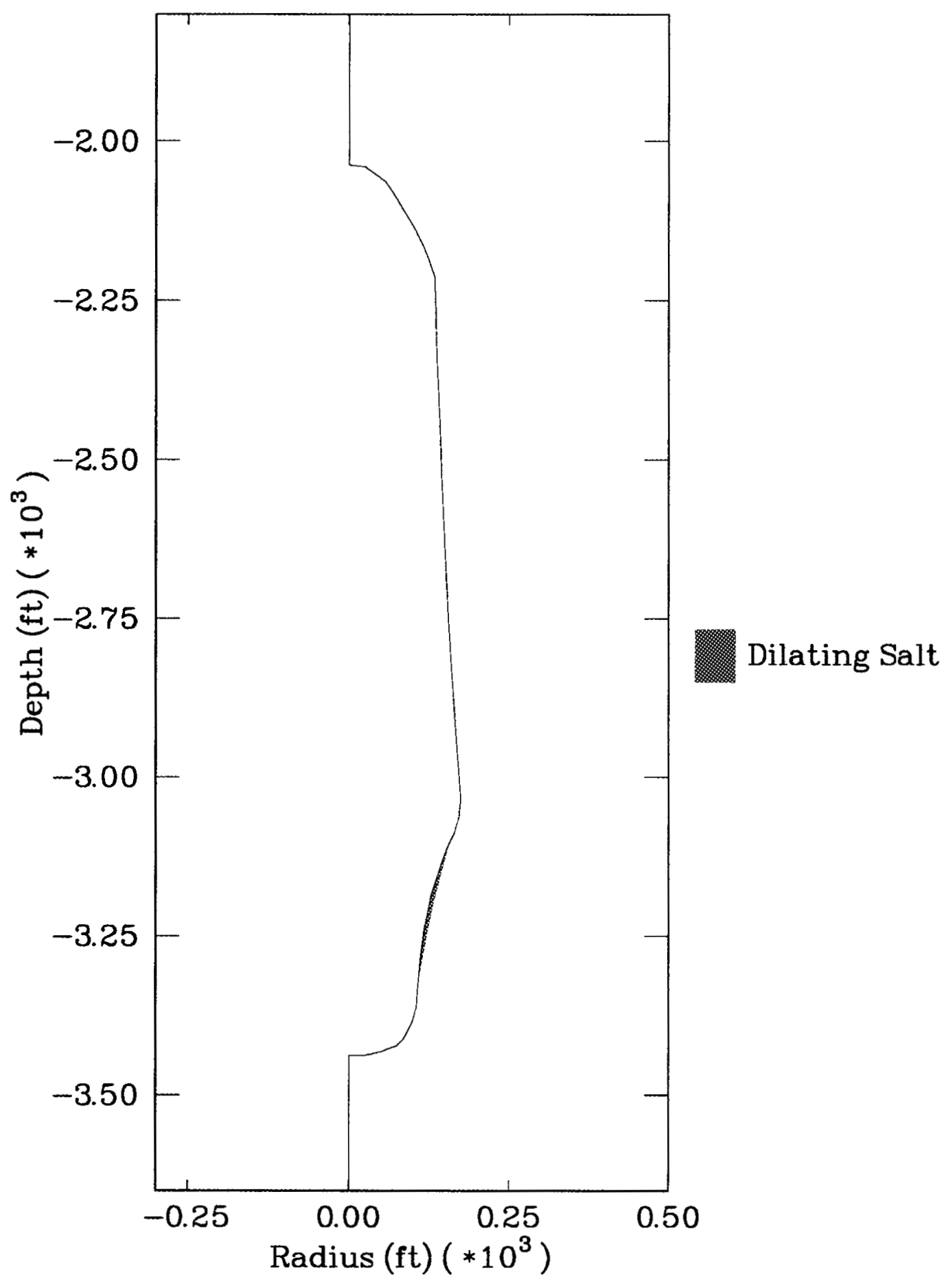

Figure 5-6. Regions of Predicted Salt Dilation Based on the MDCF Model With a Salt Impurity of 1 Percent for Cavern $A$ at a Gas Pressure of 0.07 psi/Foot of Depth at the Casing Shoe. 


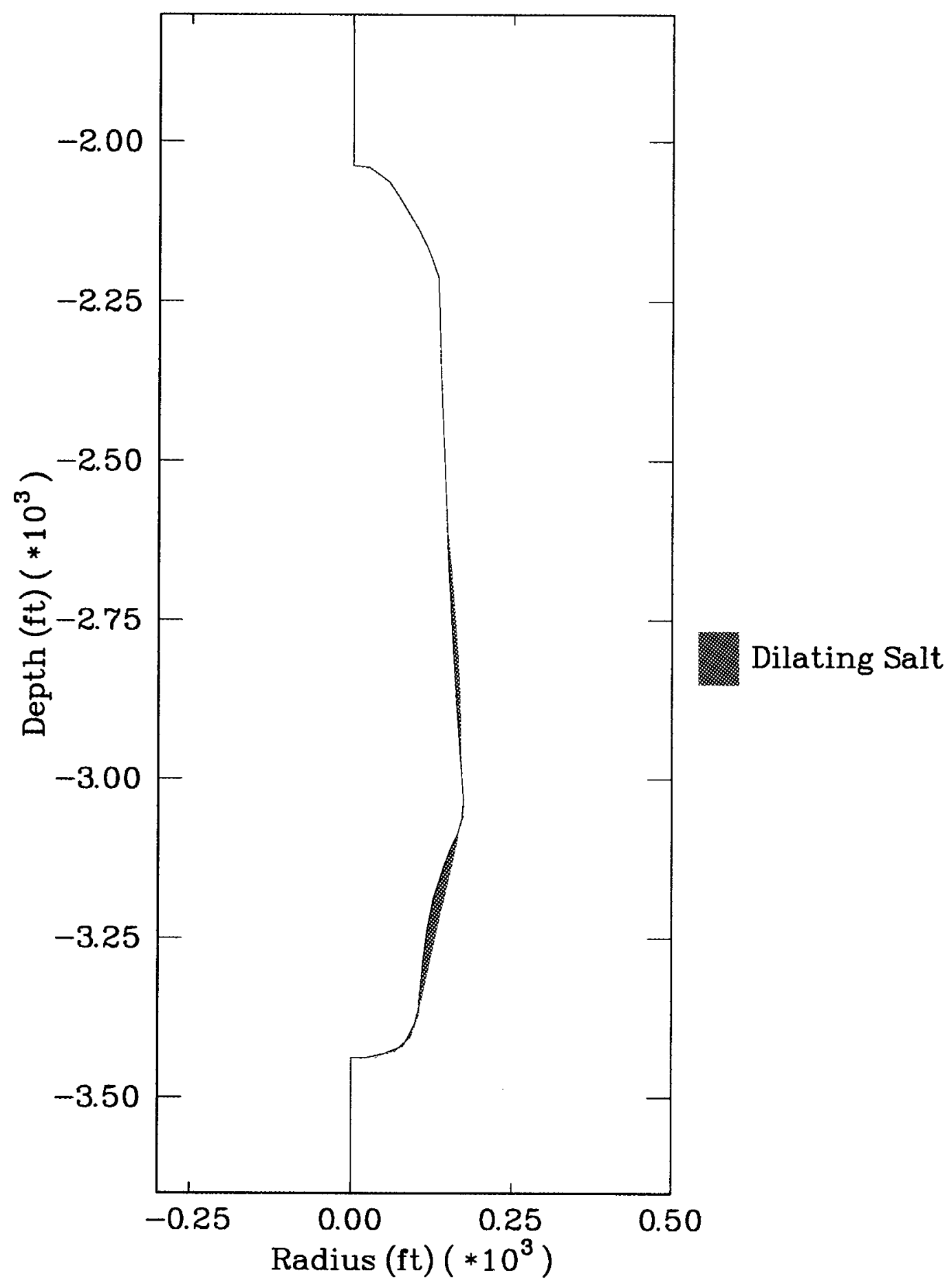

Figure 5-7. Regions of Predicted Salt Dilation Based on the MDCF Model With a Salt Impurity of 2 Percent for Cavern $A$ at a Gas Pressure of 0.07 psi/Foot of Depth at the Casing Shoe. 


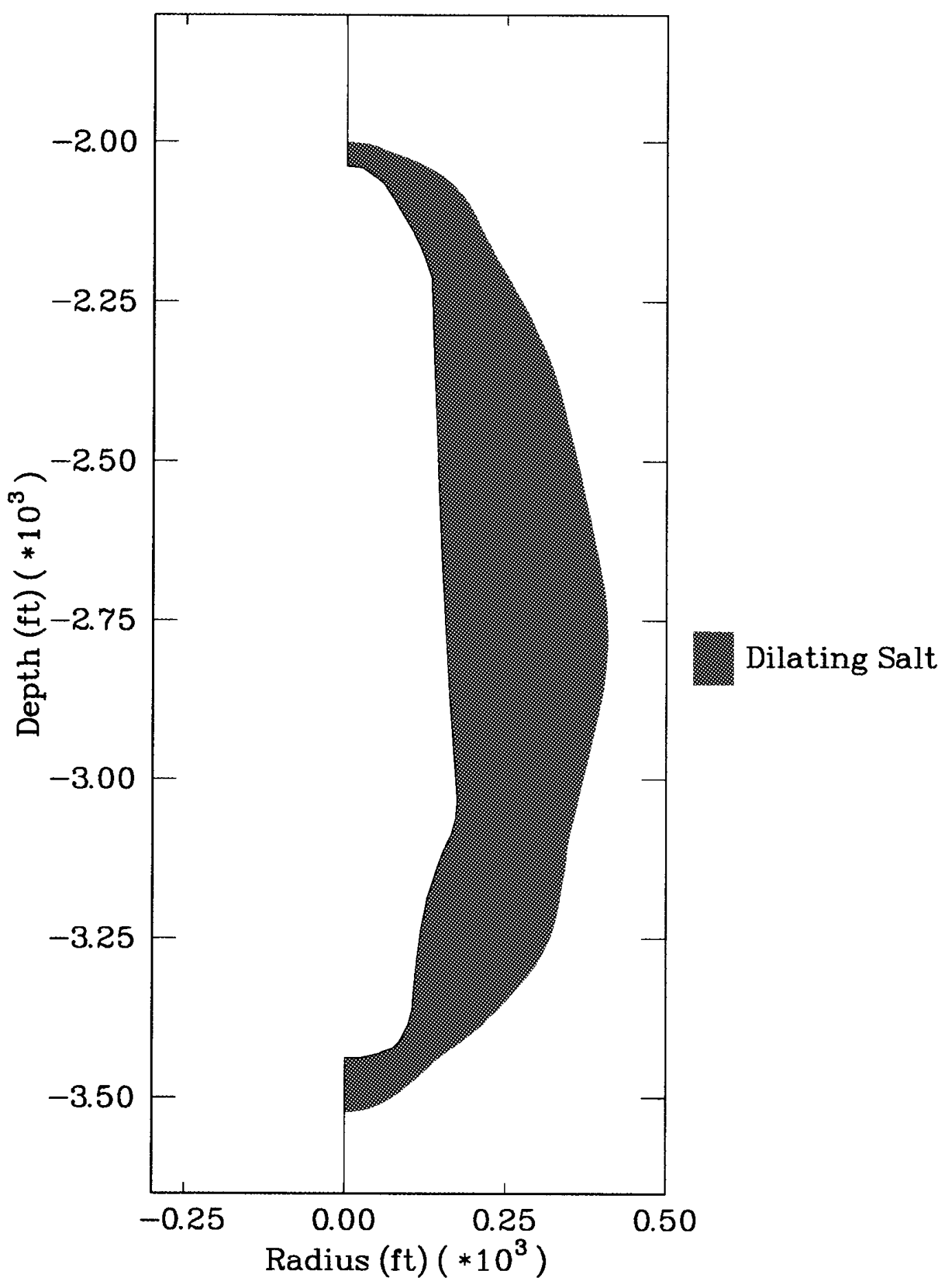

Figure 5-8. Regions of Predicted Salt Dilation Based on the MDCF Model With a Salt Impurity of 3 Percent for Cavern A at a Gas Pressure of 0.07 psi/Foot of Depth at the Casing Shoe. 


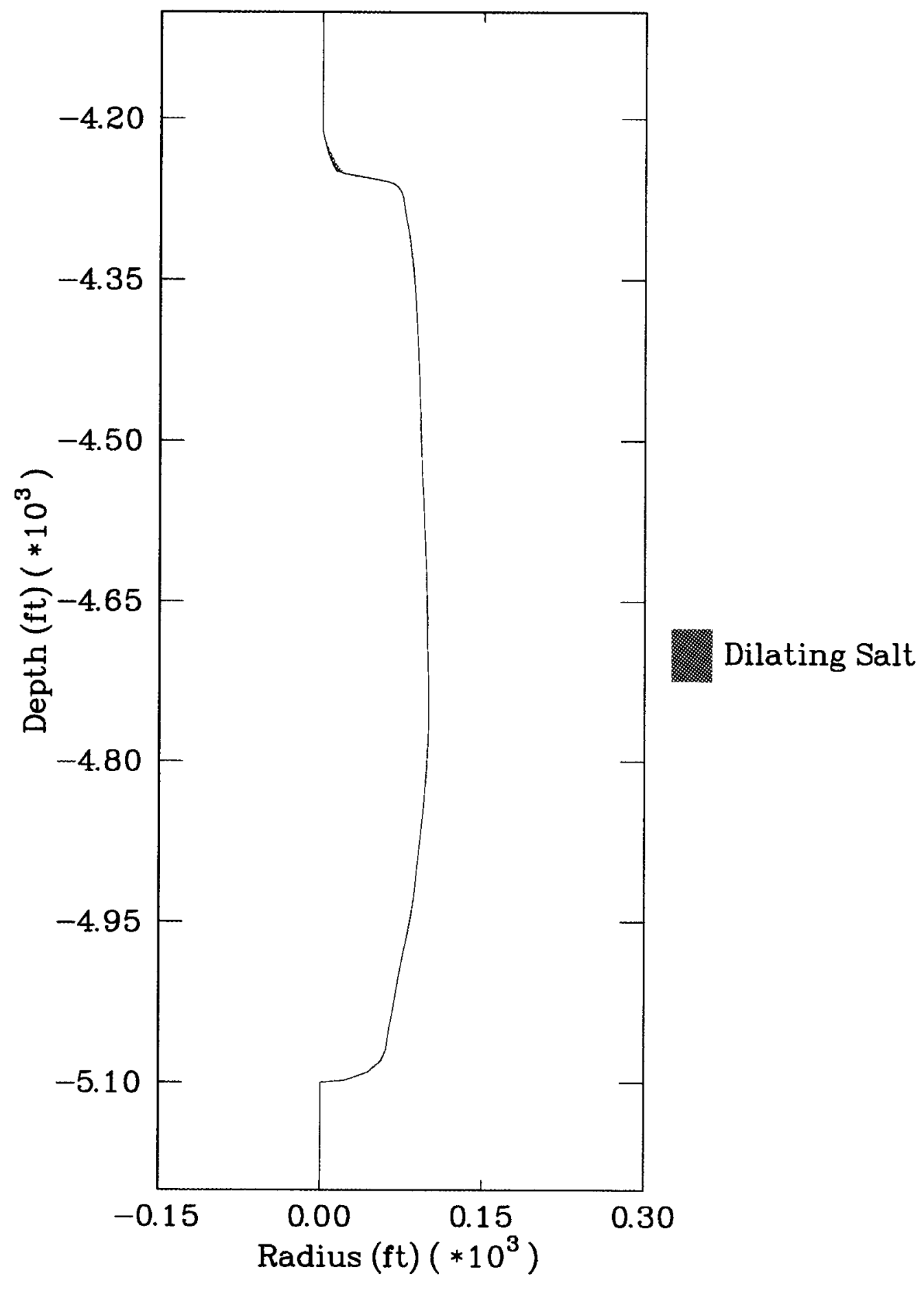

Figure 5-9. Regions of Predicted Salt Dilation Based on the Damage Potential Method for Cavern B at a Gas Pressure of 0.11 psi/Foot of Depth at the Casing Shoe. 


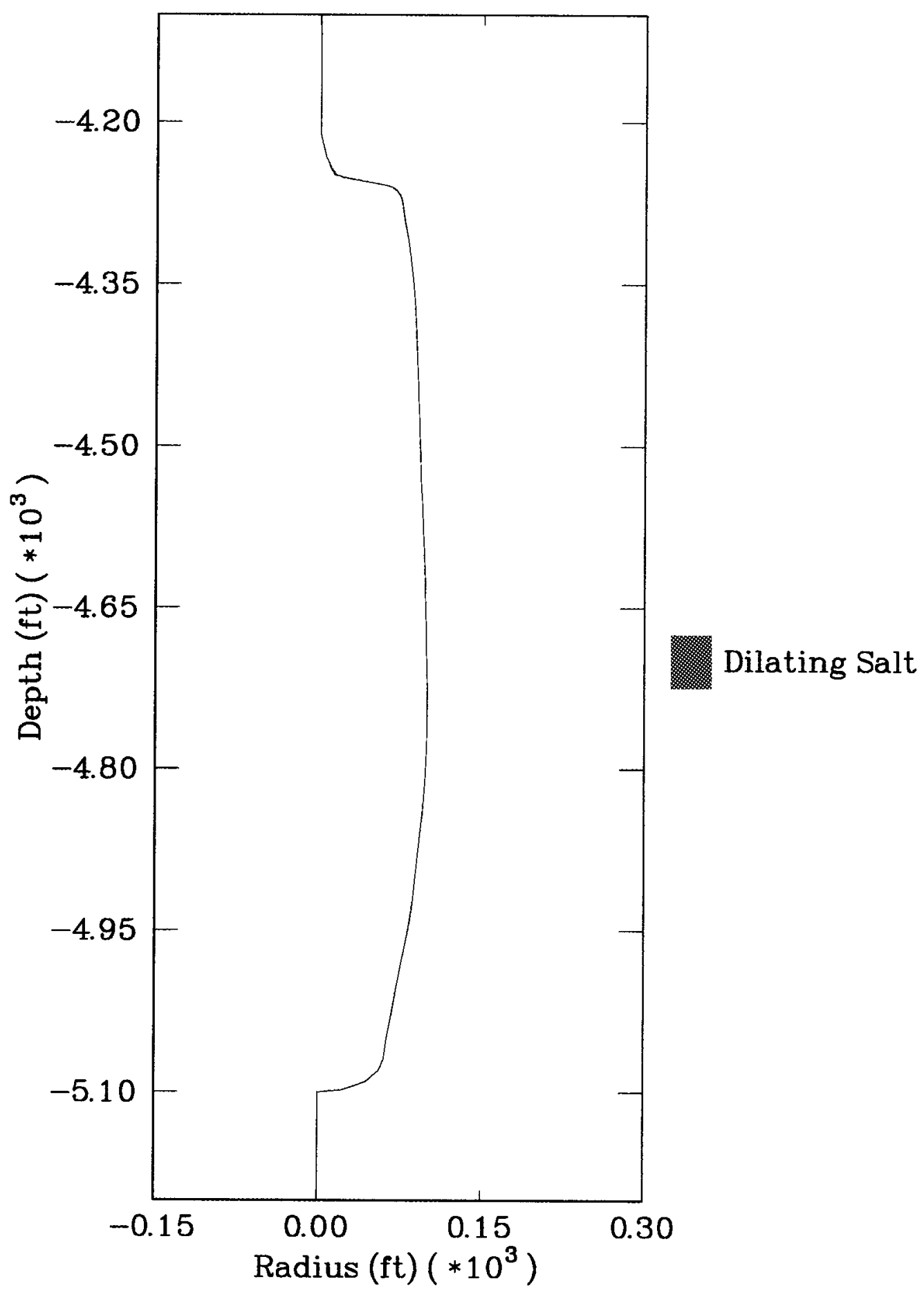

Figure 5-10. Regions of Predicted Salt Dilation Based on the MDCF Model With no Salt Impurity for Cavern B at a Gas Pressure of 0.11 psi/Foot of Depth at the Casing Shoe. 


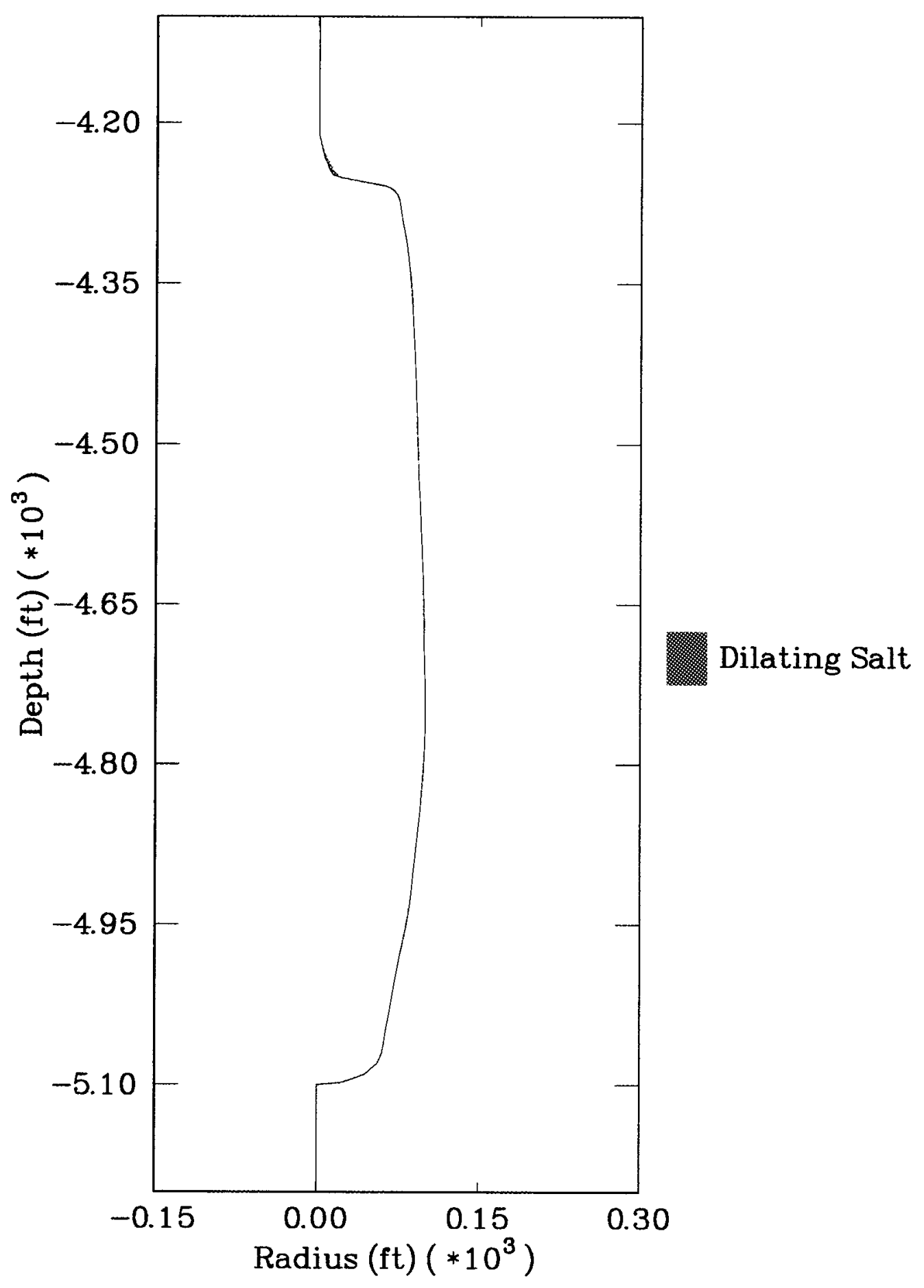

Figure 5-11. Regions of Predicted Salt Dilation Based on the MDCF Model With a Salt Impurity of 1 Percent for Cavern B at a Gas Pressure of $0.11 \mathrm{psi} /$ Foot of Depth at the Casing Shoe. 


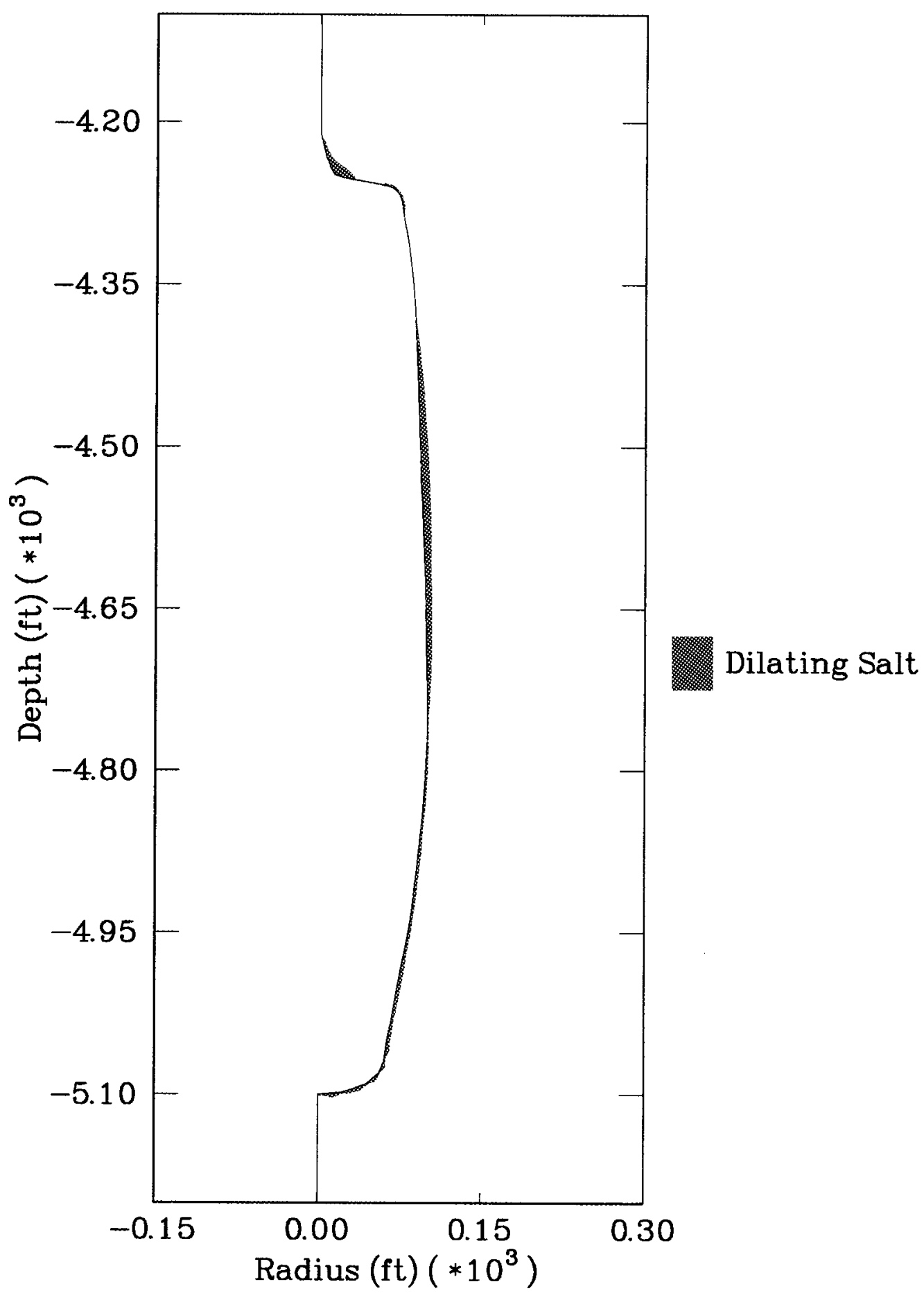

Figure 5-12. Regions of Predicted Salt Dilation Based on the MDCF Model With a Salt Impurity of 2 Percent for Cavern B at a Gas Pressure of $0.11 \mathrm{psi} /$ Foot of Depth at the Casing Shoe. 


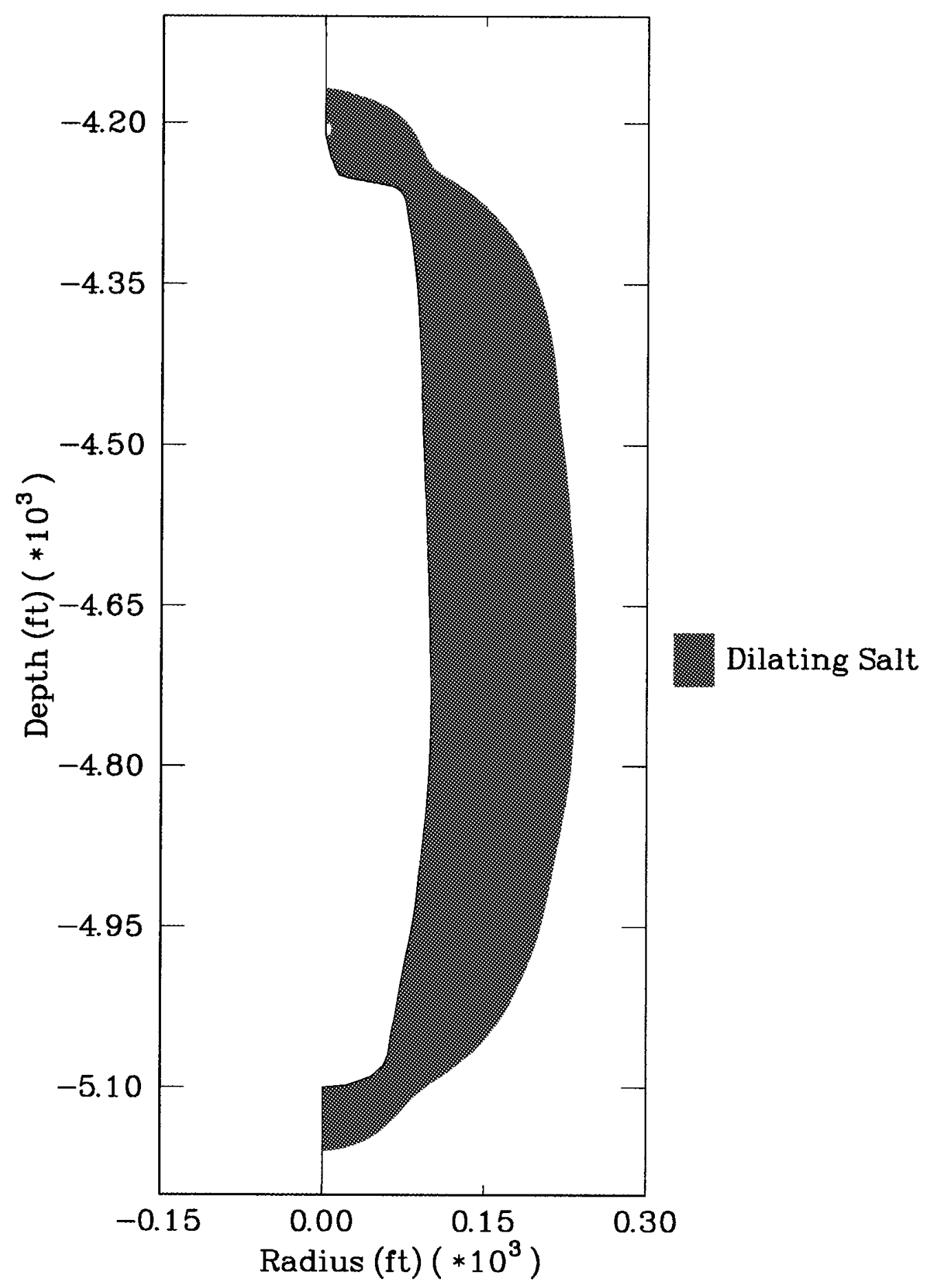

Figure 5-13. Regions of Predicted Salt Dilation Based on the MDCF Model With a Salt Impurity of 3 Percent for Cavern B at a Gas Pressure of $0.11 \mathrm{psi} /$ Foot of Depth at the Casing Shoe. 


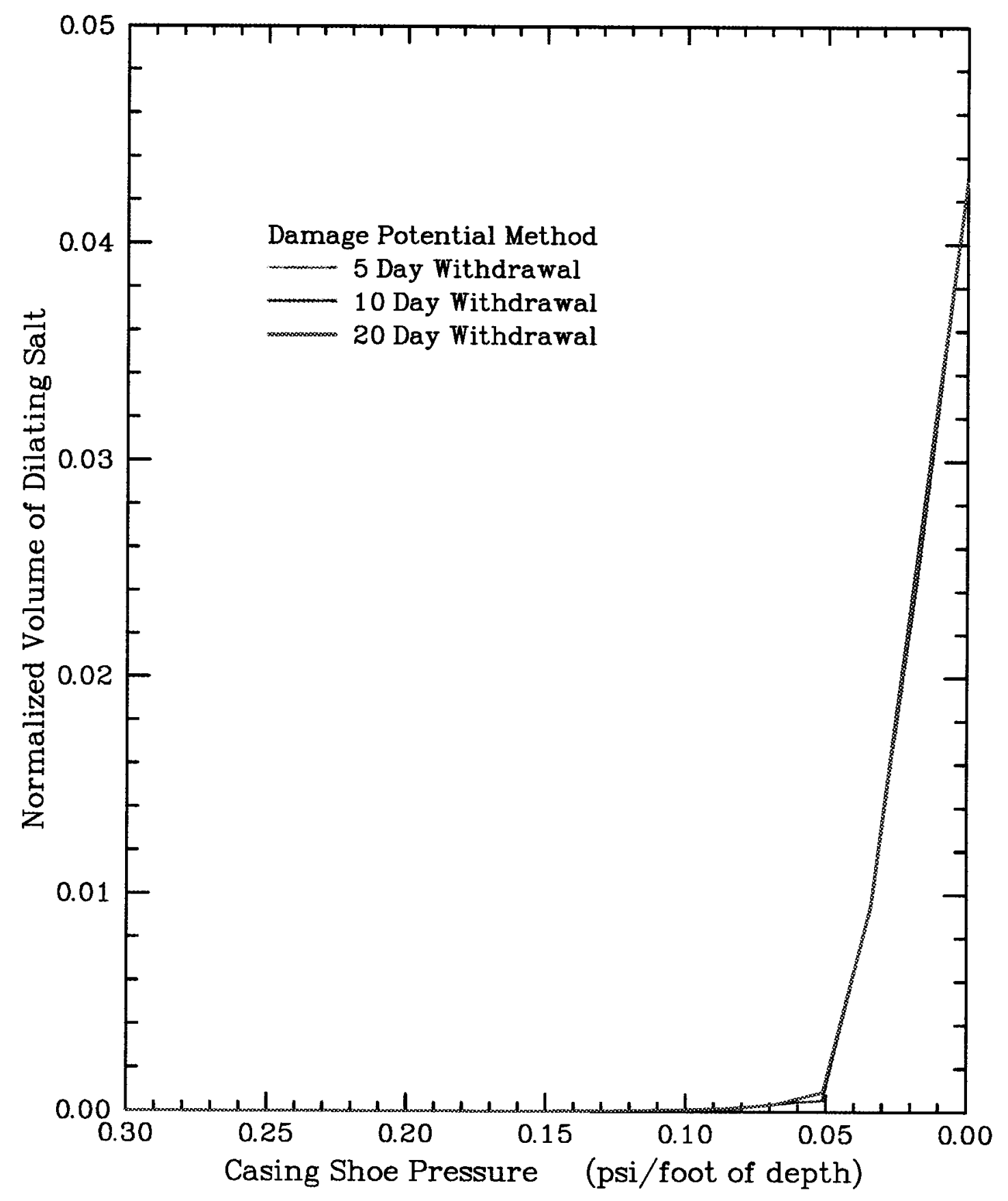

Figure 5-14. The Predicted Normalized Volume of Dilating Salt Above the Cavern Midheight Versus Gas Pressure for Cavern A Using the Damage Potential Method Dilatancy Boundary for Three Different Withdrawal Rates. 


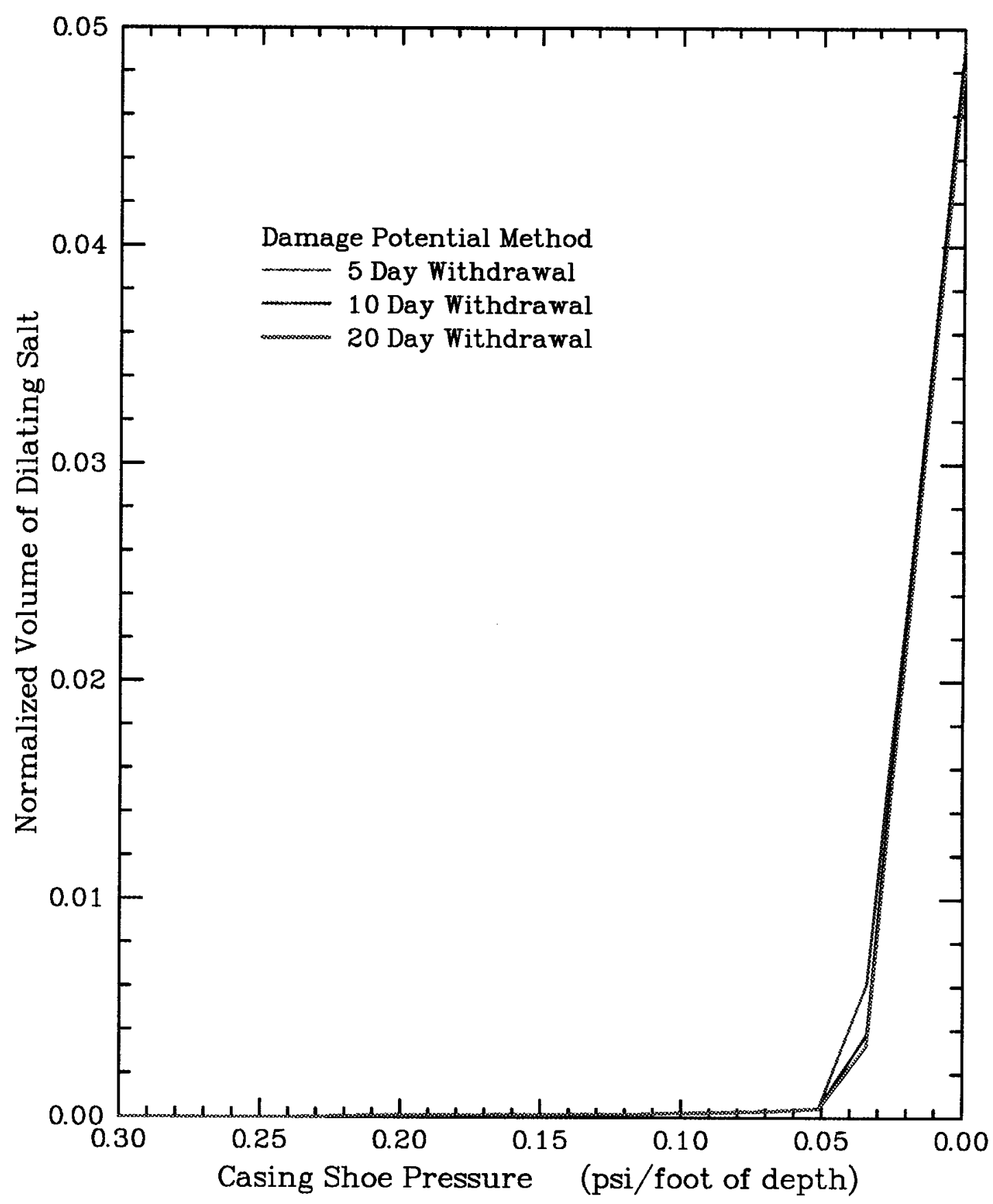

Figure 5-15. The Predicted Normalized Volume of Dilating Salt Above the Cavern Midheight Versus Gas Pressure for Cavern B Using the Damage Potential Method Dilatancy Boundary for Three Different Withdrawal Rates. 


\subsection{NUMERICAL RESULTS OF CAVERN STABILITY BASED ON DAMAGE QUANTIFICATION}

\subsection{PROBLEM DESCRIPTION}

Cavern simulations were made in which both of the caverns are drawn down to pressures below that required to initiate dilation in the salt surrounding the caverns. As a conservative measure, the MDCF model was used with an impurity of 3 percent. As shown in the previous chapter, significant volumes of salt in both caverns are predicted to dilate at this impurity level. The dilatant volumetric strain was used to track accumulated dilation or damage and also healing in the salt surrounding the caverns during simulated natural gas storage cycles. The following were evaluated:

- Sensitivity to the minimum gas pressure.

- Time required to heal damaged salt.

- Maximum allowable time at minimum pressure.

- Long-term accumulation of salt damage.

Two natural gas service cycles were used in this study to evaluate the use of the MDCF constitutive model (see Figure 6-1). These cycles are referred to as Case 1 and Case 2 throughout this report. Both cycles start at the maximum gas pressure of $0.85 \mathrm{psi} /$ foot of depth at the casing shoe and are drawn down to the minimum gas pressure over a period of 10 days. The Case 1 gas pressure cycle is held at minimum pressure for 10 days, and the Case 2 gas pressure cycle is held at minimum gas pressure for 100 days. After storage service at minimum gas pressure, both cycles repressurize the caverns back to maximum gas pressure over a 10-day period. Both cycles then hold maximum gas pressure for 100 days.

\subsection{MODELING RESULTS}

\subsubsection{Evaluation of Minimum Gas Pressure}

In the previous chapter, it was shown that using the Damage Potential dilation boundary, that salt dilation is expected when the minimum gas pressure at the casing shoe is $0.14 \mathrm{psi} / \mathrm{foot}$ of depth and $0.22 \mathrm{psi} /$ foot of depth for Cavern A and Cavern B, respectively. These pressures were used as the baseline minimum gas pressures for use with the MDCF model simulations. To evaluate the effect of minimum pressure on damage and healing, simulations with the MDCF model were made at minimum gas pressures that are 50 and 90 percent of these baseline values. 

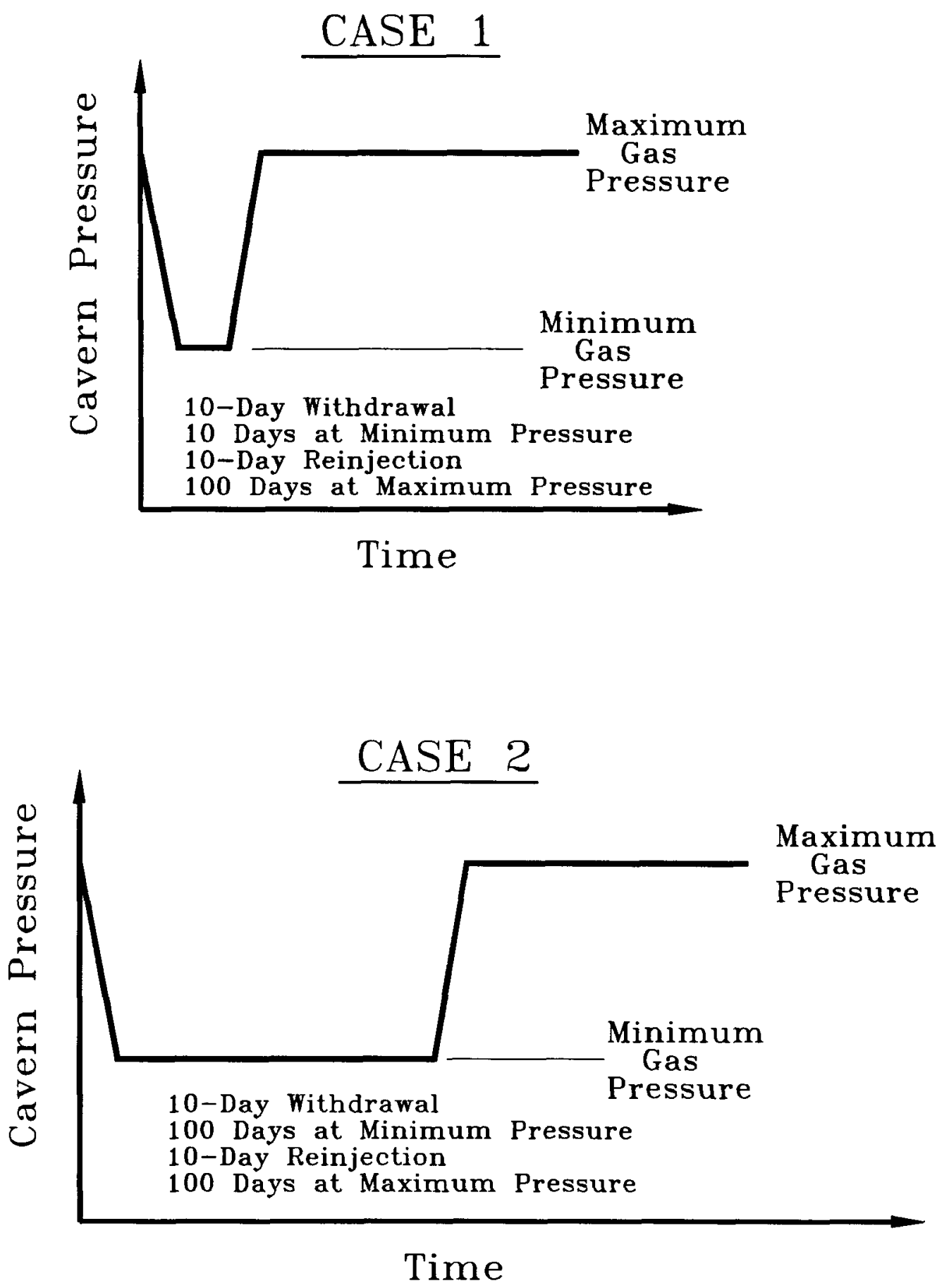

Figure 6-1. Natural Gas Service Cycles Analyzed. 
Figure 6-2 shows the normalized volume of salt above the cavern midheight which exceeds $0.1 \mu \varepsilon$ (microstrains) throughout a single Case 1 gas pressure cycle for Cavern A. No dilatant volumetric strain occurs until about halfway into the 10-day pressure drawdown. The volume of salt with dilatant volumetric strain greater than $0.1 \mu \varepsilon$ then rapidly increases throughout the rest of the withdrawal period. This volume continues to increase at a somewhat slower rate during the 10-day period at minimum pressure. The maximum volume of salt with dilatant volumetric strains occurs at the end of the 10-day period at minimum pressure. This volume then starts to decrease about midway into the 10-day repressurization when the stresses are conducive to healing. At the end of the repressurization, the healing rate decreases considerably. As shown in the figure, the volume of salt which experiences dilatant volumetric strain is strongly dependent on the minimum gas pressure. The maximum volume of salt during the cycle which experiences a dilatant volumetric strain of more than $0.1 \mu \varepsilon$ is about 20 percent higher for the simulation with a minimum gas pressure that is 50 percent of the baseline pressure than for that which is at 90 percent of the baseline pressure. Likewise, the time until complete healing of the dilatant volumetric strain is dependent on the minimum gas pressure. The volumetric strain for the simulation with a minimum pressure of 50 percent of the baseline was completely healed about 80 days after repressurization; whereas, the simulation with a minimum gas pressure of 90 percent of the minimum only required about 40 days to completely heal the dilatant strain.

Figure 6-3 shows the normalized volume of salt above the cavern midheight which exceeds $0.1 \mu \varepsilon$ throughout a single Case 1 gas pressure cycle for Cavern B for the two minimum pressures evaluated. Although the results are similar, larger differences are seen between the two pressures modeled. For Cavern B, the maximum volume of salt that experiences more than $0.1 \mu \varepsilon$ is about 50 percent larger for the simulation with a minimum gas pressure of 50 percent of the baseline pressure than that with a minimum gas pressure of 90 percent of the baseline pressure. The volumetric strain for the simulation with a minimum pressure of 50 percent of the baseline was completely healed about 70 days after repressurization; whereas, the simulation with a minimum gas pressure of 90 percent of the minimum only required about 40 days to completely heal the dilatant strain.

It is interesting to note that after repressurization of Cavern $B$, there is a period where no healing takes place. This occurs because the MDCF damage stress measure actually increases during the later portion of the repressurization. Recall from Section 3.2.4 that damage occurs when the damage stress measure is greater than zero and that healing occurs when it is less than zero. Figure 6-4 shows the MDCF damage stress measure along with the radial, vertical, and tangential stresses for an element in the cavern wall during the gas cycle. At any given time, the maximum principal stress is essentially equal to the largest of the three stress components, and the minimum principal stress is equal to the smallest of the three stress components. As shown in the figure, the damage stress measure nearly tracks the maximum principal stress. During drawdown and the period at minimum pressure, the maximum principal stress is equal to the radial stress. This is also true at the start of the repressurization period. However, as the gas pressure is increased, the tangential stresses around the 


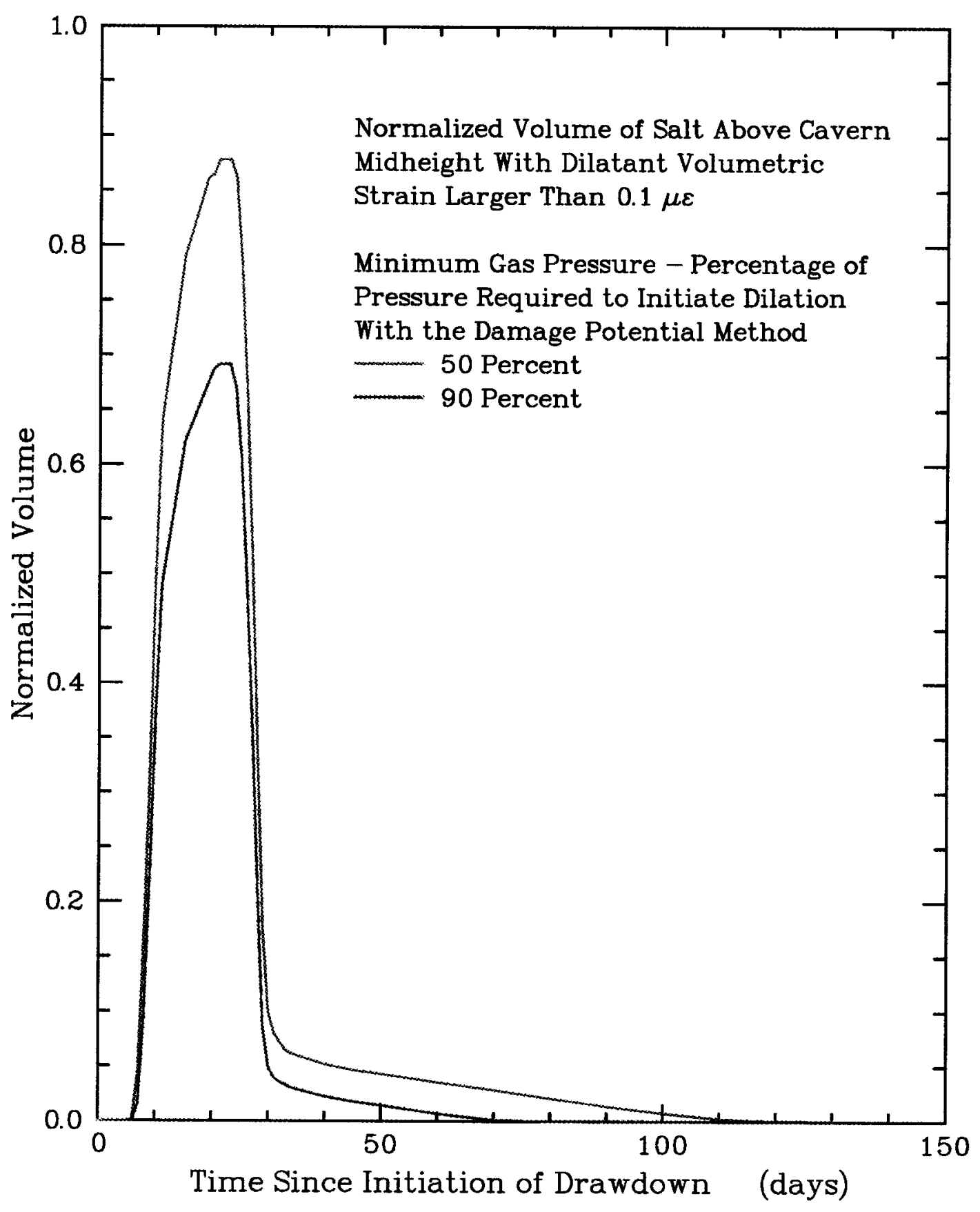

Figure 6-2. Normalized Volume of Salt Above the Cavern Midheight With Dilatant Volumetric Strain Greater Than $0.1 \mu \varepsilon$ Throughout a Single Case 1 Gas Pressure Cycle for Cavern A. 


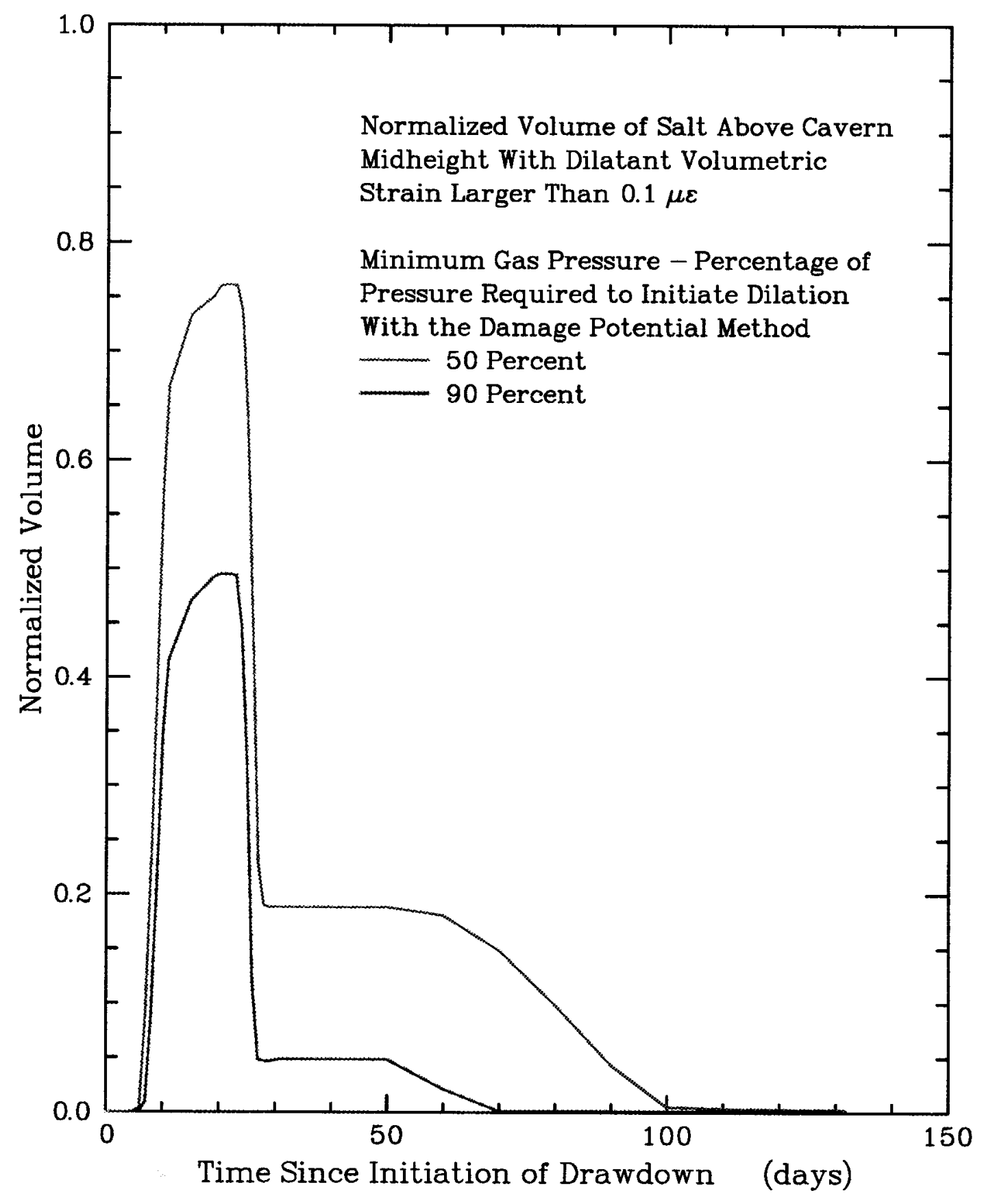

Figure 6-3. Normalized Volume of Salt Above the Cavern Midheight With Dilatant Volumetric Strain Greater Than $0.1 \mu \varepsilon$ Throughout a Single Case 1 Gas Pressure Cycle for Cavern B. 


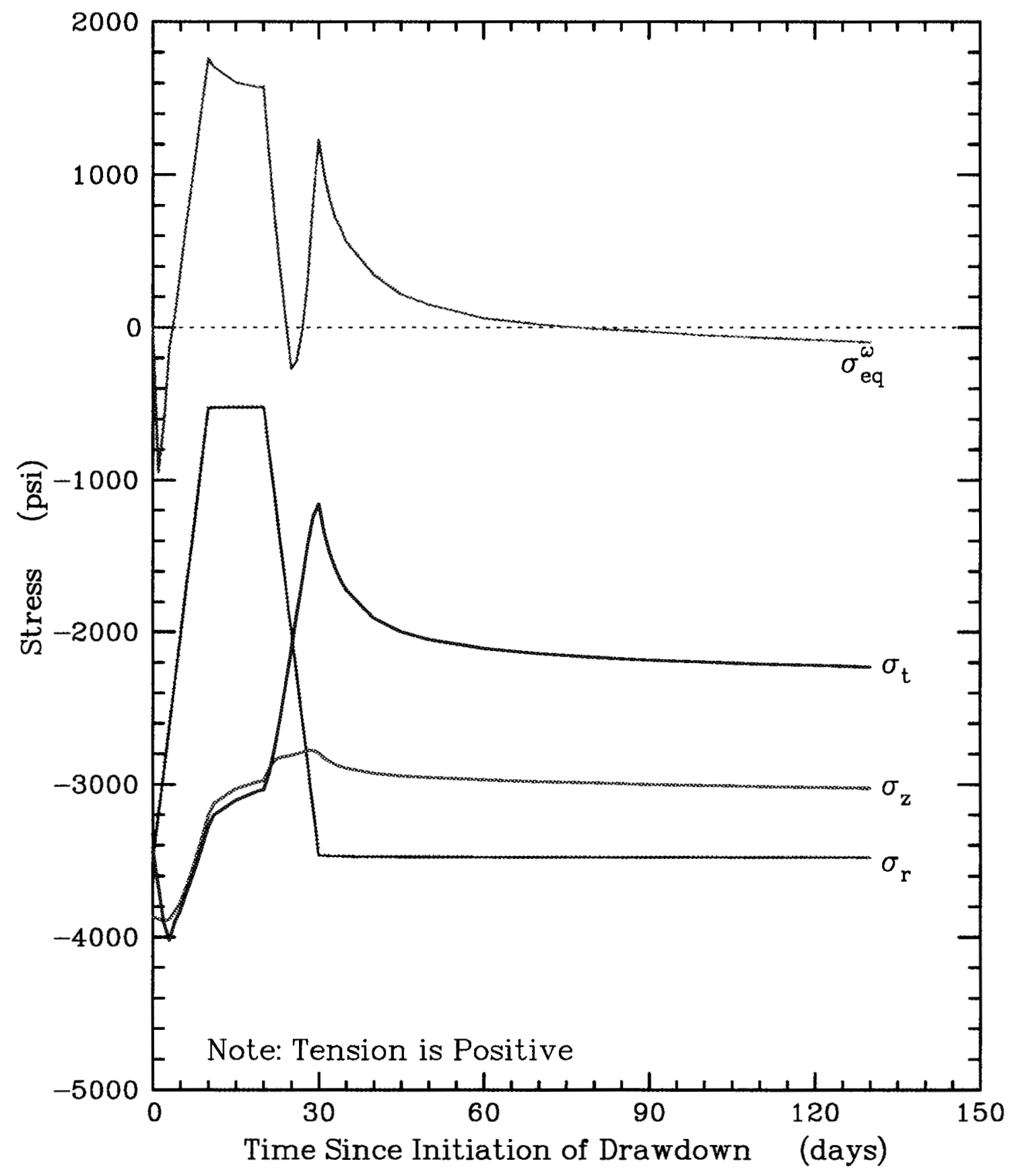

Figure 6-4. MDCF Damage Stress Measure and the Radial, Vertical, and Tangential Stresses for an Element in the Cavern Wall During a Single Case 1 Gas Pressure Cycle. 
cavern become less compressive than the radial stress which is becoming more compressive. At the point where these stresses cross, the maximum principal stress begins to increase. The damage stress measure also increases to the point where healing is stalled. After the cavern is fully pressurized, the maximum principal (tangential) stress becomes more compressive as the salt creeps to equalize the stresses. As the maximum principal stress becomes more compressive, the damage stress measure drops below zero and healing commences. This same phenomenon occurs in Cavern A, but not severely enough to stop healing during pressurization. The reverse phenomenon is seen during the drawdown periods of consecutive gas cycles.

\subsubsection{Maximum Allowable Time at Minimum Gas Pressure}

The maximum allowable time at minimum gas pressure was evaluated by monitoring the value of the MDCF damage state variable, $\omega$, as a function of time with the caverns at minimum gas pressure. As $\omega$ increases, the creep rate also increases, and eventually tertiary creep occurs, followed by creep rupture. In Section 3.2.7, it was shown that based on laboratory testing, an $\omega$ value of 0.0025 can be used as a conservative measure of the point at which creep rupture occurs. To eliminate the geometrical effects, $\omega$ was monitored at a location on the cavern wall in the upper portion of each cavern. For these simulations, the gas pressure was reduced from maximum to minimum over a 10-day period and then held at the minimum value for the remainder of the simulation. Figure 6-5 shows the $\omega$ value for this location in Cavern $A$ as a function of time at minimum gas pressure for the two minimum gas pressures evaluated. With a minimum gas pressure of 90 percent of the baseline pressure, damage accumulates very slowly and does not exceed the creep rupture value during the entire 10-year period at minimum pressure. At a minimum gas pressure of 50 percent of the baseline pressure, the salt does not reach the rupture limit until about 2,550 days or about 7 years at minimum pressure. The results are significantly different for Cavern B, as shown in Figure 6-6. In Cavern B, creep rupture occurs after about 12 and 65 days at minimum gas pressure for minimum gas pressures of 50 and 90 percent of the baseline pressure, respectively.

\subsubsection{Long-Term Damage Accumulation}

Several simulations were made to evaluate the accumulation of damage over several natural gas cycles. For each cavern, five consecutive cycles of both Cycle 1 and Cycle 2 were simulated for each cavern. The minimum gas pressure used in the simulations was 50 percent of the baseline minimum gas pressure.

Figures 6-7 and 6-8 show the normalized volume of salt above the cavern midheight with a dilatant volumetric strain greater than $0.1 \mu \varepsilon$ for Cavern A for five consecutive Case 1 and Case 2 cycles, respectively. For the Case 1 cycles with a 10-day period at minimum gas pressure, all of the salt has a dilatant volumetric strain of less than $0.1 \mu \varepsilon$ at the end of the

first cycle. However, after subsequent cycles, a small volume of salt still has a dilatant volumetric strain exceeding $0.1 \mu \varepsilon$. In fact, the volume of dilated salt at the end of each cycle 


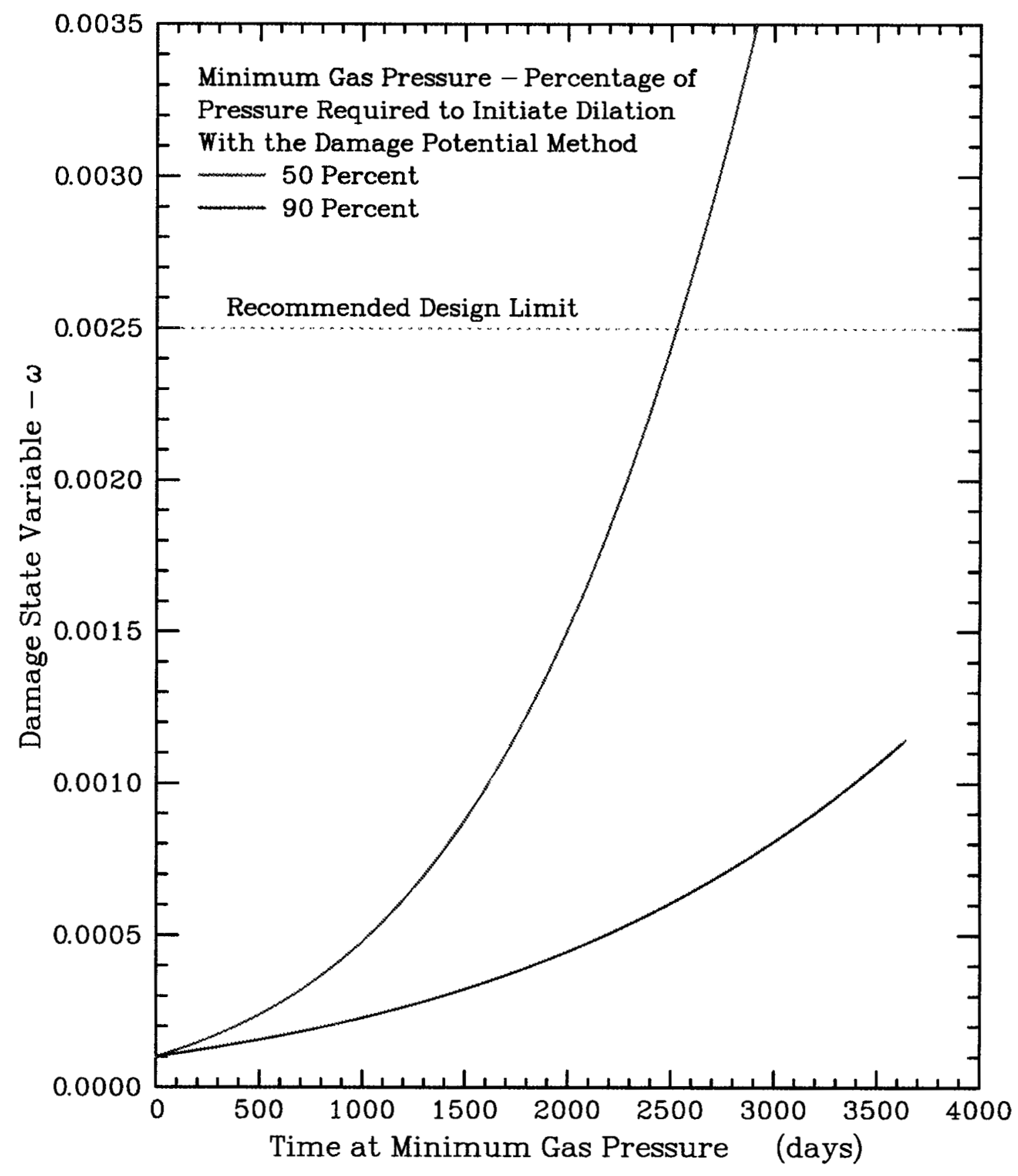

Figure 6-5. MDCF Damage State Variable in the Wall of Cavern A as a Function of Time at Minimum Gas Pressure for the Two Minimum Gas Pressures Evaluated. 


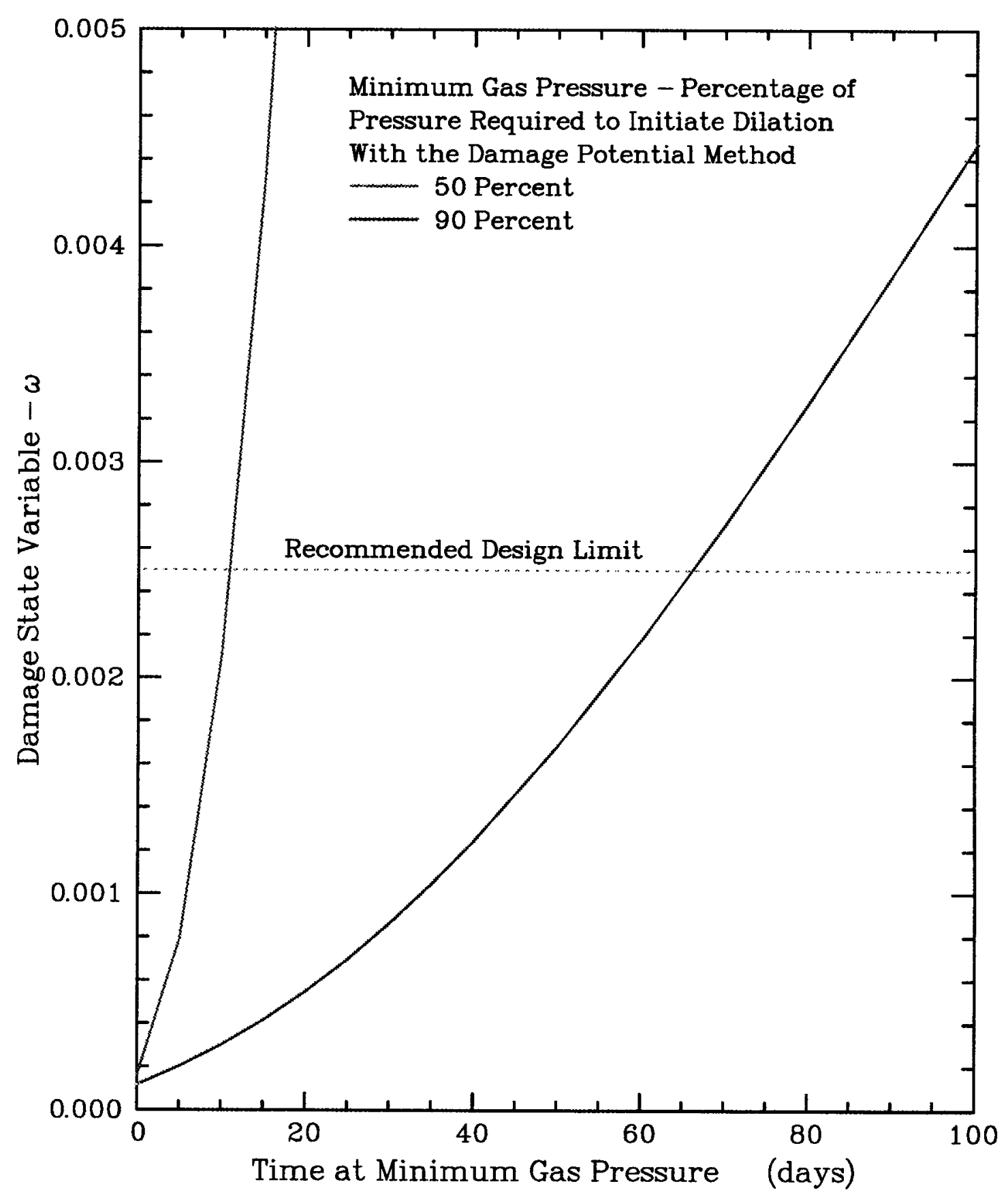

Figure 6-6. MDCF Damage State Variable in the Wall of Cavern B as a Function of Time at Minimum Gas Pressure for the Two Minimum Gas Pressures Evaluated. 


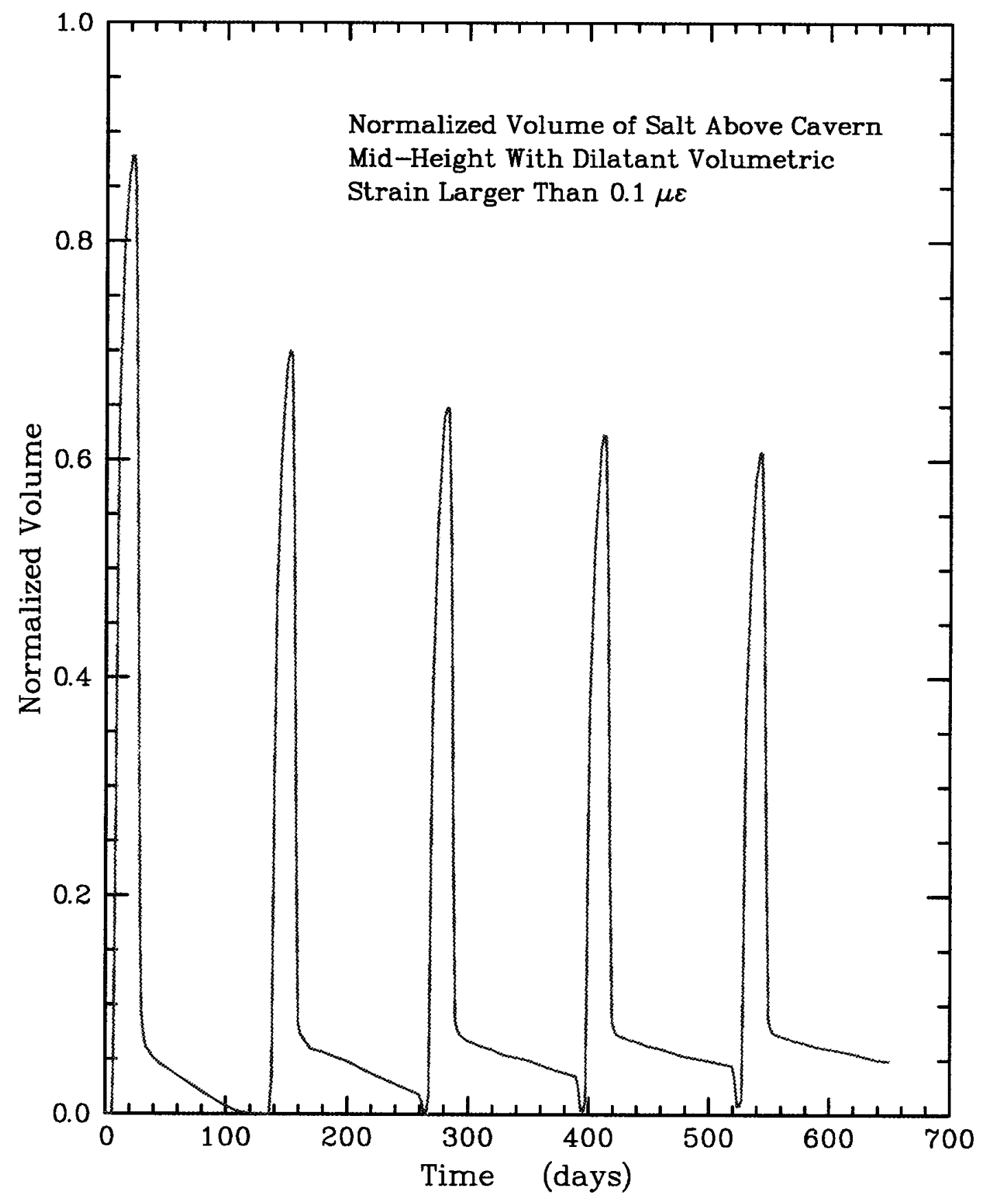

Figure 6-7. Normalized Volume of Salt Above the Cavern Midheight With Dilatant Volumetric Strain Greater Than $0.1 \mu \varepsilon$ for Cavern A Throughout Five Consecutive Case 1 Gas Pressure Cycles. 


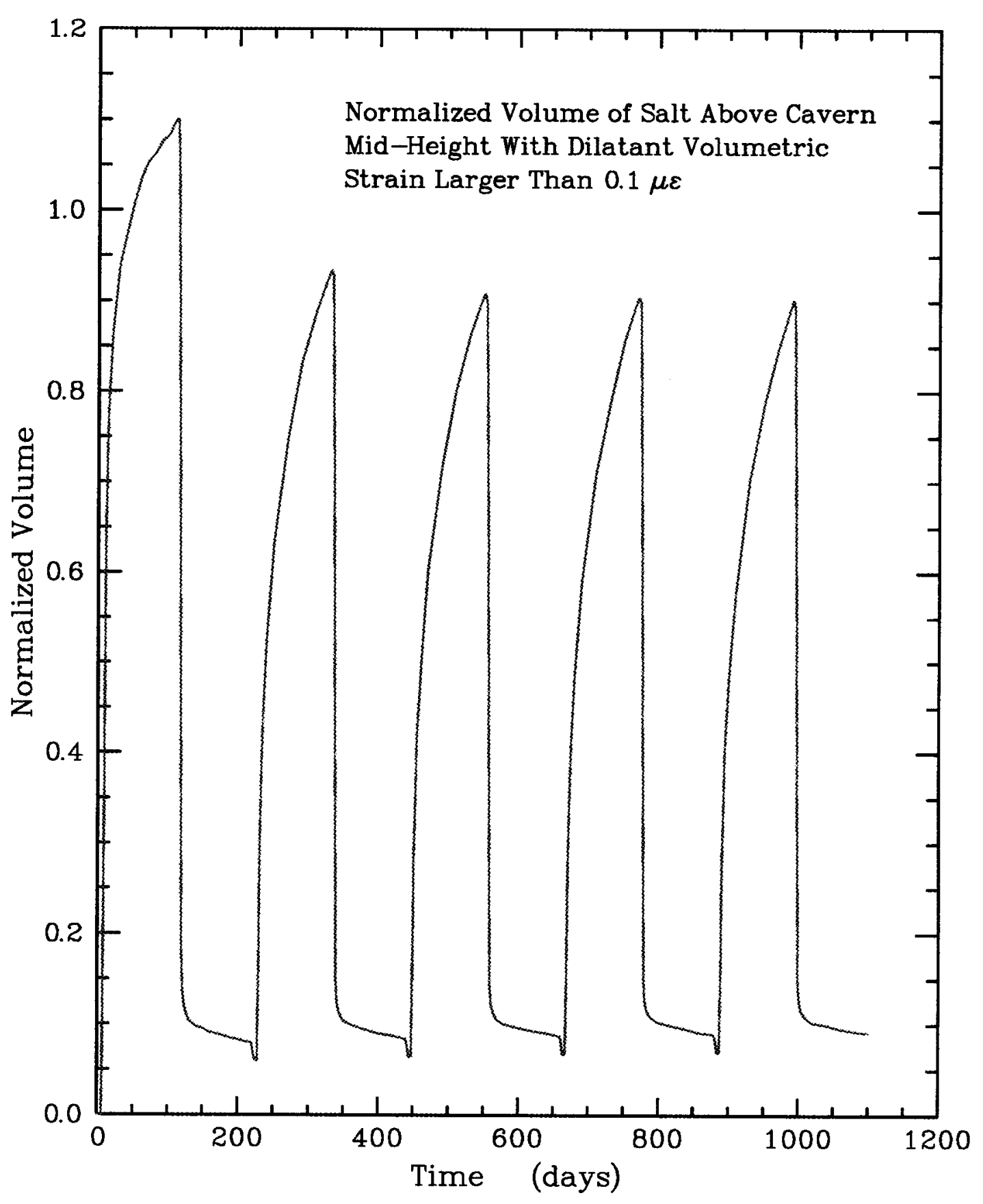

Figure 6-8. Normalized Volume of Salt Above the Cavern Midheight With Dilatant Volumetric Strain Greater Than $0.1 \mu \varepsilon$ for Cavern A Throughout Five Consecutive Case 2 Gas Pressure Cycles. 
increases slightly with each cycle. This is also evident in Figures 6-9 and 6-10, which show contours of the dilatant volumetric strain in the salt surrounding Cavern $A$ for the Case 1 cycle at the end of the first cycle and at the end of the fifth cycle. For the Case 2 cycles with a 100-day period at minimum gas pressure, the salt is not completely healed by the end of the first cycle, and again, the volume of the salt that is not completely healed increases slightly with each consecutive gas cycle. This is because the Kachanov damage variable and the inelastic volumetric strain are independent of each other during damage healing. As a result, even though the dilatant volumetric strain became vanishingly small, the value of $\omega$, although reduced, did not reach the initial value of undamaged rock salt during the healing stage. Therefore, the predicted results differ during each subsequent cycle due to the softening effect introduced by the damage variable.

For both the Case 1 and Case 2 simulations, the maximum volume of salt with dilatant volumetric strain greater than $0.1 \mu \varepsilon$ during each cycle decreases with each cycle. This is the result of strain hardening occurring during the periods at low gas pressure. This is also demonstrated in Figures 6-11 and 6-12, which show contours of the dilatant volumetric strain in the salt surrounding Cavern $A$ for the Case 1 cycle at the end of the 10-day period at minimum gas pressure during the first cycle and fifth cycle, respectively. It is also interesting to note that at the beginning of the cycles, during the first part of the gas withdrawal, the volume of salt that exceeds $0.1 \mu \varepsilon$ actually decreases. This is the result of the same phenomenon seen during the pressurization of Cavern $B$, except in reverse. As the gas pressure is decreased, the tangential stresses around the cavern become more compressive than the radial stresses, which are becoming less compressive, resulting in a short period of increased healing.

Figures 6-13 and 6-14 show the normalized volume of salt above the cavern midheight with a dilatant volumetric strain greater than $0.1 \mu \varepsilon$ for Cavern B for five consecutive Case 1 and Case 2 cycles, respectively. Unlike Cavern A, nearly all of the dilatant volumetric strain is healed by the end of the each cycle. Figures 6-15 and 6-16 show contours of the dilatant volumetric strain in the salt surrounding Cavern B for the Case 1 cycle at the end of the first cycle and at the end of the fifth cycle, respectively. As shown in these figures, the only accumulated damage is in small regions around corners in the cavern. This is true for both the Case 1 and Case 2 cycles. Like the Cavern A results, strain hardening results in decreasing the maximum volume of salt with dilatant volumetric strain greater than $0.1 \mu \varepsilon$ with each cycle. This is also revealed in Figures 6-17 and 6-18, which show contours of the dilatant volumetric strain in the salt surrounding Cavern B for the Case 1 cycle at the end of the 10-day period at minimum gas pressure during the first cycle and fifth cycle, respectively. 


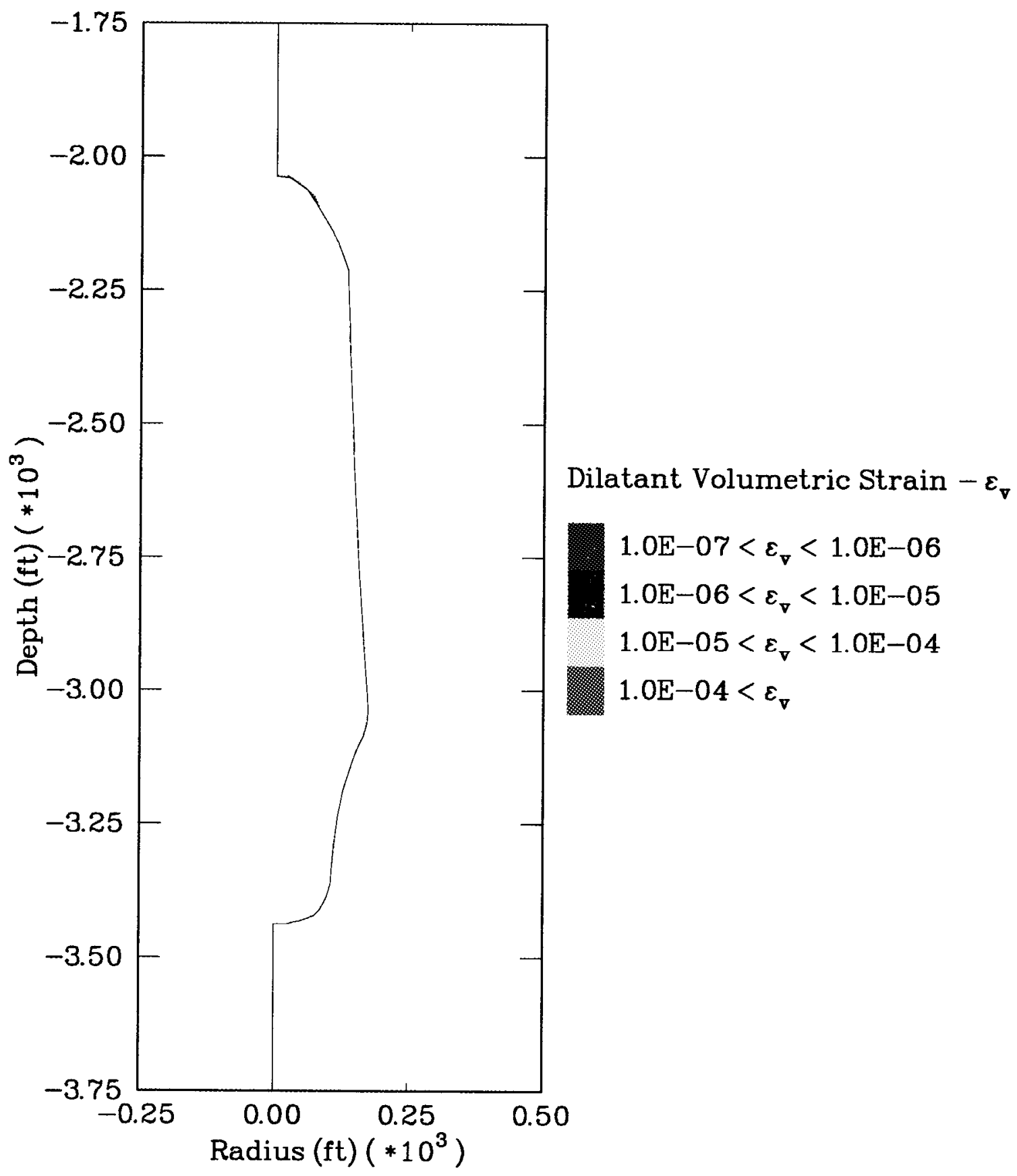

Figure 6-9. Contours of the Dilatant Volumetric Strain in the Salt Surrounding Cavern A at the End of the First Case 1 Gas Cycle. 


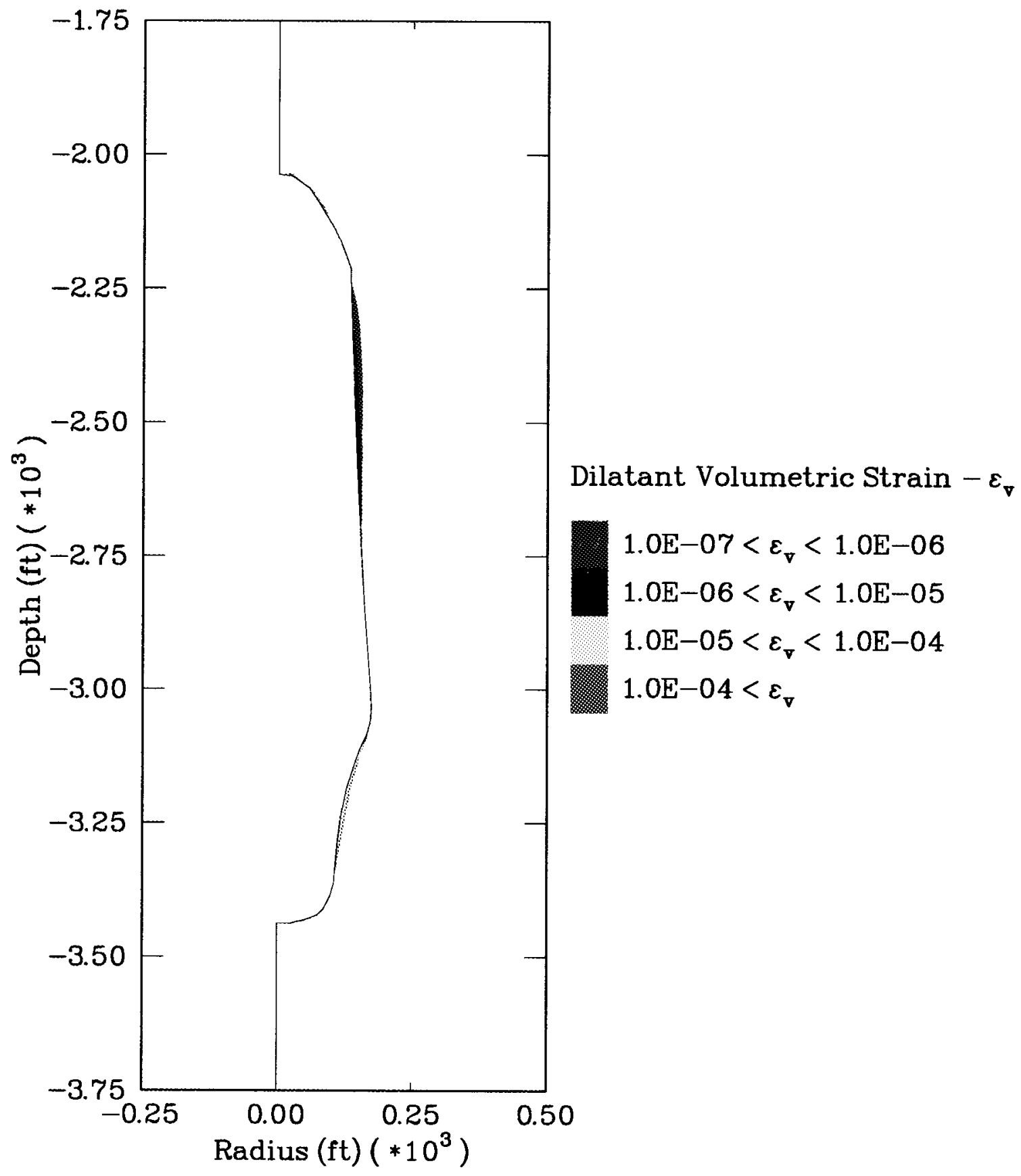

Figure 6-10. Contours of the Dilatant Volumetric Strain in the Salt Surrounding Cavern A at the End of the Fifth Case 1 Gas Cycle. 


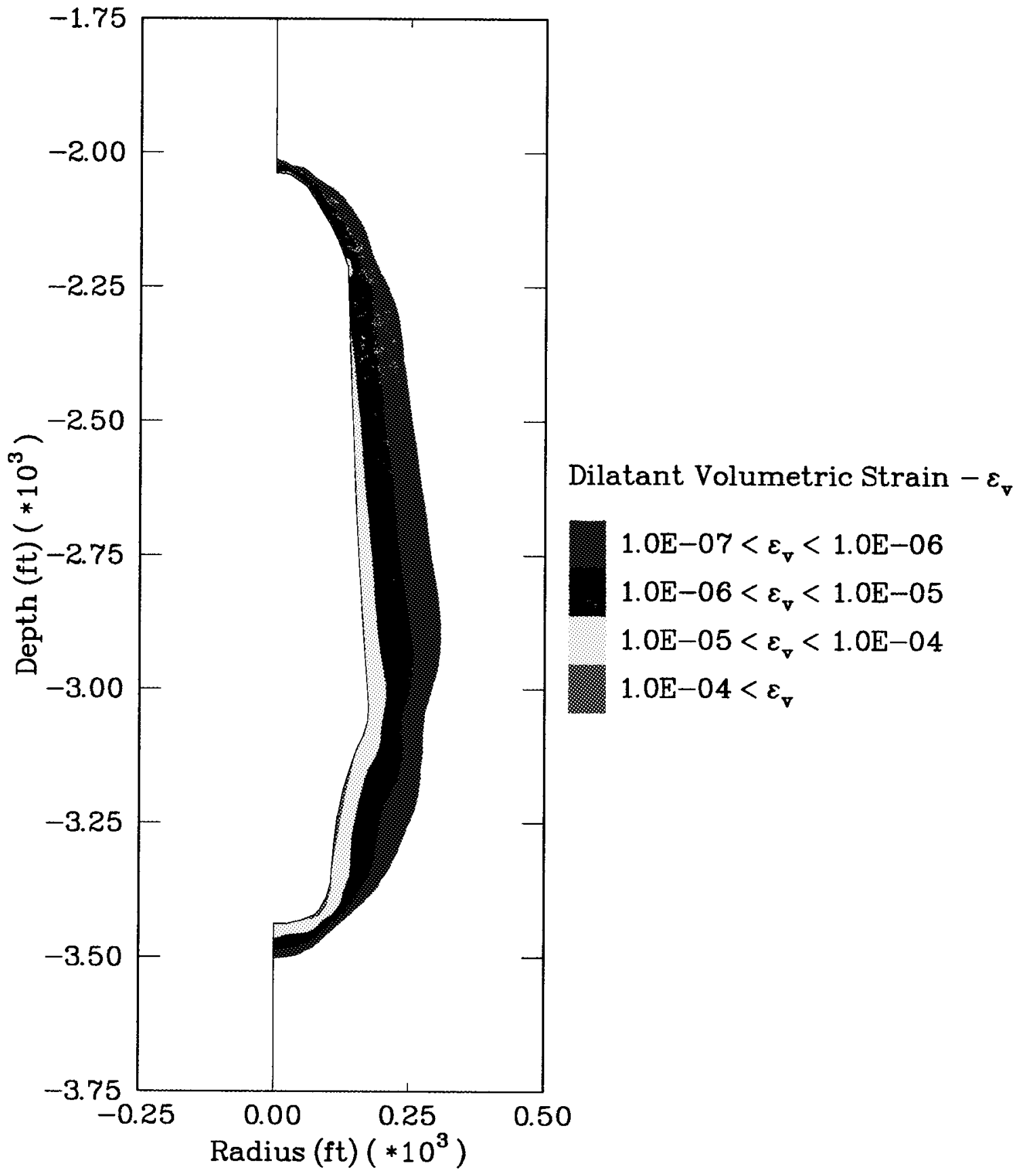

Figure 6-11. Contours of the Dilatant Volumetric Strain in the Salt Surrounding Cavern A at the End of the 10-Day Period at Minimum Gas Pressure During the First Case 1 Gas Cycle. 


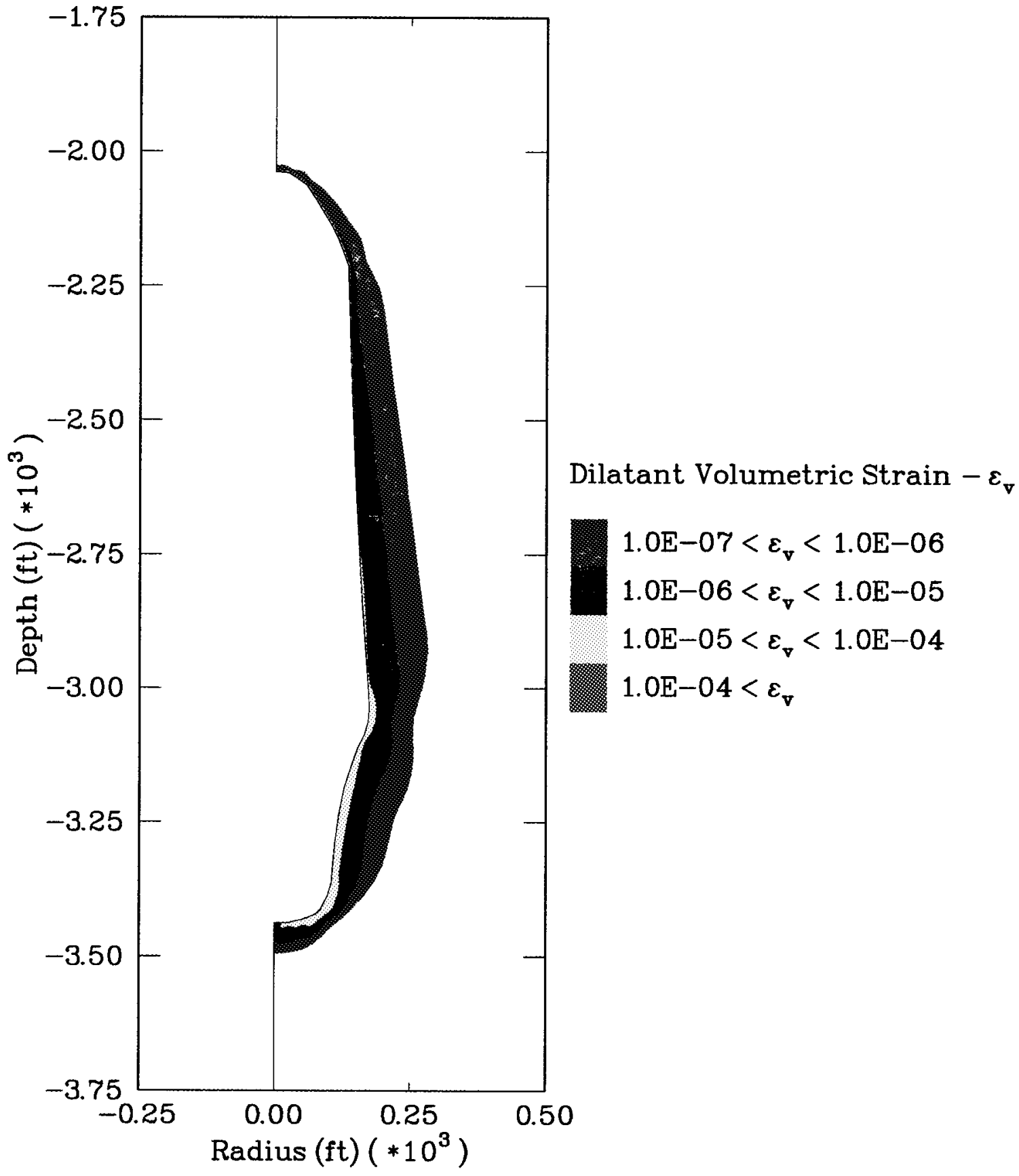

Figure 6-12. Contours of the Dilatant Volumetric Strain in the Salt Surrounding Cavern A at the End of the 10-Day Period at Minimum Gas Pressure During the Fifth Case 1 Gas Cycle. 


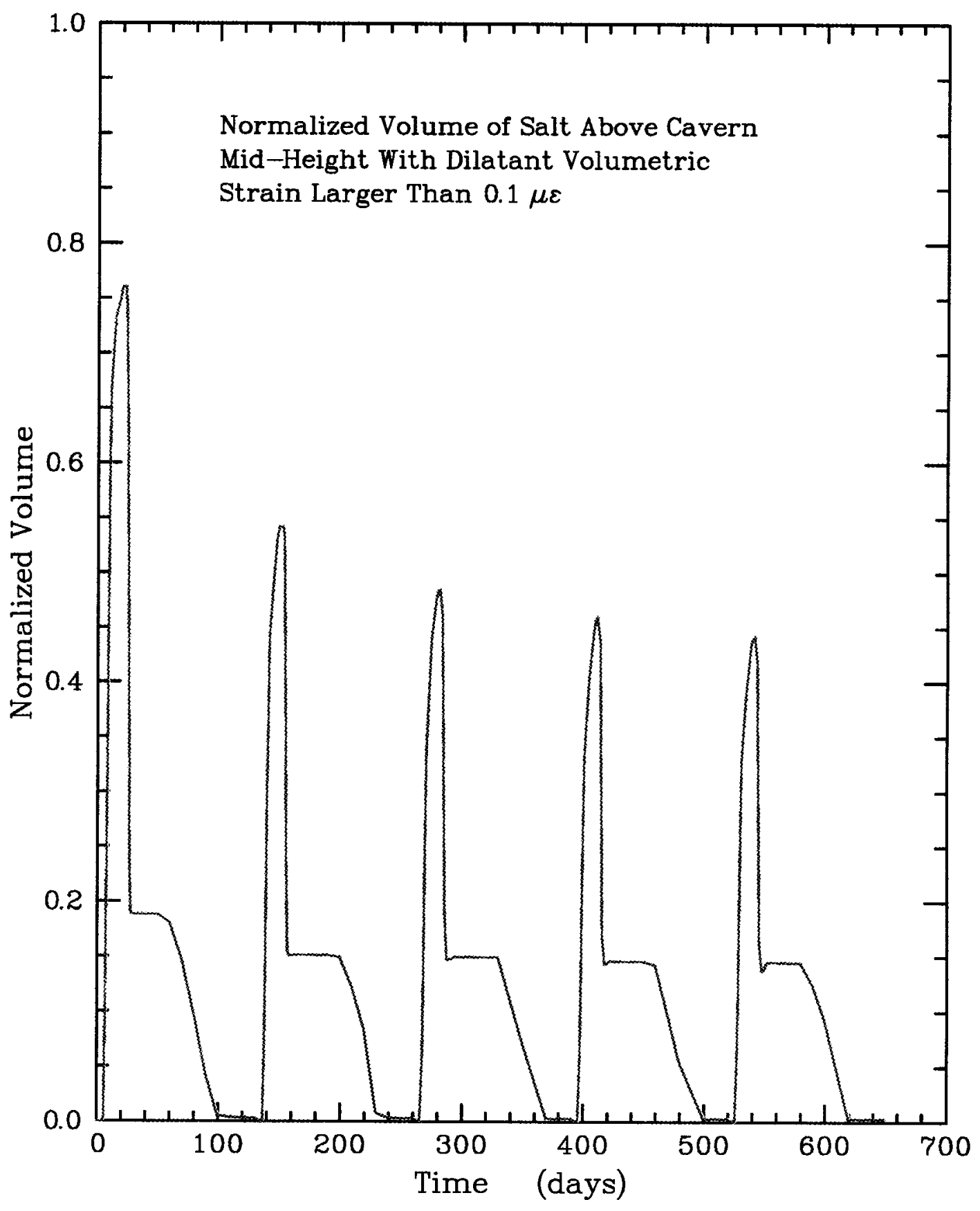

Figure 6-13. Normalized Volume of Salt Above the Cavern Midheight With Dilatant Volumetric Strain Greater Than $0.1 \mu \varepsilon$ for Cavern B Throughout Five Consecutive Case 1 Gas Pressure Cycles. 


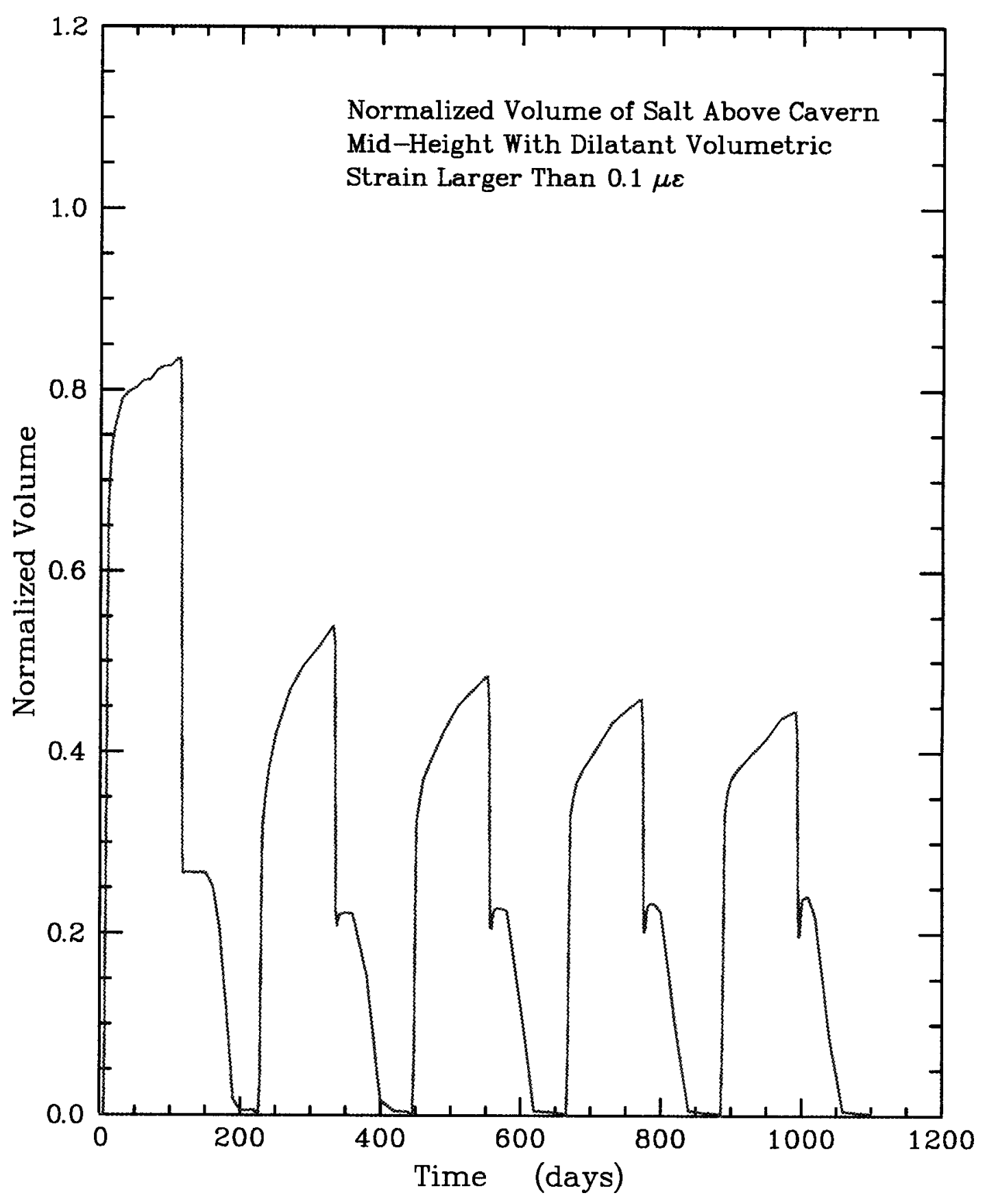

Figure 6-14. Normalized Volume of Salt Above the Cavern Midheight With Dilatant Volumetric Strain Greater Than $0.1 \mu \varepsilon$ for Cavern B Throughout Five Consecutive Case 2 Gas Pressure Cycles. 


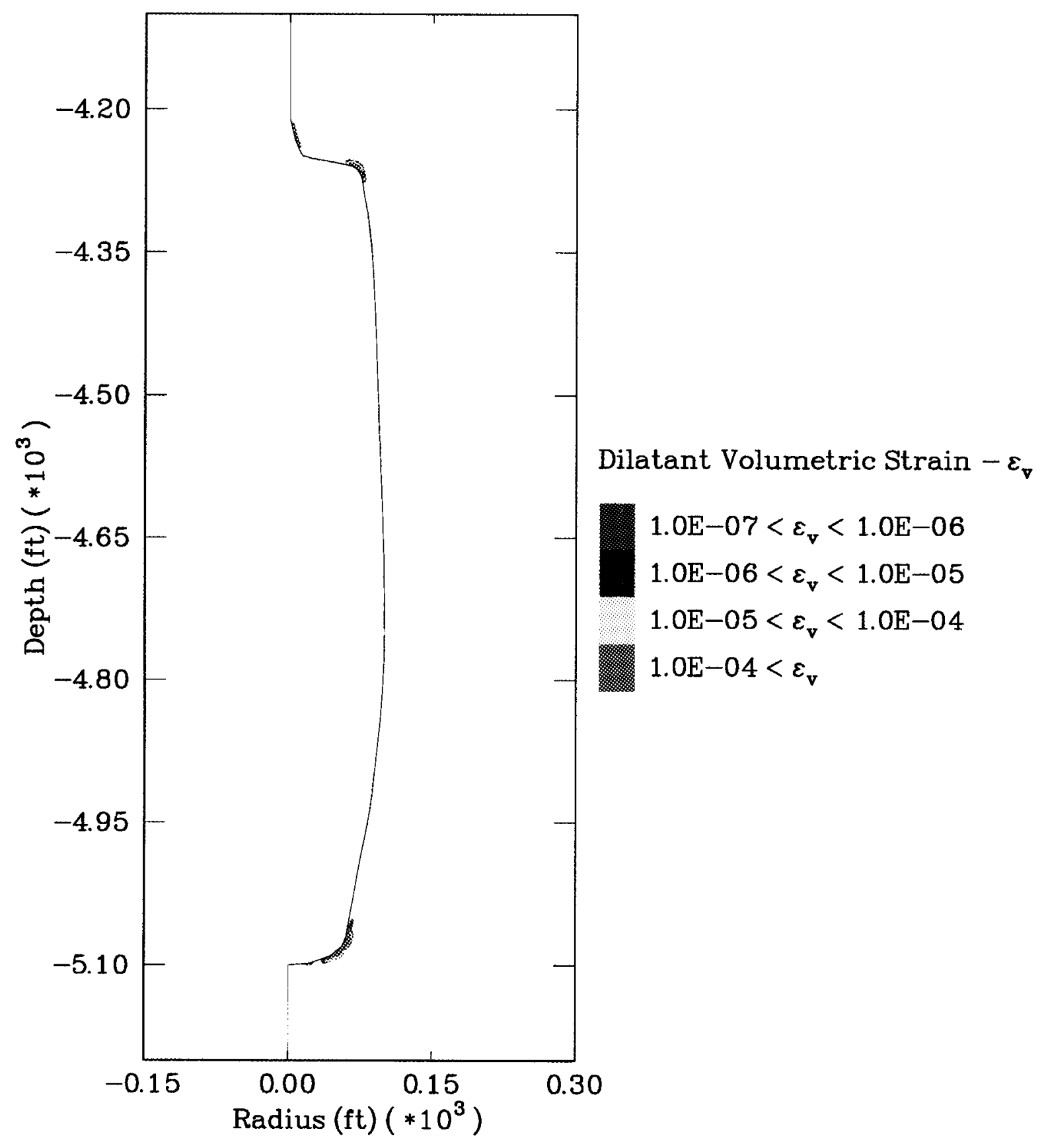

Figure 6-15. Contours of the Dilatant Volumetric Strain in the Salt Surrounding Cavern B at the End of the First Case 1 Gas Cycle. 


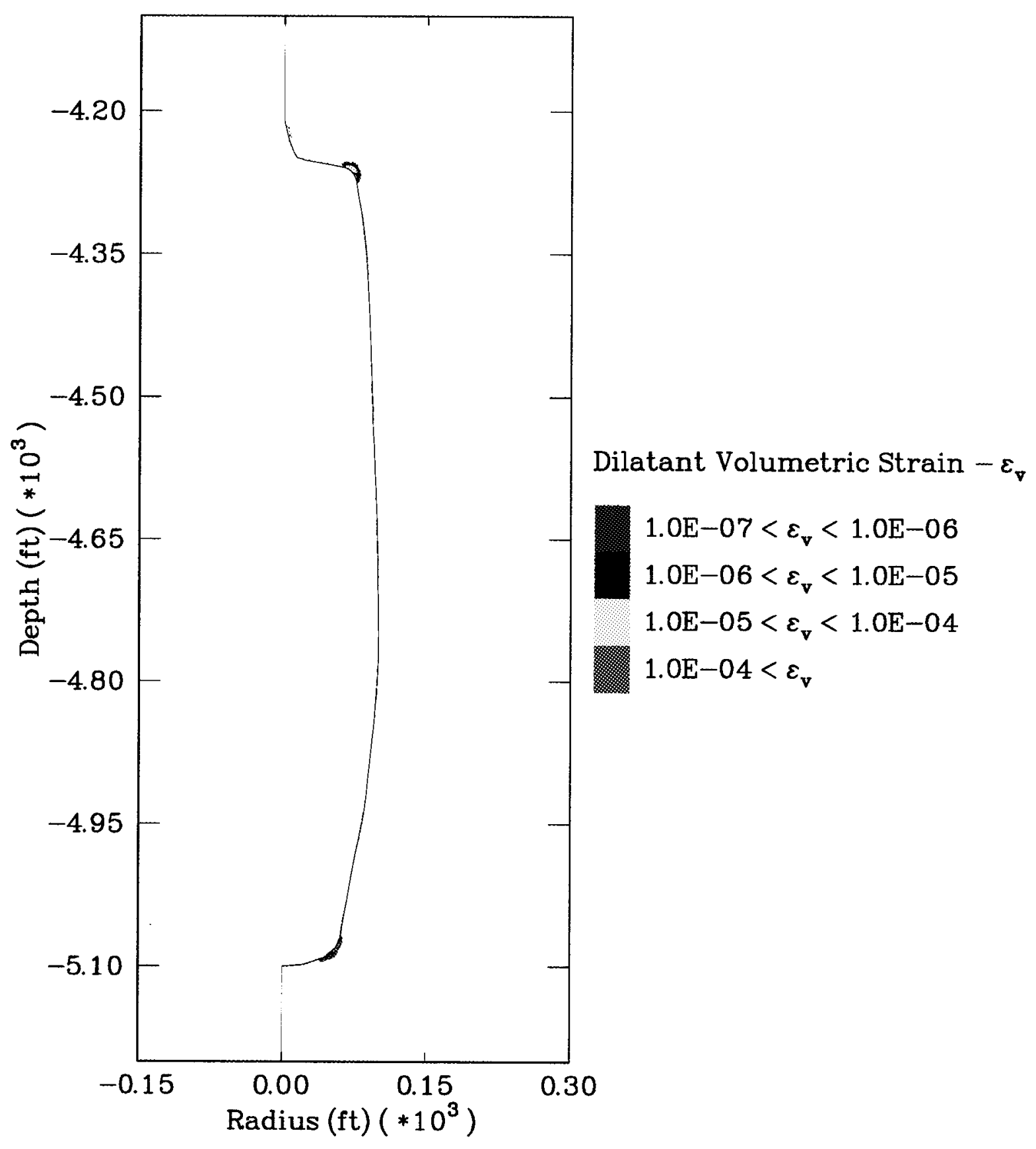

Figure 6-16. Contours of the Dilatant Volumetric Strain in the Salt Surrounding Cavern B at the End of the Fifth Case 1 Gas Cycle. 


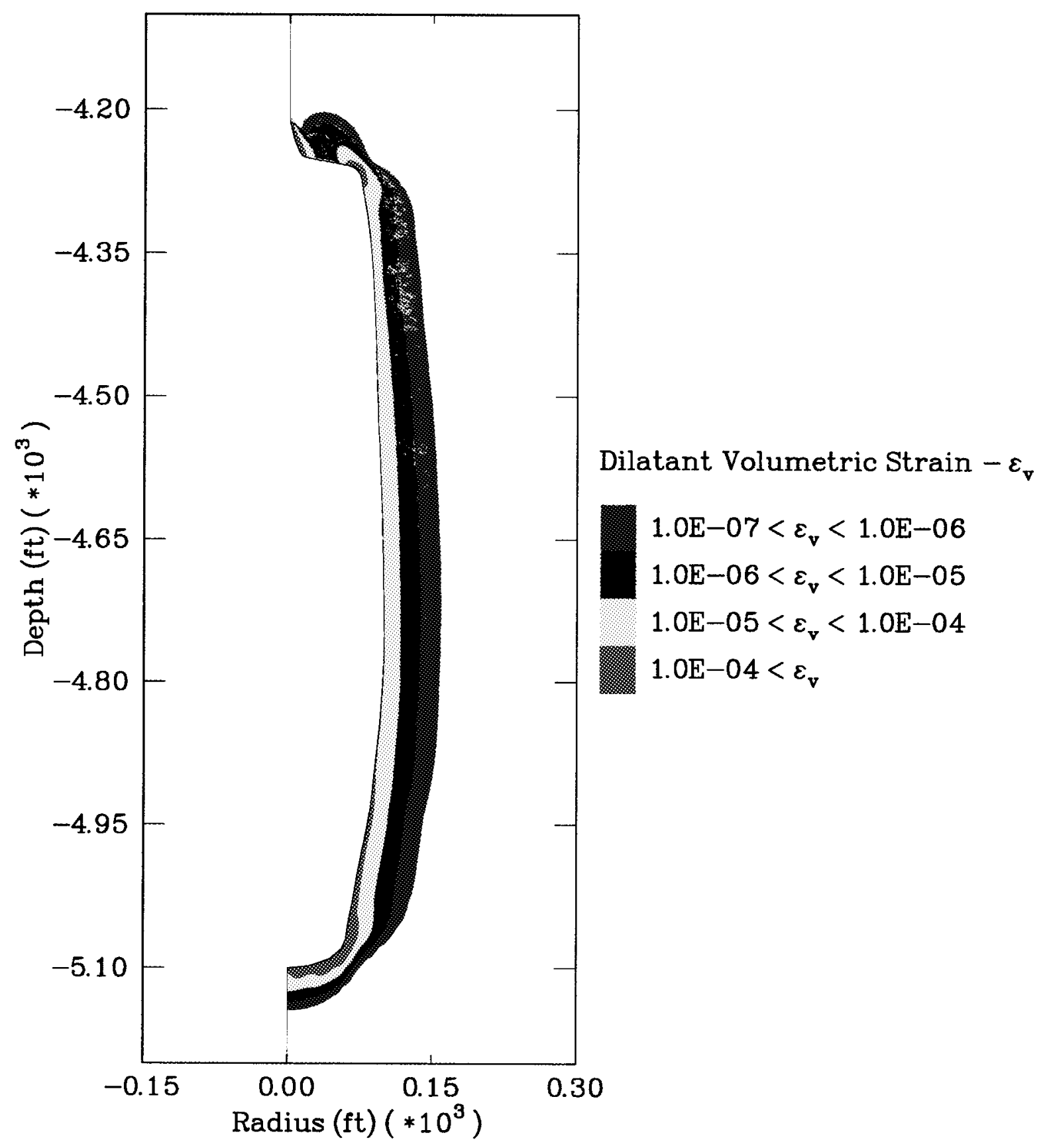

Figure 6-17. Contours of the Dilatant Volumetric Strain in the Salt Surrounding Cavern B at the End of the 10-Day Period at Minimum Gas Pressure During the First Case 1 Gas Cycle. 


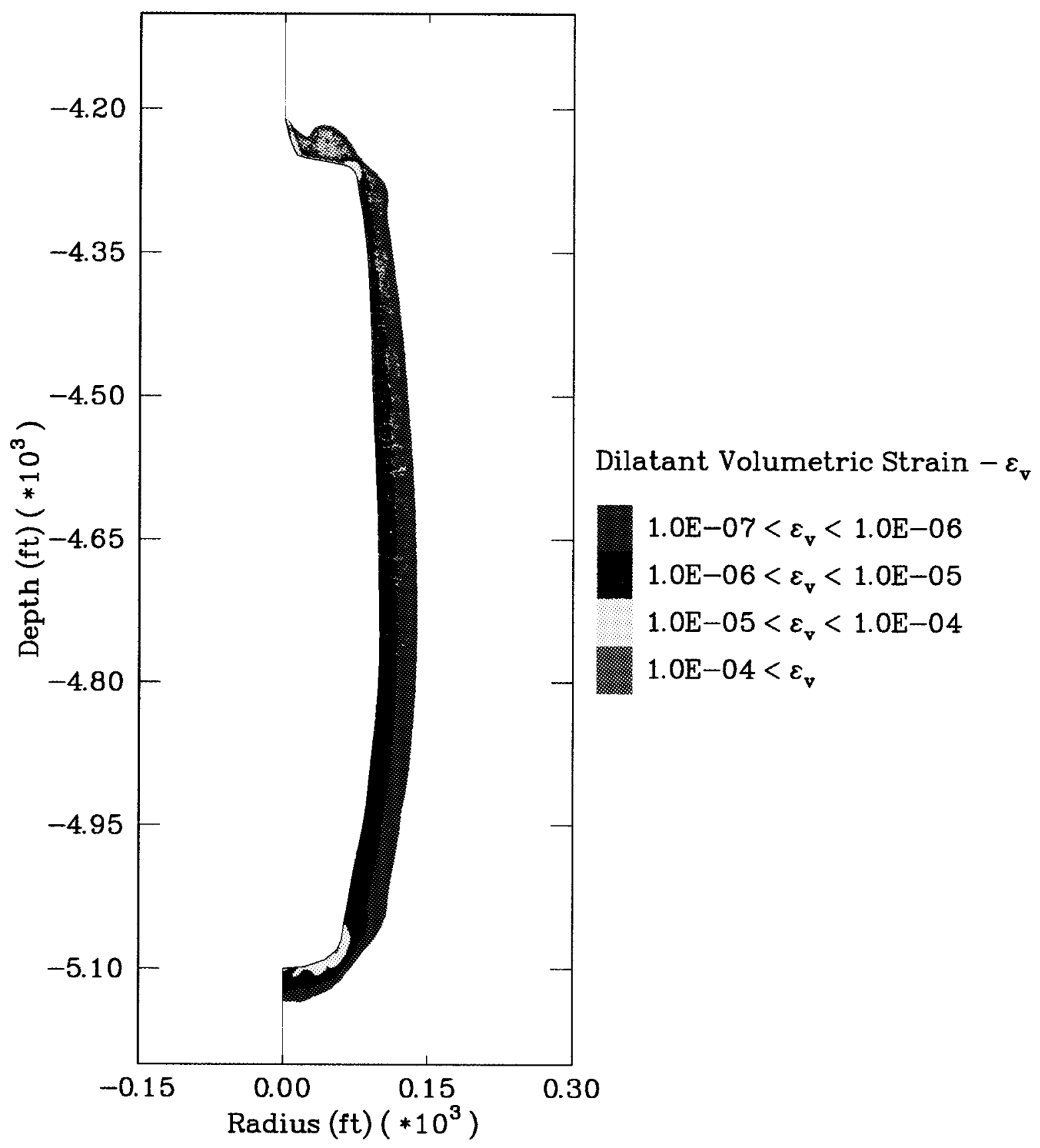

Figure 6-18. Contours of the Dilatant Volumetric Strain in the Salt Surrounding Cavern B at the End of the 10-Day Period at Minimum Gas Pressure During the Fifth Case 1 Gas Cycle. 


\subsection{SUMMARY AND CONCLUSIONS}

Geomechanical analyses were made to determine the minimum gas pressure allowable based on an existing stress-based criterion (Damage Potential) and an advanced constitutive model (MDCF model) capable of quantifying the level of damage and healing in rock salt. The MDCF model is a constitutive model developed for the WIPP to provide a continuum description of the dislocation and damage deformation of salt. The purpose of this study was to determine if the MDCF model is applicable for evaluating the minimum gas pressure of CNG storage caverns. Specifically, it was to be determined if this model would predict that the minimum gas pressure in the caverns could be lowered without compromising the stability of the cavern. Additionally, the healing behavior of the salt was analyzed to determine if complete healing of the damaged rock zone would occur during the period the cavern was at maximum gas pressure. Significant findings of this study include:

1. The predicted dilatancy boundaries for the Damage Potential method and the MDCF model can differ significantly,depending on the stress state and impurity content (porosity) of salt.

2. Based on a conservative design criterion, the MDCF model predicts that a lower minimum gas pressure can be specified without jeopardizing cavern stability than that predicted by the Damage Potential method provided the cavern is not maintained at minimum pressure for an extended period of time.

3. Based on the MDCF model, healing of the dilatant volume of salt will occur at maximum gas pressure.

4. If damage develops during a gas service cycle, sufficient time should be allowed for healing to occur after the cavern is repressurized before the next service cycle to prevent continued damage development during subsequent cycles.

5. Less damage is predicted by the MDCF model around the shallow cavern than in the salt around the deeper cavern for the minimum gas pressures and impurity content specified in this study. Unlike the Damage Potential method, the MDCF dilatancy boundary is not a linear function of the stress invariants; therefore, the potential for damage development is predicted to increase with depth.

6. Further studies are necessary to better characterize the healing response of salt. 


\subsection{FUTURE WORK}

\subsection{DETERMINATION OF AN EFFICIENT TEST MATRIX}

The mechanical behavior of salt is known to vary from site to site. Therefore, the constitutive model parameter values determined for the WIPP site may not be reliable for evaluating the material behavior of salt at other locations. Thus, the MDCF model should not be used to determine the acceptable operating pressure range for a CNG storage cavern unless site-specific properties or parameters are used. Advanced constitutive models for salt, such as the MDCF model, are highly nonlinear and contain many parameters. As discussed by Senseny and Fossum [1995], evaluation of parameters in such models is not a trivial matter because the parameters often do not have physical meaning (such as yield or failure stress do). In these cases, estimation of the parameters often requires a more rigorous approach which includes three distinct phases: (1) the design of an experimental program or test matrix comprising laboratory tests, (2) the acquisition of data from laboratory tests, and (3) the fitting of the model to the acquired data to determine estimates of the model parameters. The design of the test matrix requires the identification of test types that impose load or strain histories in which the material behavior is dominated by phenomenology that is characterized by the parameters of the model.

A methodology for determining the necessary parameter values of the MDCF model should be developed. The MDCF model parameter values have been determined for the WIPP based on laboratory tests. However, an extensive testing program such as that developed for the WIPP would not be feasible for designing CNG storage caverns because of the excessive duration of the program and the exorbitant cost. However, it may be feasible to determine parameter estimates for the MDCF model if the necessary laboratory tests required to evaluate the MDCF model parameters are minimized. An efficient test matrix can be developed by choosing tests in which the sensitivity coefficient of each parameter of the MDCF model is significantly higher than that of other parameters for a part of the test, or at least is one of the high sensitivity coefficients in some tests so that the parameter's contribution to material behavior can be determined. The estimated cost of determining the parameter estimates of the MDCF model should be evaluated against the added benefit provided by the model and potential savings.

\subsection{TEMPERATURE EFFECTS AND HEALING CHARACTERISTICS}

The database of laboratory tests used for the development of the MDCF model dislocation creep mechanisms is quite extensive. However, these tests do not provide information suitable for characterizing creep-induced damage because they were specifically performed under conditions that suppress microcracking. Therefore, development of the damage model required that the existing database used to develop the M-D model be supplemented with tests from which damage development and healing can be inferred. This supplemental database is not as 
extensive as the database developed to characterize the dislocation creep processes, and in the case of damage healing, is probably not sufficient to validate model. Additionally, very little data were collected at elevated temperatures. The influence of temperature on damage accumulation and healing should be investigated further since CNG storage caverns can operate at temperatures outside the range used to develop the MDCF model.

\subsection{PORE PRESSURE EFFECTS}

Damage, such as the type that forms in the disturbed rock zone (DRZ) around storage caverns, is known to heal under hydrostatic conditions (e.g., Brodsky [1990]). Stress states near hydrostatic can be obtained in the salt around CNG storage caverns when operated at maximum gas pressure. However, because the salt near the cavern walls could have an enhanced permeability, the gas pressure may actually gain access to the porosity created by the damaging process, and therefore, may not produce the desired effect; i.e., a compressive pressure acting over the full boundary of the cavern. If gas pressure is allowed to access the DRZ, pore pressures will build in the DRZ, and these pore pressures may reduce the potential for healing and/or increase the potential for damage because they will likely lower the overall effective mean stress (i.e., mean stress minus the pore pressure) induced in the DRZ. If the hydrologic characteristics (e.g., permeability, pore pressure, etc.) of the salt influence the mechanical behavior of the salt, the actual behavior of the salt may not be accurately described by the MDCF model. If this is the case, there is a need to understand the coupling between the hydrological and structural characteristics of the DRZ to predict more accurately the damage/healing process. 


\subsection{REFERENCES}

Aubertin, M., J. Sgaoula, and D. E. Gill, 1993. "A Damage Model for Rocksalt: Application to Tertiary Creep," Proceedings, Seventh Symposium on Salt, H. Kakihana, H. R. Hardy, Jr., T. Hoshi, and K. Toyokura (eds.), Elsevier, Amsterdam, Vol. 1, pp. 117-125.

Brodsky, N. S., 1990. Crack Closure and Healing Studies in WIPP Salt Using Compressional Wave Velocity and Attenuation Measurements: Test Methods and Results, SAND90-7076, prepared by RE/SPEC Inc., Rapid City, SD, for Sandia National Laboratories, Albuquerque, NM.

Brodsky, N. S. and D. E. Munson, 1994. "Thermomechanical Damage Recovery Parameters for Rocksalt From the Waste Isolation Pilot Plant," Proceedings, 1st North American Rock Mechanics Symposium, University of Texas-Austin, Austin, TX, June 1-3, P. P. Nelson and S. E. Laubach (eds.), A. A. Balkema, Rotterdam, pp. 731-738.

Callahan, G. D., A. F. Fossum, and D. K. Svalstad, 1989. Documentation of SPECTROM-32: A Finite Element Thermomechanical Stress Analysis Program, DOE/CH/10378-2, prepared by RE/SPEC Inc., Rapid City, SD, for the U.S. Department of Energy, Chicago Operations Office, Argonne, IL, Vol. I and II.

Chan, K. S., S. R. Bodner, A. F. Fossum, and D. E. Munson, 1992. "A Constitutive Model for Inelastic Flow and Damage Evolution in Solids Under Triaxial Compression," Mechanics of Materials, Vol. 14, pp. 1-14.

Chan, K. S., N. S. Brodsky, S. R. Bodner, A. F. Fossum, and D. E. Munson, 1994. "Damage-Induced Nonassociated Inelastic Flow in Rock Salt," International Journal of Plasticity, Vol. 10, pp. 623-642.

Chan, K. S., K. L. DeVries, S. R. Bodner, A. F. Fossum, and D. E. Munson, 1995a. "A Damage Mechanics Approach to Life Prediction for a Salt Structure," Proceedings of ICES '95, Computational Mechanics, S. N. Atluri, G. Yagawa, and T. A. Cruse (eds.), Springer, Berlin, pp. 1140-1145.

Chan, K. S., S. R. Bodner, A. F. Fossum, and D. E. Munson, 1995b. "Constitutive Representation of Damage Healing in WIPP Salt," Proceedings, 35th U.S. Symposium on Rock Mechanics, University of Nevada, Reno, NV, June 5-7, J. J. K. Daemen and R. A. Schultz (eds.), A. A. Balkema, Rotterdam, pp. $485-490$.

Chan, K. S., S. R. Bodner, D. E. Munson, and A. F. Fossum, 1996a. "Inelastic Flow Behavior of Argillaceous Salt," International Journal of Damage Mechanics, Vol. 5, No. 3, July, pp. 292-314. 
Chan, K. S., D. E. Munson, A. F. Fossum, and S. R. Bodner, 1996b. "A Constitutive Model for Representing Coupled Creep, Fracture, and Healing in Rock Salt," Proceedings, Fourth Conference of The Mechanical Behavior of Salt, École Polytechnique de Montréal, Mineral Engineering Department, Québec, Canada, June 17 and 18, M. Aubertin and H. R. Hardy Jr. (eds.), Penn State University, Trans Tech Publications, Clausthal, Germany, 1998, pp. 221-234.

Chan, K. S., D. E. Munson, S. R. Bodner, and A. F. Fossum, 1996c. "Cleavage and Creep Rupture of Rock Salt," Acta Metallurgica et Materialia, Vol. 44, No. 9, pp. 3553-3565.

Chan, K. S., S. R. Bodner, A. F. Fossum, and D. E. Munson, 1997. "A Damage Mechanics Treatment of Creep Failure in Rock Salt," International Journal of Damage Mechanics, Vol. 6, April, pp. 121-152.

Costin, L. S. and W. R. Wawersik, 1980. Creep Healing of Fractures in Rock Salt, SAND80-0392, Sandia National Laboratories, Albuquerque, NM.

Cristescu, N. D. and U. Hunsche, 1992. Finite Inelastic Deformation-Theory and Application, D. Desdo and E. Stein (eds.), Springer-Verlag, Berlin, Germany, pp. 511-523.

Fokker, P. A., 1995. The Behavior of Salt and Salt Caverns, Ph.D. Dissertation, Technische Universiteit Delft.

Hansen, F. D., M. J. Leroch, L. L. Van Sambeek, and M. S. Lin, 1993. “Gas Barrier Design for the WIPP," Proceedings, 34th U.S. Symposium on Rock Mechanics, University of Wisconsin-Madison, Madison, WI, June 27-30, B. C. Haimson (ed.), International Journal of Rock Mechanics and Mining Sciences \& Geomechanics Abstracts, Pergamon Press, Vol. 30, No. 7, pp. 1515-1518.

Harrison and Ellis, 1995. Risk Assessment of Converting Salt Caverns to Natural Gas Storage, GRI-95/0377, prepared by Radian Corporation, Austin, TX, for the Gas Research Institute, Chicago, IL.

Kachanov, L. M., 1958. "On the Creep Fracture Time," Izv. Akad. Nauk, USSR, Otdgel. Tekh, Nauk., Vol. 8, p. 26.

Lin, M. S. and L. L. Van Sambeek, 1992. Waste Isolation Pilot Plant Alcove Gas Barrier Final Design Report, SAND92-7307, prepared by Parsons Brinckerhoff Quade \& Douglas, Inc., San Francisco, CA, and RE/SPEC Inc., Rapid City, SD, for Sandia National Laboratories, Albuquerque, NM.

Munson, D. E., 1979. Preliminary Deformation-Mechanism Map for Salt (With Application to WIPP), SAND79-0076, Sandia National Laboratories, Albuquerque, NM. 
Munson, D. E. and P. R. Dawson, 1979. Constitutive Model for the Low Temperature Creep of Salt (With Application to WIPP), SAND79-1853, Sandia National Laboratories, Albuquerque, NM.

Munson, D. E., A. F. Fossum, and P. E. Senseny, 1989. Advances in Resolution of Discrepancies Between Predicted and Measured In Situ WIPP Room Closures, SAND88-2948, Sandia National Laboratories, Albuquerque, NM.

Nemat-Nasser, S. 1983. Proceeding, ICF International Symposium on Fracture Mechanics, Beijing Science Press, Beijing, China, pp. 185-97.

Pfeifle, T. W. and L. D. Hurtado, 1998. "Permeability of Natural Rock Salt From the Waste Isolation Pilot Plant (WIPP) During Damage Evolution and Healing," Proceedings, 3rd North American Rock Mechanics Symposium, Cancún, Mexico, June 3-5.

Ratigan, J. L., L. L. Van Sambeek, K. L. DeVries, and J. D. Nieland, 1991. The Influence of Seal Design on the Development of the Disturbed Rock Zone in the WIPP Alcove Seal Tests, RSI-0400, prepared by RE/SPEC Inc., Rapid City, SD, for Sandia National Laboratories, Albuquerque, NM.

Ratigan, J. L., J. D. Nieland, and J. D. Osnes, 1993. "Rock Mechanics Aspects of Natural Gas Storage in Domal Salt," presented at the Solution Mining Research Institute Fall Meeting, Lafayette, LA, October 25-26.

Senseny, P. E. and A. F. Fossum, 1995. "On Testing Requirements for Viscoplastic Constitutive Parameter Estimation," Journal of Engineering Materials and Technology, Vol. 117, April, pp. 151-154.

Van Sambeek, L. L., D. D. Luo, M. S. Lin, W. Ostrowski, and D. Oyenuga, 1993. Seal Design Alternatives Study, SAND92-7340, prepared by Parsons Brinckerhoff Quade \& Douglas, San Francisco, CA, and RE/SPEC Inc., Rapid City, SD, for Sandia National Laboratories, Albuquerque, NM. 


\section{APPENDIX A}

SUMMARY OF THE MDCF MODEL

A-1 


\section{APPENDIX A}

\section{SUMMARY OF THE MDCF MODEL}

The MDCF model is a constitutive model that provides a continuum description of the creep response and the associated damage evolution and healing of rock salt. Both dislocation motion and creep-induced damage are assumed to contribute directly to the macroscopic inelastic strain rate. In addition to a direct contribution to the inelastic strain rate, the MDCF model was formulated such that damage also produces a softening effect as proposed by Kachanov [1958]. The Kachanov damage variable, $\omega$, reduces the load-bearing capacity through a reduction in the effective area using a continuum damage mechanics approach. The damage variable is determined from an evolutionary equation and provides a measure for the level of damage. For the MDCF model, the contribution of creep-induced damage and healing to the inelastic strain rate is incorporated through additional kinetic equations that are independent of the kinetic equation for dislocation mechanisms. The terms are combined using the approach given by Fossum et al. [1988] to derive a proper three-dimensional generalization using classical thermodynamic principles. The generalized form of the MDCF model is given by:

$$
\dot{\varepsilon}_{i j}^{i}=\frac{\partial \sigma_{e q}^{c}}{\partial \sigma_{i j}} \dot{\varepsilon}_{e q}^{c}+\frac{\partial \sigma_{e q}^{\omega}:}{\partial \sigma_{i j}} \dot{\varepsilon}_{e q}^{\omega}+\frac{\partial \sigma_{e q}^{\omega_{i}}}{\partial \sigma_{i j}} \dot{\varepsilon}_{e q}^{\omega_{i}}+\frac{\partial \sigma_{e q}^{h}}{\partial \sigma_{i j}} \dot{\varepsilon}_{e q}^{h}
$$

where $\sigma_{e q}^{c}, \sigma_{e q}^{\omega_{i}^{*}}, \sigma_{e q}^{\omega_{t}}, \sigma_{e q}^{h}, \dot{\varepsilon}_{e q}^{c}, \dot{\varepsilon}_{e q}^{\omega_{t}}, \dot{\varepsilon}_{e q}^{\omega_{i}}$, and $\dot{\varepsilon}_{e q}^{h}$ are power-conjugate equivalent stress measures and equivalent inelastic strain rates for the dislocation creep $(c)$, shear damage $\left(\omega_{s}\right)$, tensile damage $\left(\omega_{t}\right)$, and damage healing $(h)$ mechanisms, respectively. Details of the power-conjugate stress measures, kinetic equations, the flow laws, and the evolution equation for damage in the MDCF model are summarized below. Note that compression is taken to be negative.

\section{Kinetic Equation for Dislocation Flow}

The kinetic equation representing the creep rate, $\dot{\varepsilon}_{e q}^{c}$, due to dislocation mechanisms is based on the modified M-D model [Munson et al., 1989]. The formulation remains unchanged with the exception that the six occurrences of the effective stress are divided by the term $(1-\omega)$, which represents the reduction in the effective load-bearing area caused by the presence of damage. The kinetic equation for the dislocation mechanisms is:

$$
\dot{\varepsilon}_{e q}^{c}=F \dot{\varepsilon}_{s}
$$

where $F$ is the transient function representing transient creep behavior, and $\dot{\varepsilon}_{a}$ is the steadystate strain rate. The steady-state creep of salt is the sum of three dominant mechanisms: (1) a high temperature, low stress regime controlled by dislocation climb; (2) a low temperature, low stress regime controlled by an undefined mechanism; and (3) a high stress regime controlled by 
various possible dislocation slip mechanisms. The steady-state creep rates of the three relevant mechanisms, respectively, are given by:

$$
\begin{gathered}
\dot{\varepsilon}_{s_{1}}=A_{1} e^{-Q_{1} / R T}\left(\frac{\sigma_{e q}^{c}}{\mu(1-\omega)}\right)^{n_{1}} \\
\dot{\varepsilon}_{s_{2}}=A_{2} e^{-Q_{2} / R T}\left(\frac{\sigma_{e q}^{c}}{\mu(1-\omega)}\right)^{n_{2}} \\
\dot{\varepsilon}_{s_{s}}=|H|\left(B_{1} e^{-Q_{1} / R T}+B_{2} e^{-Q_{2} / R T}\right) \sinh \left[\frac{q\left(\frac{\sigma_{e q}^{c}}{(1-\omega)}-\sigma_{0}\right)}{\mu}\right]
\end{gathered}
$$

where the $A$ 's and $B$ 's are constants, $Q$ 's are activation energies, $T$ is the absolute temperature, $R$ is the universal gas constant, $\mu$ is the shear modulus, $n$ 's are the stress exponents, $q$ is the stress constant, and $\sigma_{0}$ is the stress limit of the dislocation slip mechanism. $|H|$ is a Heaviside step function with the argument $\left(\frac{\sigma_{e q}^{\kappa}}{1-\omega}-\sigma_{0}\right)$. The transient creep function $F$ is given by:

$$
F=\left\{\begin{array}{c}
\exp \left[\Delta\left(1-\frac{\zeta}{\varepsilon_{t}^{*}}\right)^{2}\right], \zeta<\varepsilon_{t}^{*} \\
1, \zeta=\varepsilon_{t}^{*} \\
\exp \left[-\delta\left(1-\frac{\zeta}{\varepsilon_{t}^{*}}\right)^{2}\right], \zeta>\varepsilon_{t}^{*}
\end{array}\right.
$$

which is composed of a work-hardening branch, an equilibrium branch, and a recovery branch, respectively. In Equation A-6, $\Delta$ and $\delta$ represent the work-hardening and recovery parameters, respectively, and $\varepsilon_{t}^{*}$ is the transient strain limit. The transient strain limit is a function of temperature and stress and is represented by:

$$
\varepsilon_{t}^{*}=K_{0} e^{c T}\left(\frac{\sigma_{e q}^{c}}{\mu(1-\omega)}\right)^{m}
$$

where $K_{0}, c$, and $m$ are constants. The work-hardening and recovery parameters are functions of stress given by: 


$$
\begin{gathered}
\Delta=\alpha_{w}+\beta_{w} \log \left(\frac{\sigma_{e q}^{c}}{\mu(1-\omega)}\right) \\
\delta=\alpha_{r}+\beta_{r} \log \left(\frac{\sigma_{e q}^{c}}{\mu(1-\omega)}\right)
\end{gathered}
$$

where the $\alpha$ 's and $\beta$ 's are constants with the subscripts denoting either work-hardening $(w)$ or recovery $(r)$. $\delta$ was taken as a constant in this paper since insufficient experimental data are available to determine the stress dependency of the recovery parameters, and little of the salt surrounding the underground cavern is expected to be in recovery for the service cycle simulated. The evolution rate, $\dot{\zeta}$, of the internal variable $\zeta$ is governed by:

$$
\dot{\zeta}=(F-1) \dot{\varepsilon}_{s}
$$

which diminishes to zero when the steady-state condition is achieved.

The maximum shear stress or Tresca criterion is used here for dislocation-induced flow. The power-conjugate equivalent stress measure, $\sigma_{e q}^{c}$, for the dislocation mechanisms, assuming the Tresca criterion, is given by:

$$
\sigma_{e q}^{c}=2 \cos \psi \sqrt{J_{2}}=\sigma_{1}-\sigma_{3}
$$

where $\psi$ is the Lode angle, $J_{2}$ is the second invariant of the deviatoric stress tensor, and $\sigma_{1}$ and $\sigma_{3}$ are the maximum and minimum principal stresses, respectively.

\section{Flow Law for Dislocation Deformation}

The shear-induced dislocation flow of rock salt is assumed to be associative. The flow potential is an important factor in extending data obtained from constant stress laboratory creep tests to generalized three-dimensional states of stress. Differentiation of the power-conjugate stress given by Equation A-11 with respect to stress leads to:

$$
\frac{\partial \sigma_{e q}^{c}}{\partial \sigma_{i j}}=\left[\frac{\cos 2 \psi}{\cos 3 \psi}\right] \frac{s_{i j}}{\sqrt{J_{2}}}+\left[\frac{\sqrt{3} \sin \psi}{J_{2} \cos 3 \psi}\right] t_{i j}
$$

where $s_{i j}$ is the deviatoric stress tensor and $t_{i j}=s_{i p} s_{p j}-2 / 3 J_{2} \delta_{i j}$. Equation A-12 is indeterminate when $\psi \rightarrow \pm \pi / 6$. To eliminate this problem computationally, the flow potential is taken as the average of the flow potentials on either side of the indeterminacy and evaluated 
in the limit as $\psi \rightarrow \pm \pi / 6$ whenever the lode angle is within 0.25 degree of the indeterminacy. For both conditions, the result is:

$$
\frac{\partial \sigma_{e q}^{c}}{\partial \sigma_{i j}}=\frac{s_{i j}}{2 \sqrt{3 J_{2}}}
$$

Thus, at the corners of the Tresca potential, the indeterminacies are removed by assuming a von Mises flow which makes the direction of straining unique.

\section{Kinetic Equations for Damage-Induced Flow}

The kinetic equations for damage-induced flow are similar in nature to dislocation flow in that damage-induced transient creep is accommodated in the model through a multiplier on the kinetic equations for damage-induced flow during steady-state creep. The model was developed assuming damage can occur in compression as a result of sliding of microcracks by shear and the opening of wing-tip cleavage cracks that develop on some of the shear cracks. Tensile creep damage is also accounted for in the model and is based on the formation of cleavage microcracks aligned normal to the tensile stress. The kinetics of tensile damage in salt are substantially faster than shear damage and is therefore treated as a separate term. The equations describing the shear-induced $(s)$ and tension-induced $(t)$ damage are similar in form. Thus, the subscript $i$ is used to represent $s$ and $t$ in the equations to follow. The equivalent inelastic strain rate is given by:

$$
\dot{\varepsilon}_{e q}^{\omega_{i}}=\mathrm{F}^{\omega_{i}} \dot{\varepsilon}_{s}^{\omega_{i}}
$$

where:

$$
\begin{aligned}
& F^{\omega_{0}}=F \exp \left[\frac{c_{4}\left(\sigma_{e q}^{c}-c_{5}\right)}{\sigma_{0}(1-\rho)}\right] \\
& F^{\omega_{t}}=F \exp \left[\frac{c_{4}\left(\sigma_{e q}^{\omega_{t}}-c_{5}\right)}{\sigma_{0}(1-\rho)}\right]
\end{aligned}
$$

are the functions that account for the damage-induced inelastic strain rate in the transient region and $\rho$ is the volume fraction of clay particles. The kinetic equation for damage-induced flow during steady-state creep is given by: 


$$
\dot{\varepsilon}_{s}^{\omega_{1}}=c_{1} \omega_{o} \exp \left(c_{3} \omega\right)\left[\sinh \left(\frac{c_{2} \sigma_{e q}^{\omega_{1}} H\left(\sigma_{e q}^{\omega_{i}}\right)}{(1-\omega)(1-\rho) \mu}\right)\right]^{n_{3}}
$$

with:

$$
c_{1}=c_{0}\left(B_{1} e^{\left(-Q_{1} / R T\right)}+B_{2} e^{\left(-Q_{2} / R T\right)}\right)
$$

where the $c$ 's and $n_{3}$ are material constants, $\omega_{0}$ is the initial value of the damage variable $(\omega)$ and the $B$ 's and $Q$ 's are constants of the dislocation glide mechanisms. As shown in Equation A-16, the Heaviside step function prevents accumulation of damage whenever the power-conjugate equivalent stress measure is negative.

The power-conjugate equivalent stress measures are given by:

$$
\begin{gathered}
\sigma_{e q}^{\omega}=\left|\sigma_{1}-\sigma_{3}\right|+f_{p} x_{2} x_{7} \operatorname{sgn}\left(I_{1}-\sigma_{3}\right)\left(\frac{I_{1}-\sigma_{3}}{3 x_{7} \operatorname{sgn}\left(I_{1}-\sigma_{3}\right)}\right)^{x_{6}} \\
\sigma_{e q}^{\omega_{2}}=x_{1} \sigma_{1} H\left(\sigma_{1}\right)
\end{gathered}
$$

where $x_{1}, x_{2}, x_{6}$, and $x_{7}$ are material constants of the damage model; $I_{1}$ is the first stress invariant; and $\sigma_{1}$ and $\sigma_{3}$ are the maximum and minimum principal stresses, respectively, with compression assumed to be negative. The first term in Equation A-19 represents the driving force for shear-induced damage, which leads to the opening of "wing-tip" microcracks or grain boundary cracks. The second term in Equation A-19 represents the suppression of microcrack growth by a confining pressure. This term was recently extended to account for the increase in damage accumulation associated with increasing impurity of clay content [Chan et al., 1996a]. The material parameter $f_{\mathrm{p}}$ is related to the impurity content by:

$$
f_{p}=1-p_{1} \rho
$$

where $\rho$ is the clay content parameter and $p_{1}$ is a material parameter, which is analogous to a local stress intensity factor.

The preceding equations include the damage $(\omega)$, which is described in terms of an evolutionary equation. The damage evolution equation is taken as:

$$
\dot{\omega}=\dot{\omega}_{s}+\dot{\omega}_{t}-\dot{h}
$$


where the damage rate components for the shear-induced and tension-induced damage are given by:

$$
\begin{aligned}
& \dot{\omega}_{s}=\frac{x_{4}}{t_{0}} \omega\left[\ln \left(\frac{1}{\omega}\right)\right]^{x_{4}+1}\left[\frac{\sigma_{e q}^{\omega_{s}} H\left(\sigma_{e q}^{\omega_{s}}\right)}{(1-\rho) \xi_{s}}\right]^{x_{\mathrm{s}}} \\
& \dot{\omega}_{t}=\frac{x_{4}}{t_{0}} \omega\left[\ln \left(\frac{1}{\omega}\right)\right]^{x_{4}+1}\left[\frac{\sigma_{e q}^{\omega_{t}} H\left(\sigma_{e q}^{\omega_{t}}\right)}{(1-\rho) \xi_{t}}\right]^{x_{s t}}
\end{aligned}
$$

where $x_{4}, x_{3 s}, x_{3 t}, \xi_{s}, \xi_{t}$, and $t_{0}$ are material constants. The parameter $\xi_{s}$ may have different values according to the magnitude of the effective shear-induced damage stress; i.e.,

$$
\begin{aligned}
& \xi_{s}=\xi_{s}^{1} \text { for } \sigma_{e q}^{c} /(1-\omega)>\sigma_{0} \\
& \xi_{s}=\xi_{s}^{2} \text { for } \sigma_{e q}^{c} /(1-\omega) \leq \sigma_{0}
\end{aligned}
$$

The healing term or damage recovery rate is discussed later under the discussion of the kinetic equation for healing.

\section{Flow Law for Damage-Induced Inelastic Deformation}

The shear-induced inelastic damage flow is assumed to be nonassociative. The flow potential power-conjugate stress measure for shear-induced damage is given by (cf. Equation A-19):

$$
\sigma_{e q}^{\omega:}=\left|\sigma_{1}-\sigma_{3}\right|+\frac{x_{2} x_{8}}{3}\left(I_{1}-\sigma_{3}\right)
$$

where $x_{8}$ is a material constant. Differentiation of the power-conjugate stress given by Equation A-26 with respect to stress leads to:

$$
\frac{\partial \sigma_{e q}^{\omega:}}{\partial \sigma_{i j}}=b_{1} \frac{s_{i j}}{\sqrt{3 J_{2}} \cos 3 \psi}+b_{2} \frac{t_{i j}}{J_{2} \cos 3 \psi}+2 b_{4} \frac{\delta_{i j}}{3}
$$

where:

$$
\begin{gathered}
b_{1}=\sqrt{3} \cos 2 \psi-b_{4} \sin \left(2 \psi-\frac{\pi}{3}\right) \\
b_{2}=\sqrt{3} \sin \psi-b_{4} \cos \left(\psi+\frac{\pi}{3}\right)
\end{gathered}
$$




$$
b_{4}=\frac{x_{2} x_{8}}{3}
$$

The flow potential power-conjugate stress measure for tension-induced damage is given by:

$$
\sigma_{e q}^{\omega}=x_{1} \sigma_{1} H\left(\sigma_{1}\right)
$$

where $x_{1}$ is a material constant. Differentiation of the work conjugate stress given by Equation A-31 with respect to stress leads to:

$$
\frac{\partial \sigma_{e q}^{\omega_{i}}}{\partial \sigma_{i j}}=x_{1} H\left(\sigma_{1}\right)\left[\sin \left(2 \psi+\frac{\pi}{3}\right) \frac{s_{i j}}{\sqrt{3 J_{2}} \cos 3 \psi}+\cos \left(\psi-\frac{\pi}{3}\right) \frac{t_{i j}}{J_{2} \cos 3 \psi}+\frac{\delta_{i j}}{3}\right]
$$

Reviewing the flow laws for the shear-induced and tension-induced damage, one observes an indeterminacy when $\psi= \pm \pi / 6$. To eliminate this problem computationally, the flow potential is taken as the average of the flow potentials on either side of the corner and evaluated in the limit as $\psi \rightarrow \pm \pi / 6$. Performing this limiting operation as $\psi$ approaches $\pi / 6$ (the triaxial compression corner), Equation A-27 for the shear-induced damage term becomes:

$$
\frac{\partial \sigma_{e q}^{\omega_{i}}}{\partial \sigma_{i j}}=b_{1}^{\prime}\left(\frac{s_{i j}}{\sqrt{3 J_{2}}}-\frac{t_{i j}}{2 J_{2}}\right)+2 b_{4} \frac{\delta_{i j}}{3}
$$

where:

$$
b_{1}^{\prime}=1+\frac{2 b_{4}}{3}
$$

and at the triaxial extension corner $(\psi=-\pi / 6)$ :

$$
\frac{\partial \sigma_{e q}^{\omega_{i}}}{\partial \sigma_{i j}}=b_{1}^{\prime \prime}\left(\frac{s_{i j}}{\sqrt{3 J_{2}}}+\frac{t_{i j}}{2 J_{2}}\right)+2 b_{4} \frac{\delta_{i j}}{3}
$$

where:

$$
b_{1}^{\prime \prime}=1+\frac{b_{4}}{3}
$$

which are used in SPECTROM-32 when the Lode angle is within 0.25 degree of \pm 30 degrees.

Performing this limiting operation as $\psi$ approaches $\pi / 6$ (the triaxial compression corner), Equation A-32 for the tension-induced damage term becomes: 


$$
\frac{\partial \sigma_{e q}^{\omega_{i}}}{\partial \sigma_{i j}}=\frac{x_{1} H\left(\sigma_{1}\right)}{3}\left(\frac{s_{i j}}{\sqrt{3 J_{2}}}-\frac{t_{i j}}{2 J_{2}}+\delta_{i j}\right)
$$

and at the triaxial extension corner $(\psi=-\pi / 6)$ :

$$
\frac{\partial \sigma_{e q}^{\omega_{i}}}{\partial \sigma_{i j}}=\frac{2 x_{1} H\left(\sigma_{1}\right)}{3}\left(\frac{s_{i j}}{\sqrt{3 J_{2}}}+\frac{t_{i j}}{2 J_{2}}+\frac{\delta_{i j}}{2}\right)
$$

which are used in SPECTROM-32 when the Lode angle is within 0.25 degree of \pm 30 degrees

\section{Kinetic Equation for Damage Recovery Flow (Healing)}

Reduction of damage in rock salt can occur by the closure of open microcracks and the sintering of microcracks. The kinetic equation representing the healing or damage recovery gives the total inelastic healing rate as follows:

$$
\dot{\varepsilon}_{i j}^{h}=\dot{\varepsilon}_{e q}^{h} \frac{\partial \sigma_{e q}^{h}}{\partial \sigma_{i j}}
$$

where $\sigma_{e q}^{h}$ and $\dot{\varepsilon}_{e q}^{h}$ are the power-conjugate equivalent stress measure and the equivalent inelastic strain rate for the healing mechanisms, respectively.

The equivalent inelastic healing strain rate in Equation A-39 is given as [Chan et al., 1996b]:

$$
\dot{\varepsilon}_{e q}^{h}=\frac{\varepsilon_{k k}^{i}\left(\sigma_{e q}^{h}-\sigma_{b}\right) H\left(\sigma_{b}-\sigma_{e q}^{h}\right)}{\tau \mu}
$$

where $\varepsilon_{k k}^{i}$ is the inelastic volumetric strain, $\tau$ is a characteristic time constant, and $\mu$ is the shear modulus. $H()$ is the Heaviside function; thus, the healing rate is zero if the equivalent stress measure $\sigma_{e q}^{h}$ is less than $\sigma_{b}$. The equivalent stress measure used to describe the magnitude of the healing strain rate is different than the power-conjugate equivalent stress measure used to describe the flow potential (nonassociative formulation) and is given by:

$$
\sigma_{e q}^{h}=\frac{1}{3}\left(I_{1}-\sigma_{3}\right)
$$

The value for $\sigma_{b}$ is determined from Equation A-19 by solving for the value of $\sigma_{e q}^{h}$ when $\sigma_{e q}^{\omega_{s}}=0$, which is given by: 


$$
\sigma_{b}=-x_{7}\left[\frac{\sigma_{1}-\sigma_{3}}{f_{p} x_{2} x_{7}}\right]^{\frac{1}{x_{8}}}
$$

Then the quantity $\sigma_{e q}^{h}-\sigma_{b}$ overlays the curve that describes the damage so that damage accumulation occurs above the curve and damage recovery (healing) occurs below the curve. The characteristic time constant $(\tau)$ is taken to be a function of the inelastic volumetric strain and is written as:

$$
\tau=\tau_{0} \exp \left(-k_{1} \varepsilon_{k k}^{i}\right)+\tau_{1}
$$

where $k_{1}$ is a material constant and $\tau_{0}$ and $\tau_{1}$ are characteristic time constants. When the volumetric strain is large, the exponential term becomes insignificant and the limiting value for $\tau$ is $\tau_{1} . \tau_{1}$ is then the characteristic time associated with microcrack crack closure when the level of damage is high. When the inelastic volumetric strain becomes small, the limiting value of $\tau$ is $\tau_{0}+\tau_{1}$, which is the characteristic time constant associated with crack sintering.

The damage variable $(\omega)$ is described in terms of the evolutionary equation given in Equation A-22. The healing portion of the equation (modified with the initial damage Heaviside) is taken from [Chan et al., 1996b]:

$$
\dot{h}=\frac{\omega H\left(\omega-\omega_{0}\right)\left(\sigma_{e q}^{h}-\sigma_{b}\right) H\left(\sigma_{b}-\sigma_{e q}^{h}\right)}{\tau \mu}
$$

\section{Flow Law for Healing-Induced Inelastic Deformation}

The healing (damage recovery) inelastic damage flow is anisotropic in nature because damage will typically accumulate normal to the major principal stress (compression negative). To implement the anisotropic nature of the healing, Chan et al. [1996b] have developed the flow potential based on stress-induced anisotropy. However, the state of stress does not provide information regarding the direction of damage. In addition, Chan's development includes indeterminant conditions under hydrostatic states of stress. Also, under triaxial extension test conditions, Chan's flow potential predicts axial shortening; whereas, under triaxial compression test conditions, axial lengthening is predicted. This condition creates deformation in the opposite direction of loading regardless of the magnitude of the load. For these reasons, a simple isotropic flow based only on mean stress was adopted. Thus, the power-conjugate effective stress measure describing the flow potential is:

$$
\sigma_{e q}^{h \cdot}=\sigma_{m}
$$


and flow potential is given by:

$$
\frac{\partial \sigma_{e q}^{h^{*}}}{\partial \sigma_{i j}}=\frac{\delta_{i j}}{3}
$$

\section{$\underline{\text { References }}$}

Chan, K. S., S. R. Bodner, D. E. Munson, and A. F. Fossum, 1996a. "Inelastic Flow Behavior of Argillaceous Salt," International Journal of Damage Mechanics, Vol. 5, No. 3, July, pp. $292-314$.

Chan, K. S., D. E. Munson, A. F. Fossum, and S. R. Bodner, 1996b. “A Constitutive Model for Representing Coupled Creep, Fracture, and Healing in Rock Salt," Proceedings, Fourth Conference of The Mechanical Behavior of Salt, École Polytechnique de Montréal, Mineral Engineering Department, Québec, Canada, June 17 and 18, M. Aubertin and H. R. Hardy Jr. (eds.), Penn State University, Trans Tech Publications, Clausthal, Germany, 1998, pp. 221-234.

Fossum, A. F., G. D. Callahan, L. L. Van Sambeek, and P. E. Senseny, 1988. "How Should One-Dimensional Laboratory Equations be Cast Into Three-Dimensional Form?," Proceedings, 29th U.S. Symposium on Rock Mechanics, University of Minnesota, Minneapolis, MN, June 13-15, P. A. Cundall, R. L. Sterling, and A. M. Starfield (eds.), A. A. Balkema, Rotterdam, pp. 35-41.

Kachanov, L. M., 1958. "On the Creep Fracture Time," Izv. Akad. Nauk, USSR, Otdgel. Tekh, Nauk., Vol. 8, p. 26.

Munson, D. E., A. F. Fossum, and P. E. Senseny, 1989. Advances in Resolution of Discrepancies Between Predicted and Measured In Situ WIPP Room Closures, SAND88-2948, Sandia National Laboratories, Albuquerque, NM. 


\section{APPENDIX B}

MDCF PARAMETER VALUES 


\section{APPENDIX B}

\section{MDCF PARAMETER VALUES}

In order to provide the most accurate description of the mechanical response of the two storage caverns evaluated in this study, site-specific parameter values were used where available. Elastic properties and parameter estimates for the MDCF model dislocation mechanisms have been determined in separate studies for both Cavern A and Cavern B. The elastic properties and parameter values for the dislocation mechanisms of the MDCF model are presented in Table B-1. Parameter values for the damage mechanisms have only been determined for WIPP salt. Without experimental evidence, determination of the parameter values for the damage model is impossible. Therefore, parameter values determined for WIPP salt are used in this study. The parameter values for the damage mechanism for pure halite are presented in Table B-2. All of the parameter values were obtained from laboratory experiments on WIPP salt, independent of field measurements. These tables contain the necessary information to define the inelastic deformation of salt using the MDCF model with one exception. The remaining variable necessary to define the inelastic deformation of salt is the impurity content $(\rho)$. In this study, the impurity content was varied to provide a range for the dilatancy boundary that would encompass expected variances in material properties for domal salt. 
Table B-1. MDCF Elastic and Dislocation Creep Model Constants

\begin{tabular}{|c|c|c|c|}
\hline Parameter & Units & Cavern A & Cavern B \\
\hline \multicolumn{4}{|c|}{ Elastic Parameter Values } \\
\hline$E$ & psi & $3.59 \times 10^{6}$ & $2.63 \times 10^{6}$ \\
\hline$v$ & - & 0.30 & 0.18 \\
\hline \multicolumn{4}{|c|}{ Dislocation Creep Parameter Values } \\
\hline$A_{1}$ & day $^{-1}$ & $5.87 \times 10^{27}$ & $3.82 \times 10^{27}$ \\
\hline$A_{2}$ & $\mathrm{day}^{-1}$ & $3.19 \times 10^{15}$ & $2.07 \times 10^{15}$ \\
\hline$Q_{1} / R$ & $\mathbf{R}$ & $2.27 \times 10^{4}$ & $2.27 \times 10^{4}$ \\
\hline$Q_{2} / R$ & $\mathbf{R}$ & $1.17 \times 10^{4}$ & $1.17 \times 10^{4}$ \\
\hline$n_{1}$ & 一 & 5.5 & 5.5 \\
\hline$n_{2}$ & 一 & 3.73 & 3.68 \\
\hline$B_{1}$ & $\mathrm{day}^{-1}$ & $1.67 \times 10^{12}$ & $1.08 \times 10^{12}$ \\
\hline$B_{2}$ & $\operatorname{day}^{-1}$ & $5.30 \times 10^{4}$ & $3.44 \times 10^{4}$ \\
\hline$q$ & 一 & 3,330 & 2,800 \\
\hline$\sigma_{o}$ & psi & 1,930 & 1,280 \\
\hline$\mu$ & psi & $1.40 \times 10^{6}$ & $1.40 \times 10^{6}$ \\
\hline$m$ & - & 3 & 3 \\
\hline$K_{o}$ & 一 & $3.73 \times 10^{6}$ & $5.27 \times 10^{4}$ \\
\hline$c$ & $\mathrm{R}^{-1}$ & $5.11 \times 10^{-3}$ & $5.11 \times 10^{-3}$ \\
\hline$\alpha$ & - & -1.25 & -10.39 \\
\hline$\beta$ & - & -2.07 & -6.17 \\
\hline$\delta$ & - & 0.2417 & 0.2417 \\
\hline
\end{tabular}


Table B-2. MDCF Damage Model Constants

\begin{tabular}{|c|c|c|c|}
\hline Parameter & Units & Cavern A & Cavern B \\
\hline$x_{1}$ & - & 6 & 6 \\
\hline$x_{2}$ & - & 9 & 9 \\
\hline$x_{3 s}$ & - & 5.5 & 5.5 \\
\hline$x_{3 t}$ & - & 40 & 40 \\
\hline$x_{4}$ & 一 & 3 & 3 \\
\hline$\xi_{\mathrm{s}}^{1}$ & psi & $3.35 \times 10^{4}$ & $3.35 \times 10^{4}$ \\
\hline$\xi_{s}^{2}$ & psi & $5.09 \times 10^{4}$ & $5.09 \times 10^{4}$ \\
\hline$\xi_{\mathrm{t}}$ & psi & 2,197 & 2,197 \\
\hline$x_{6}$ & - & 0.75 & 0.75 \\
\hline$x_{7}$ & psi & 145 & 145 \\
\hline$x_{8}$ & - & 0.1 & 0.1 \\
\hline$x_{10}$ & - & 1 & 1 \\
\hline$t_{0}$ & day & $1.16 \times 10^{-5}$ & $1.16 \times 10^{-5}$ \\
\hline$\tau_{0}$ & day & 4.34 & 4.34 \\
\hline$\tau$ & day & $2.17 \times 10^{-4}$ & $2.17 \times 10^{-4}$ \\
\hline$c_{0}$ & - & 50,000 & 50,000 \\
\hline$c_{2}$ & - & 850 & 850 \\
\hline$c_{3}$ & - & 10 & 10 \\
\hline$c_{4}$ & - & 6 & 6 \\
\hline$c_{5}$ & psi & 3,626 & 3,626 \\
\hline$n_{3}$ & - & 3 & 3 \\
\hline$k$ & 一 & 5,000 & 5,000 \\
\hline$\sigma_{t h}$ & psi & -508 & -508 \\
\hline$p_{1}$ & 一 & 28 & 28 \\
\hline$\omega_{0}$ & - & 0.0001 & 0.0001 \\
\hline$\rho$ & - & 0 to 0.03 & 0 to 0.03 \\
\hline
\end{tabular}


APPENDIX C

PROPERTIES OF WELL FLUIDS

C-1 


\section{APPENDIX C}

\section{PROPERTIES OF WELL FLUIDS}

The mechanical response of natural gas storage caverns depends not only on the material properties of the salt surrounding the cavern but also on the material properties of the fluids inside the cavern. It is assumed that the cavern will be filled with saturated brine after solutioning is complete and before the cavern is dewatered. The cavern will subsequently be filled with compressed natural gas. In the simulations of the cavern, these fluids are represented by their pressures applied as normal tractions to the surfaces of the cavern. An equation of state relating the fluid's pressure to its density and temperature was assumed for each fluid. In the following two subsections, the assumed equations of state used to predict the vertical pressure gradients are presented for natural gas and for saturated brine.

\section{Natural Gas Characteristics}

The gas pressure, $P$, in a well can be described as:

$$
P=P_{0}+\int_{0}^{z} \rho g d z
$$

where:

$$
\begin{aligned}
& P_{0}=\text { the wellhead pressure } \\
& \rho=\text { the density of the gas } \\
& g=\text { the gravitational acceleration } \\
& z=\text { the depth below wellhead. }
\end{aligned}
$$

The density of natural gas is dependent on pressure and temperature, both of which change with depth. A compressibility equation for natural gas described by Coker [1993] was used to calculate the density as a function of pressure and temperature. Equation C-1 was integrated numerically to determine the pressure versus depth data to determine a linear pressure gradient for the gas at the various pressures simulated.

\section{Brine Characteristics}

Because of the very small compressibility of brine, approximately $1.9\left(10^{-6}\right) / \mathrm{psi}$, the increase in brine density associated with the hydrostatic pressure increases over the height of the cavern is negligible (about 0.1 percent change per 1,000 feet). Consequently, the brine density was assumed to remain a constant $75 \mathrm{pcf}$, resulting in a vertical pressure gradient of $0.52 \mathrm{psi} /$ foot. 


\section{$\underline{\text { References }}$}

Coker, A. K., 1993. "Program Calculates Z-Factor for Natural Gas," Oil \& Gas Journal, February 15, pp. 75-75. 